\title{
2. CONTENIDO Y DINÁMICA DE LA ESTRUCTURA GUBERNAMENTAL EN ESPAÑA
}

\author{
ANTONIO BAR CENDON \\ Catedrático de Derecho Constitucional \\ Universidad de Cantabria
}




\section{SUMARIO}

I. INTRODUCCIÓN. 1. Precisiones previas. 2. Los Gobiernos.II. Cambio y estabilidad gubernamental. 1. Discontinuidad con el período franquista. 2. Estabilidad y duración. 3. Movilidad ministerial.- III. LA FORMACIÓN PROFESIONAL DE LOS MIEMBROS DEL GoBIERNO. 1. Algunos datos personales. a) La edad. b) El sexo. 2. La formación y la actividad previas de los Ministros. a) La formación académica. b) La actividad profesional. - IV. LA CARRERA POLITICA DE LOS MINISTROS. 1. La carrera politico-administrativa. 2. La carrera político-parlamentaria. 3. Los Ministros-parlamentarios.- V. LA ESPECIALIZACIÓN MINISTERIAL.- VI. CONCLUSIONES. 


\title{
2. CONTENIDO Y DINÁMICA DE LA ESTRUCTURA GUBERNAMENTAL EN ESPAÑA ${ }^{1}$
}

\author{
POR \\ ANTONIO BAR CENDON \\ Catedrático de Derecho Constitucional \\ Universidad de Cantabria
}

\section{INTRODUCCION}

\section{Precisiones previas}

El tratamiento de la estructura gubernamental que se realiza en este trabajo requiere una pequeña precisión inicial. Se trata de analizar aquí una de las facetas especificas del Gobierno, cual es el contenido personal del mismo y su dinámica, y para ello, es preciso delimitar el propio concepto de Gobierno como punto de partida, con el objeto, siquiera sea metodológico, de establecer un marco limitativo al análisis. No se pretende aquí, sin embargo, entrar de lleno en un tema de tan profunda y densa dimensión como el que se refiere a la sustancia de la institución gubernamental, ni definir en términos abstractos al Gobierno - de ello ya me he ocupado parcialmente en anterior ocasión- ${ }^{2}$. Se trata aquí sólo, por un lado, de hacer explícito el verdadero carácter y significado del Gobierno en España,

1 Este trabajo debe muchas de sus ideas a la discusión e intima colaboración, desde hace ya más de tres años, con un grupo internacional de universitarios, del que formo parte, y que, dirigido por el profesor Jean Blondel, analiza en términos comparativos los Gobiernos de la Europa occidental. Una beca Jean Monnet del European University Institute, de Florencia, y una larga estancia en aquel magnifico centro han permitido su culminación. En la labor de documentación he recibido la inestimable ayuda de Cristina Placer, Lucas Ramirez, Carlos Fatás y José M. Gómez. A todos los mencionados expreso, pues, mi sincero agradecimiento.

2 A. BAR, «La estructura y funcionamiento del Gobierno en España: Una aproximación analítica", en A. BAR et al., El Gobierno en la Constitución Española y en los Estatutos de Autonomia. Barcelona, Diputació, 1985, pp. 13-50. 
como Gabinete parlamentario, a modo de fundamentación objetiva del estudio que a continuación se aborda; y, por otro, de delimitar simple y llanamente, y con la finalidad analítica mencionada, qué es lo que constituye en España un Gabinete, cada Gobierno concreto, y ello a partir del propio ordenamiento jurídico-político vigente.

A) En primer lugar, y en el pirmer sentido, debe resaltarse la idea de que el Gobierno español -como el sistema político en el que se incardina (art. 1.3 CE) - es un Gobierno parlamentario, en el sentido técnicoconstitucional del término. Es decir, se trata de una entidad que se fundamenta en el Parlamento, en las Cortes Generales, de las que deriva no sólo su legitimación, sino su propia existencia. De acuerdo con las previsiones constitucionales, en su inicio, el Gobierno se forma en base a la mayoria parlamentaria, sea ésta homogénea o no (art. $99 \mathrm{CE}$ ), sus miembros pueden ser miembros de las Cámaras (art. 70.1.b CE) y, aunque no lo fueren, tienen acceso a las sesiones de las mismas (art. $110 \mathrm{CE}$ ); y, a lo largo de su vida, el Gobierno es responsable solidariamente por su gestión política ante las Cortes (arts. 98.2, 108 y $111 \mathrm{CE}$ ), pudiendo llegar a ser removido por éstas — por el Congreso de los Diputados-en los casos de denegación de su confianza o de aprobación de una moción de censura (arts. 101 y $114 \mathrm{CE}$ ). Pero, en segundo lugar, el Gobierno es también la cabeza del Poder Ejecutivo y, por lo tanto, no sólo es el diseñador e impulsor de la política general del Estado, sino el director del aparato ejecutivo-administrativo que ha de llevarla a efecto en sus aspectos más importantes (art. 97). Esta doble dimensión -como órgano político-representativo y como órgano ejecutivo-administrativo-plantea al Gobierno una serie de exigencias que condicionan su propia conformación y le caracterizan. Pero, al mismo tiempo, y como una condición recíproca, dependiendo de cuál sea precisamente esa conformación, el Gobierno podrá cumplir de mejor o peor manera su papel en ambos aspectos.

La primera dimensión es la que cabe denominar como representativa. Esta dimensión expresa el carácter más político del Gobierno, su vinculación parlamentaria y su relación-dependencia con los sujetos principales del proceso político - los partidos politicos, etc.- . Su caracterización como representativa viene dada precisamente porque el Gobierno se conforma como una representación -dicho sea en términos no jurídicos- del o los partidos o grupos políticos mayoritarios en el Parlamento $y$, consiguientemente, en la sociedad. Este carácter político, o representativo, supone, pues, una condición, en la medida en que el Gobierno no podría existir de no adaptarse a esa mayoria parlamentaria. Pero, por otra parte, supone también un elemento de eficacia, en la medida en que dependiendo de cuál sea el carácter de esa adaptación, la actuación del Gobierno vendrá dificultada o facilitada. Es decir, para poder llevar su política adelante, el Gobierno en general, y los Ministros en particular, no sólo han de proceder de la mayoría parlamentaria, sino que han de ser capaces de 
controlar el Parlamento, de relacionarse adecuadamente con la institución y los sujetos que la componen, $y$, por lo mismo, con las fuerzas que determinan su composición, partidos, coaliciones, grupos de presión, etc. Así, los miembros del Gobierno habrán de provenir preferentemente de las propias Cámaras y deberían ser parlamentarios experimentados, tras su elección previa en varias legislaturas. Deberian ser políticos, en el más pleno y común significado del término.

La segunda dimensión puede ser denominada como ejecutiva, 0 administrativa. Su sustancia viene determinada por la necesidad de la materialización de la política gubernamental y por la vinculación, con este objeto, del Gobierno al aparato ejecutivo del Estado. En este sentido, las demandas que se presentan son más bien de tipo técnico: se requiere una capacidad de dirección y gestión administrativa. $Y$, en función de cuál sea el carácter de esta adaptación a las exigencias técnicas de la función ejecutiva, el Gobierno será más o menos eficaz en la realización de su política. Es decir, de acuerdo con las exigencias de esta dimensión, los Ministros deberían ser verdaderos conocedores profundos de los aparatos del Estado, de la función ejecutiva, directores o gestores administrativos competentes, capaces de organizar y coordinar adecuadamente el entramado funcionarial de su Departamento. Y, lógicamente, el área de procedencia o de formación más adecuada para esta especial capacitación de los Ministros seria la propia Administración Pública, entendida en términos amplios.

Ahora bien, como es obvio, es prácticamente imposible satisfacer plenamente los requisitos de este modelo ideal y que estas características se den en toda su intensidad y en todos y cada uno de los casos. Lo más normal es que el elemento representativo y el elemento administrativo aparezcan con diferentes matices y casi siempre de manera desequilibrada. Los Gobiernos parlamentarios se componen así de personas en las que uno u otro aspecto está presente, predominantemente o de manera exclusiva; y ello determina el carácter mismo del Gobierno y su tipo de actuación.

Asi pues, en lo que se refiere al Gobierno como un todo, esta doble dimensión, que es distinguible analíticamente, se encuentra completamente entremezclada en la realidad, de tal manera que los Gobiernos, como ocurre con algunos de sus Ministros, son al mismo tiempo politicos y administrativos, gestores y representantes. Sin embargo, aunque ambas dimensiones existen siempre, por propia definición, en el Gobierno parlamentario, la verdad es que la intensidad de las mismas no se manifiesta en todo momento de una manera equilibrada, predominando en unos casos el elemento o dimensión política, y en otros el elemento o dimensión administrativa.

Por otra parte, esta doble dimensión del Gobierno parlamentario no agota la descripción de los elementos condicionantes de su eficacia . Como se verá más adelante con detalle, existe una tercera dimensión que, en 
realidad, subsume a las otras dos, y cuya existencia, siquiera sea hasta determinado nivel, se manifiesta como imprescindible en la acción gubernamental, sobre todo en las nuevas condiciones históricas del presente en las que se desenvuelve ésta. Se trata de lo que en este trabajo se denomina. especialización ministerial. La especialización ministerial, en términos generales y en el sentido en que es aqui entendida, supone el conocimiento profundo por parte de los miembros del Gobierno de las materias que son objeto de la decisión gubernamental, y más específicamente, de la materia que es objeto propio de la gestión del respectivo Departamento. En este sentido, se presupone que la eficacia de la gestión gubernamental requiere por parte de los miembros del Ejecutivo un conocimiento previo de las materias sobre las que va a versar su actuación; conocimiento que puede ser más o menos profundo en cada caso, y que puede extenderse a todos o parte de los miembros del Gabinete, pero que sería impensable que no existiera en absoluto en el seno del Gobierno. La especialización ministerial es, pues, un requisito imprescindible de la actuación gubernamental.

Ahora bien, la especilización ministerial subsume a la dimensión representativa y a la dimensión administrativa en la medida en que se adquiere precisamente debido a la presencia previa de los futuros Ministros en los escaños parlamentarios o en los altos cargos políticos de la Administración Pública, en lo que cabe denominar como su carrera política hacia el Gobierno. Pero el concepto de especialización ministerial es más amplio, en la medida en que no sólo a través de esas dos vías - la político-parlamentaria y la político-administrativa - se puede llegar al Gobierno, sino que a éste se puede acceder también por cauces externos, no políticos, sin necesidad de haber desempeñado previamente cargo público alguno, representativo o de gestión. $Y$, consiguientemente, la especialización se puede adquirir también en estos otros terrenos de la actividad profesional del futuro Ministro. (Como se verá más adelante, es precisamente en este campo donde se consiguen las dosis más altas de especialización ministerial). En cualquier caso, el testimonio más obvio, de este equilibrio entre las dimensiones representativa y administrativa, $y$, sobre todo, del nivel necesario de especialización ministerial; $y$, por consiguiente, la manifestación sustancial del carácter propio del Gobierno, lo constituye su componente personal.

El análisis de la composición personal del Gobierno se presenta, pues, como un elemento imprescindible -además de los jurídico-constitucionales - para completar la caracterización formal proporcionada por la Constitución. Y este es el estudio que pretende abordar este trabajo. Sin embargo, debe precisarse también que no se trata aquí de hacer una sociología de la élite ministerial, de ofrecer un perfil completo y acabado de los Ministros españoles. Ni es ésta la intención, ni el estrecho marco de este estudio lo permitiria ${ }^{3}$. Se trata solamente de analizar aquellos aspec-

3 Sobre esta materia se han producido ya interesantes estudios, sobre todo en lo que hace referencia al período de la dictadura del general Franco. Vid. EQUIPo MuNDo, Los noventa 
tos que inciden precisamente sobre las dimensiones mencionadas de la esencia gubernamental y que permitan caracterizar politicamente al Gobierno.

En este sentido, se analizan a continuación las carreras politicas ministeriales desde dos puntos de vista. En primer lugar, desde el punto de vista de la especialización, es decir, atendiendo al carácter político y/o administrativo de los currículos de los miembros del Gobierno; y, en segundo lugar, desde el punto de vista de la duración. Pues, cualquiera que sea el carácter predominantemente político o técnico de la composición gubernamental, su efecto sobre la condición y eficacia del Gobierno estará en función del tiempo que éste, o sus miembros, tengan para actuar. La estabilidad gubernamental aparece asi como un nuevo factor de gran trascendencia, no sólo en la simple caracterización del Gobierno, sino de todo el sistema politico-constitucional ${ }^{4}$.

B) Si desde el punto de vista de su contenido institucional, el Gobierno aparece claramente delimitado en la Constitución, que lo define como un conjunto compuesto "del Presidente, de los Vicepresidentes en su caso, de los Ministros y de los demás miembros que establezca la ley" (art. 98.1) —cargos que son precisamente los formantes del Consejo de Ministros (art. 4.1 LOACE) - ; como quiera que la ley no ha llegado a crear posteriormente nuevos miembros de éste en sentido propio, técnico-juridico, constituyen Gobierno, pues, el Presidente, el o los Vicepresidentes que puedan existir, y los Ministros, cualquiera que fuere su estatuto o posición en la organización interna del Gabinete. Ellos son, por tanto, el objeto material de este análisis.

Ahora bien, el Gobierno, por su propia sustancia, es una entidad viva, dinámica, que puede experimentar importantes transformaciones en su configuración a lo largo del tiempo, a la par que mantener una cierta continuidad. En este sentido, la definición del art. 98.1 CE se queda un poco corta y, si bien nos da una radiografía de la estructura básica, esencial, del Gobierno y en términos abstractos, no permite una delimitación exacta del mismo en su dinámica, en su devenir temporal. El artículo 98.1 nos dice

\footnotetext{
Ministros de Franco. Barcelona, Dopesa, 1970; P. H. LEWIS, "The Spanish Ministerial Elite, $1938-$ 1969", Comparative Politics, 5, 1972, pp. 83-106; A. DE MIGUEL, Sociologia del franquismo. Barcelona, Euros, 1975; M. BAENA, «Los Ministros burbcratas", ICE, 522, 1977; M. JEREZ, Elites politicas y centros de extracción en España, 1938-1957. Madrid, CIS, 1982; J. M. CUENCA TORIBIO, S. MiRAnda Garcla, "La élite ministerial franquista», Revista de Estudios Politicos, 57, 1987, pp. 107-148, y "Notas para una sociologia de la élite de poder ministerial en la transición (1975-86)", en Homenaje al profesor Sampedro. Madrid 1987, pp. 81-113.

4 Con respecto a todo lo expuesto véanse los trabajos de J. BLonDELL, The Organization of Governments. London, Sage, 1982; Government Ministers in the Contemporary World. London, Sage, 1985; "Introduction", en J. BLondeLL, F. MüLlER-Rommel (Eds.), Cabinets in Western Europe. London, Macmillan, 1988, y «Ministerial Careers and the Nature of Paliamentary Government», European Journal for Political Research, en prensa.
} 
qué constituye el Gobierno, pero no alcanza a decir o delimitar qué constituye cada Gobierno, a diferencia de los anteriores o de los sucesivos. Se requiere, pues, complementar este concepto y evitar asi la confusión existente al respecto en ciertos medios. En otras palabras, se plantea la duda sobre si constituye o no un solo y único Gobierno el presidido por un mismo Presidente a través de sucesivas transformaciones o cambios en su contenido personal, de sucesivos procesos electorales, etc. O si, por el contrario, constituyen Gobiernos o Gabinetes diferentes cada una de las modificaciones realizadas en el contenido personal de la institución, con independencia de quién sea su Presidente o del alcance de las mismas.

Tratando de solventar esta confusión y de complementar el concepto que del Gobierno nos da el artículo 98.1 CE, y atendiendo tanto a su aspecto estático como al dinámico, a su contenido como a su duración, entiendo que, desde el punto de vista de este trabajo, definen o distinguen a cada Gobierno dos tipos de elementos: a) su Presidente, y b) cada nombramiento de éste para el puesto, tras la celebración de elecciones generales, tras la dimisión o fallecimiento del Presidente del Gobierno anterior, o tras la retirada de la confianza parlamentaria a este último. En este sentido, por un lado, no constituyen un Gobierno diferente los varios cambios o reajustes ministeriales que el Gabinete pueda experimentar bajo una misma presidencia y durante una misma legislatura, por muy amplios que éstos puedan ser; ni, por otro, en sentido contrario, han de entenderse como parte de un mismo Gobierno los diferentes Gabinetes que un mismo Presidente pueda formar, de manera consecutiva, tras sucesivos nombramientos para el cargo, subsiguientes a triunfos de su grupo político en elecciones generales sucesivas, por el mero hecho de que sea la misma persona la que presida estos Gobiernos ${ }^{5}$.

$Y$ ello es asi por un cuádruple motivo: $1 .^{\circ}$ Porque para cada nombramiento cada Presidente ha de obtener la confianza previa del Congreso de los Diputados, para lo que ha de presentar un programa político ante la Cámara. Este voto explícito de confianza, requerido constitucionalmente en cada ocasión - renovación del Congreso de los Diputados, pérdida de la confianza parlamentaria y dimisión o fallecimiento del Presidente del Gobierno anterior (arts. 99, 101 y $114 \mathrm{CE}$ )- y realizado sobre un nuevo programa político - por mucho que el posterior se parezca o continúe las líneas generales del anterior - establece una clara solución de continuidad, aunque la persona del Presidente del Gobierno sea la misma. El Congreso ha de pronunciarse, pues, de nuevo y expresar su confianza, la cual recae

5 Así, y a modo de ejemplo, hasta el momento de redactar estas líneas el PSOE ha formado dos Gobiernos, tras las elecciones generales de 1982 y tras las de 1986 . No puede decirse, pues, como es frecuente en algunos medios, que hayan sido cuatro estos Gobiernos, por el hecho de que se hubieran producido dos remodelaciones de los mismos; ni, en sentido contrario, que haya habido un solo Gobierno socialista, por el mero hecho de que ambos hayan sido presididos por la misma persona - F. González- o provengan de la misma mayoría parlamentaria, el PSOE. 
indistintamente sobre el binomio candidato-programa. Es muy difícil, por tanto, poder hablar de un mismo Gobierno o Gabinete cuando la Constitución exige la activación del proceso de expresión de la confianza parlamentaria en cada uno de los casos mencionados, con ignorancia de quién haya sido el anterior ocupante de la Presidencia; con excepción hecha, claro está, de los supuestos previstos en el artículo $114 \mathrm{CE}$, que obligan a la presentación de un candidato diferente al cargo. $2 .^{\circ}$ Porque el nombramiento de un Presidente del Gobierno significa también, en cada ocasión, el nombramiento de todos los demás miembros del Gobierno (art. $100 \mathrm{CE}$ ), los cuales pueden, o no, cambiar en su totalidad con respecto a los que formaban el anterior Gabinete, pero no por ello han de dejar de ser vueltos a nombrar formalmente. Así, no por el hecho de que aun la mayoria de los Ministros hayan sido nombrados de nuevo puede hablarse de un mismo Gabinete, dado que la exigencia de un nuevo nombramiento general permite, en términos constitucionales, hablar verdaderamente de un Gobierno diferente. $3 .^{\circ}$ Porque cada nuevo nombramiento de un Presidente, aunque recaiga en la misma persona, puede suponer - de hecho, suele hacerlono sólo una reestructuración formal del Gobierno, con cambios orgánicos, personales y programáticos, sino también una nueva línea de acción, una nueva política real; lo que establecería un elemento diferenciador más, de carácter sustancial. $4 .^{\circ}$ Porque, en sentido contrario, cuando se trata de una mera remodelación ministerial, por muy amplia que ésta pueda ser, el nombramiento formal sólo se produce con respecto a los nuevos Ministros que entran en el Gobierno, pero no con respecto a aquellos que permanecen en el mismo, incluido su Presidente. No existe, pues, en este caso obligación constitucional alguna de pasar por el proceso de obtención de la confianza parlamentaria que supone la investidura prevista en el artículo 99 de la Constitución (por más que sea una loable práctica política explicar a las Cortes los cambios producidos e, incluso, tratar de renovar la confianza de la Cámara) ${ }^{6}$. Y $5 .^{\circ}$ desde un punto de vista puramente metodológico, porque si hubiera que considerar un mismo Gabinete los Gobiernos sucesivos formados por un mismo Presidente o mayoria parlamentaria, tras los correspondientes procesos electorales y nombramientos formales; o, a la inversa, si hubiera que considerar como Gabinetes diferentes las varias reestructuraciones que un mismo Gobierno pueda experimentar a lo largo de su existencia, se crearia una enorme confusión a la hora de delimitar y analizar su componente personal, el número de nombramientos realizados, la duración y repetición de los mismos, y, en definitiva, de medir el grado de estabilidad y/o continuidad gubernamental existente en el sistema, debido a la introducción de elementos analíticos ajenos al mismo.

6 De hecho, la primera y única cuestión de confianza hasta el momento presentada ha tenido lugar el 16 de septiembre de 1980, y sería ejercitada por A. Suárez, para renovar los apoyos parlamentarios a su tercer Gabinete, tras la importante remodelación del mismo llevada a cabo aquel mismo mes. La confianza sería concedida por una diferencia de 16 votos. 
Así pues, los Gobiernos habidos en España desde el año 1975 hasta nuestros dias son clasificados y analizados en este trabajo de acuerdo con este criterio, que, por otra parte -como se ha visto-, viene impuesto por el propio ordenamiento politico-constitucional.

\section{Los Gobiernos}

Desde la muerte del general Franco, en noviembre de 1975, hasta el verano de 1988 se han formado en España siete Gobiernos, el último de los cuales, presidido por Felipe González, se encuentra en ejercicio en el momento de redactar estas líneas. Estos Gobiernos han sido los presididos por Carlos Arias Navarro, en una ocasión (12-diciembre-1975 a 2-julio1976) '; por Adolfo Suárez González, en tres ocasiones (I: 3-julio-1976 a 4-julio-1977; II: 4-julio-1977 a 31-marzo-1979; y III: 31-marzo-1979 a 25-febrero-1981); por Leopoldo Calvo Sotelo, en una ocasión (25-febrero-1981 a 1-diciembre-1982); y por Felipe González Márquez, en dos ocasiones (I: 1diciembre-1982 a 23-julio-1986; y II: 23-julio-1986 al presente). Todos ellos, con la excepción del primero, han experimentado cambios en su formación en diferentes momentos de su existencia, de mayor o menor importancia y extensión. Así, a lo largo de este periodo de 12 años han llegado a formar parte del Gobierno, o, en otras palabras, de cada uno de los siete Gabinetes mencionados, 107 personas, las cuales han ocupado los respectivos cargos de rango ministerial, incluidos los Presidentes del Gobierno indicados. (Vid. Cuadro 1.)

En este ya largo periodo de 12 años España ha experimentado transformaciones políticas de importancia fundamental las cuales no han podido menos que afectar a la estructura del Gobierno. Asi, la aparentemente rápida sucesión de Gobiernos y las respectivas remodelaciones, y, aun, los cambios orgánicos producidos - todo ello se analiza en detalle más adelante-, no han sido caprichosos y son una expresión fiel de la situación politica por la que ha pasado el pais a la salida de la larga dictadura del general Franco. Entonces, hubo de formarse una nueva clase política, crearse un sistema de partidos, además, claro está, de reinstituir la práctica totalidad de la organización estatal y consolidar un sistema democrático parlamentario, de estructura casi-federal. Es prácticamente imposible, pues, que en esta vorágine de hechos los Gabinetes que tuvieron que afrontarlos permaneciesen incólumes y durasen más de lo que en realidad han durado, y lo hiciesen de manera muy diferente a como lo hicieron. En cualquier caso, si la motivación general para los cambios de Gobierno - y en los Gobiernos- producidos es la expresada, los motivos inmediatos fueron diferentes en cada uno de los casos.

Arias Navarro presidió antes su primer Gabinete y el último de los Gob
general Franco, entre el 29 de diciembre de 1973 y el 12 de diciembre de 1975. 


\section{CUADRO 1. GOBIERNOS DEL PERÍODO 1975-1988}

\begin{tabular}{llrl}
\hline \multicolumn{1}{c}{ TITULAR } & \multicolumn{2}{c}{ DURACIÓN } & CAMBIOS \\
\hline & & \\
Arias II & $11.12 .75-1.7 .76:$ & 7 meses & 0 \\
Suárez I & $7.7 .76-4.7 .77:$ & 12 meses & 3 \\
Suárez II & $4.7 .77-31.3 .79:$ & 21 meses & 3 \\
Suárez III & $31.3 .79-25.2 .81:$ & 23 meses & 3 \\
Calvo-Sotelo & $26.2 .81-1.12 .82:$ & 21 meses & 4 \\
González I & $1.12 .82-23.7 .86:$ & 44 meses & 1 \\
González II & $23.7 .86-\ldots$ & & 1 \\
\hline
\end{tabular}

Duración media total: 21,33 meses *

Duración media sin cambio alguno: 6,29 meses

\section{* Excluido el Gobierno González II}

El primer cambio político importante, que marca precisamente el inicio de esta periodización y de la materia objeto de este análisis, se produce con el fallecimiento del general Franco, el cual abre el camino de la transición a la democracia. El acceso del Rey Juan Carlos a la Jefatura del Estado supuso el nombramiento del Gobierno Arias II, primero de los Gabinetes aquí analizados. Su caida vino determinada por el fracaso de su intento de realizar una reforma del régimen franquista en la continuidad, desde dentro del mismo; reforma que suscitó una fuerte oposición, tanto entre las filas de los sectores democráticos, como entre las de los sectores más recalcitrantes del franquismo, lo que la hizo totalmente imposible. Su corta duración — siete meses-impidió también que llegase a experimentar remodelación alguna.

El Gobierno Suárez I, que sigue inmediatamente, supuso un cambio radical en la línea política seguida hasta entonces. Este Gobierno se encargaria de la clausura definitiva del régimen franquista y dirigiría los cambios y modificaciones decisivos que permitieron, primero, la celebración de unas elecciones generales libres - las primeras después de cuarenta años-y, más tarde, el verdadero establecimiento de la democracia en España. El primer Gabinete Suárez experimentaria tres cambios: los dos primeros de ellos, que afectaron precisamente a dos carteras militares, tuvieron su origen en la oposición de los militares apegados al antiguo régimen a todo intento de cambio sustancial de la vieja situación política ${ }^{8}$;

- El primer cambio daría entrada en la Vicepresidencia del Gobierno al general Gutiérrez Mellado, que realizaría un importante papel en la transición a la democracia. Y el 
mientras que el tercero se debió a la dimisión del Ministro de Obras Públicas, Calvo Sotelo, para poder presentarse a las próximas elecciones ${ }^{9}$. Este Gobierno finalizaria tras la celebración de las elecciones generales del 15 de junio de 1977.

Tras estas elecciones, Suárez formaria su segundo Gobierno, el cual, clausurado ya el régimen franquista, se encargaría de adoptar las primeras medidas positivas en la construcción del nuevo sistema democrático, la más importante de las cuales fue, sin duda alguna, la elaboración de la nueva Constitución, que seria refrendada por el pueblo el 6 de diciembre de 1978. Este Gobierno experimentaria tres cambios: el primero supondría simplemente la dimisión de I. Camuñas como Ministro para las Relaciones con las Cortes, por problemas en su función, precisamente en el momento clave en el que se iniciaba en las Cámaras la redacción de la Constitución. El segundo cambio supuso el nombramiento de Calvo-Sotelo como Ministro para las Relaciones con las Comunidades Europeas, cuando comienza a abordarse en serio la negociación para la integración de España. $Y$ el tercero de los cambios, a los pocos días, se produce como producto de los enfrentamientos intragubernamentales sobre la politica económica, la aprobación del Plan Energético Nacional, etc. Los Departamentos afectados fueron precisamente los de este carácter, y lo más llamativo fue, desde luego, la dimisión de E. Fuentes Quintana, que entonces dirigia esta área de la política gubernamental.

La entrada en vigor de la Constitución de 1978 determinó al Presidente Suárez a realizar la disolución de las Cortes Constituyentes, con el fin de que ello permitiese la plena entrada en funcionamiento de los mecanismos parlamentarios previstos en la nueva norma fundamental. Las elecciones generales se celebrarian el 1 de marzo de 1979 y, tras las mismas, se formaría el Gobierno Suárez III. Este Gabinete, el más largo de los presididos por Suárez - 23 meses_- finalizaría sus días con la dimisión del Presidente en febrero de $1981^{10}$, como producto de una amplia problemática política, cuyo relato excede los límites e intención de este trabajo, y que se culminaria con un fracasado golpe de Estado unos días más tarde (23 de febrero). El Gobierno Suárez III experimentaria también tres cambios: el pimero de ellos se produjo con motivo de la política regional seguida por la UCD, que promocionaba la vía lenta de acceso a la autonomía -art. 143 de la Constitución- para la totalidad de las regiones, excepto para las denominadas "nacionalidades históricas»-Galicia, País Vasco y Cataluña-, lo que produjo la protesta y dimisión del Ministro andaluz

ségundo cambio se produciría con motivo del llamativo hecho de la legálización del Partido Comunista, que provocó la dimisión del entonces Ministro de Marina, G. Pita da Veiga.

$\checkmark$ Las normas electorales entonces vigentes impedían a los Ministros presentarse a las elecciones (art. 4.1 RD-L. 20/1977, 18 marzo). Se trataba de una garantía de limpieza del proceso electoral impuesta por la oposición democrática en aquellos momentos de transición y para aquellas primeras elecciones.

10 Suárez presentaria su dimisión el 29 de enero de 1981. 
M. Clavero. La crisis fue aprovechada para realizar una pequeña remodelación que afectó en total a dos Departamentos. El segundo cambio, de mayor importancia - afectó a nueve carteras-, vendría determinado tanto por la propia problemática autonómica, cuyo debate se encontraba entonces en uno de sus puntos más elevados, como por las tensiones internas dentro de la UCD, cuyos «barones" presionaban por hacerse con mayores parcelas de poder. De la cartera de Administración Territorial se encargaria entonces uno de los hombres de más peso en el partido, Pérez Llorca. El tercer cambio se produjo en medio de una fuerte crisis interna, cuando el Gobierno había recibido ya una moción de censura y perdía progresivamente apoyos en las Cámaras. Se hacia necesaria una actuación en profundidad y ello supuso un extenso cambio ministerial que afectó a once carteras - diecinueve personas, entre los que entraron y salieron del Gobierno o cambiaron de puesto-. Esta vez sí, los «barones" se impusieron y el Gabinete resultante, trató de ser un equilibrio entre las diferentes «familias" de la UCD. Así, los aspectos más llamativos del cambio fueron la salida del Gobierno de Abril Martorell, que habia dirigido hasta entonces el área económica y que gozaba de un enorme peso en el seno del Gabinete, y la elevación del rango de once Ministros, que pasan a ser nombrados «Ministros de Estado».

A Suárez le sustituiría en febrero de 1981 Calvo-Sotelo. El Gobierno Calvo-Sotelo se encargaría de finalizar la legislatura, la cual -extinguida la mayoria gubernamental de la UCD, debido a las múltiples disputas internas- se produjo mediante la disolución anticipada de las Cortes el 27 de agosto de 1982. Este Gobierno experimentaria cuatro cambios ministeriales: el primer cambio vendría determinado por la dimisión de Fernández Ordóñez como Ministro de Justicia - quien se pasaria al PSOE con las elecciones de 1982- y afectaría a dos Departamentos. El segundo cambio, de gran importancia - afectó a diez carteras-, vino determinado por la continuación de la crisis interna de la UCD, la confrontación Gobierno-Grupo Parlamentario y las reestructuraciones realizadas recientemente en el seno del propio partido, con la intención de frenar la crisis. Lo más llamativo del mismo fue la inclusión, por primera vez desde la Segunda República, de una mujer en el Gobierno: Soledad Becerril, que ocupó entonces la cartera de Cultura. El tercer y cuarto cambios se produjeron ya cuando la convocatoria de nuevas elecciones se hacia inminente, ante la desintegración prácticamente total de la UCD, y se debieron a simples reajustes producidos por las dimisiones de tres y un Ministro respectivamente ${ }^{11}$.

"Sobre la UCD y sus Gobiernos, vid. E. ATTARD, Vida y muerte de la UCD. Barcelona, Planeta, 1983. C. Huneeus, La Unión de Centro Democrático y la transición a la democracia en España. Madrid, CIS, 1985; E. Chamorao, Viaje al centro de la UCD. Barcelona, Planeta, 1981; F. JAuregui, M. Soriano, La otra historia de UCD. Madrid, E. Escolar, 1980; J. Figuero, UCD: "La empresa" que creó Adolfo Suárez. Barcelona, Grijalbo, 1981; R. GuNTHER, "El hundimiento de UCD, en J. J. LINZ, J. R. MonTERo (eds.), Crisis y cambio: Electores y partidos en la España de los años ochenta. Madrid, CEC, 1986. 
Las elecciones generales de octubre de 1982 dieron una aplastante victoria al PSOE y supusieron la llegada de los socialistas al Gobierno, del que habian estado apartados desde los años treinta; si bien ahora la mayoria absoluta les iba a permitir gobernar en solitario. Asi se formó el primer Gabinete González, que ha sido, hasta el presente, el de más larga duración - 44 meses-. Su existencia finalizaría con una nueva disolución anticipada de las Cámaras, poco antes de que se consumase de manera natural la legislatura. Este Gobierno experimentaría solamente un cambio, que afectó a seis de Departamentos. El motivo principal de este cambio puede encontrarse en una lucha intragubernamental por el dominio de la coordinación de la política interna, que el Ministro de Economia y Hacienda, $M$. Boyer, pretendía hacer desde el área económica. La no consecución de sus objetivos determinó su dimisión y la reestructuración gubernamental mencionada.

En julio de 1986, tras las elecciones generales del 22 de junio, que volvieron a dar al PSOE la mayoría absoluta, F. González formaría su segundo Gobierno, que continúa en ejercicio en el momento de redactar estas líneas. Este Gabinete experimentaria también un cambio, en julio de 1988, a los dos años justos de su existencia, que afectaria a ocho carteras. En este caso, las motivaciones del cambio se encuentran en el agotamiento de la politica de algunos Departamentos, que se encontraba en verdadera situación de bloqueo, debido a los múltiples problemas acumulados y a la incapacidad de sus titulares para darles una adecuada solución -Educación, Justicia, Interior y Transportes, principalmente- La sustitución de los Ministros afectados pretendió, pues, dar un nuevo impulso a la actuación gubernamental aportando Ministros de refresco. Quizá lo más llamativo de esta reestructuración haya sido la vuelta de las mujeres al Gobierno - Matilde Fernández y Rosa Conde-, para las que se crearon dos nuevos Departamentos - Asuntos Sociales y Portavoz del Gobierno-, y el nombramiento de un intelectual de prestigio, destacado militante del partido comunista en los años cincuenta, para la cartera de Cultura - Jorge Semprún-.

En resumen, pues, los motivos de los cambios, tanto de Gobierno, como intragubernamentales, han sido varios. Tratando de resumir lo expuesto, en lo que se refiere a los cambios de Gobierno, solamente uno de ellos ha caido como producto de una intervención del Jefe del Estado, de una destitución de su Presidente: el Gobierno Arias II. Sin embargo, debe tenerse en cuenta que aquel Gobierno y su destitución se produjeron bajo la legalidad del régimen franquista, todavia imperante en aquel momento, que permitía al Rey este tipo de actuación. Hoy en día, la Constitución de 1978 impide al Jefe del Estado la destitución discrecional de un Gobierno. Otro Gobierno finalizó sus días por la dimisión de su Presidente - Gobierno Suárez III- y los cuatro restantes (el Gobierno González II se encuentra aún en ejercicio) finalizaron debido a la disolución de las Cámaras y la 
convocatoria de nuevas elecciones; vía que parece institucionalizarse, siguiendo la vieja tradición parlamentaria española ${ }^{12}$.

Con respecto a los cambios intragubernamentales, éstos ofrecen un más amplio abanico de motivaciones, muchas de las cuales se encuentran entremezcladas como determinantes de un mismo cambio. Tratando de simplificar los datos mencionados, el motivo más común ha sido las discrepancias o confrontaciones en el seno del partido o mayoria que sostiene al Gobierno, que han afectado al 25 por 100 de los cambios. Le siguen inmediatamente las discrepancias de los Ministros en cuestión con la política general del Gobierno, lo que afecta al 20 por 100 de los cambios. $Y$, con el mismo porcentaje -20 por 100 de los cambios- se encuentran los conflictos con motivo de una politica concreta del Gobierno, que en el período analizado han sido principalmente la política económica -10 por 100 de los cambios - y la política regional o autonómica -10 por 100 de los cambios-. Después se encuentra la simple dimisión del Ministro, debida a motivos menores, de nula relevancia política: 15 por 100 de los cambios. Ya a mayor distancia se encuentran la incompetencia o bloqueo de la actuación ministerial: 10 por 100 de los cambios. $Y$, finalmente, con igual porcentaje -5 por 100 de los cambios - se encuentran, respectivamente, el deseo de atender mejor una determinada área de la política gubernamental, y las diferencias internas de otro tipo surgidas en el seno del Gabinete.

En definitiva, pues, ninguno de los Gobiernos del período ha sido derribado por el ejercicio correspondiente de los mecanismos de control o exigencia de responsabilidad política por parte de las Cortes, previstos a partir de la Constitución de 1978; por más que éstos hubieran sido ejercitados en más de una ocasión: la moción de censura sería presentada por primera vez el 21 de mayo de 1980; entonces el grupo socialista pretendió derribar al Gobierno Suárez III, proponiendo como candidato alternativo a la presidencia del Gobierno a F. González. La segunda moción de censura la presentaria Alianza Popular contra el Gobierno González II, el 22 de marzo de 1987, proponiendo como candidato a la presidencia del Gobierno a A. Hernández Mancha. En ambos casos las mociones fueron rechazadas. La cuestión de confianza, en cambio, sería ejercitada una sola vez y por A. Suárez, el 16 de septiembre de 1980, tras la importante remodelación -tercera- de su tercer Gabinete, realizada aquel mismo mes. En este caso la confianza sería concedida por una diferencia de 16 votos.

12 Vid. al respecto, G. BAYÓN CHACÓN, El derecho de disolución del Parlamento. Madrid 1935; A. BAR, La disolución de las Cámaras legislativas en el ordenamiento constitucional español, Madrid, Congreso, 1989. 


\section{CAMBIO Y ESTABILIDAD GUBERNAMENTAL}

\section{Discontinuidad con el periodo franquista}

En conjunto, y desde el punto de vista de este análisis, el período estudiado —diciembre 1975-julio 1988- puede ser dividido en dos grandes etapas: a) la primera de ellas es la etapa transicional, aquella que va desde el fallecimiento del general Franco y la formación del Gobierno Arias II hasta la celebración de las elecciones de junio de 1977. Esta etapa se caracteriza por el inicio del progresivo cambio en la clase política gubernamental y, lo que es más relevante para este trabajo, por la ausencia de un Parlamento democrático. En este sentido, esta etapa es aquí denominada preparlamentaria. A ella pertenecen los Gobiernos Arias II y Suárez I. Y b) la segunda etapa es aquella que va desde las elecciones generales de 1977 hasta nuestros dias. Esta etapa se caracteriza sustancialmente por el cambio radical en el componente personal del Gobierno, con respecto al periodo franquista, y por la existencia de un Parlamento democrático, el cual va a operar ya, no sólo como un mecanismo de control de la acción gubernamental ${ }^{13}$, sino como un ámbito de formación y de selección de la clase ministerial. Esta etapa podría ser subdividida, a su vez, en otras dos -y con ello toda la periodización-: aquélla previa a la elaboración de la Constitución, o fase preconstitucional, y aquélla posterior a la entrada en vigor del texto constitucional de 1978, o fase constitucional. Sin embargo, dado el tipo de datos que se pretende manejar en este estudio, esta subdivisión es menos relevante y no va a ser prácticamente considerada. En cualquier caso, debe señalarse finalmente, que a la fase preconstitucional de esta etapa pertenece el Gobierno Suárez II, y a la fase constitucional los Gobiernos Calvo-Sotelo y González I y II.

Lo primero que llama la atención, y es digno de ser resaltado, es la falta de continuidad existente, no sólo con respecto al régimen anterior, sino entre las diferentes etapas de esta periodización. En total, de los 107 Ministros habidos de diciembre de 1975 al momento presente, 33 lo fueron en la etapa preparlamentaria y 83 en la etapa parlamentaria; por lo que solamente nueve miembros del Gobierno llegaron a serlo en ambas etapas. Pero, lo que es más significativo aún, solamente seis de los 107 Ministros del periodo de referencia lo fueron también bajo la dictadura del general Franco, la mayoría de los cuales - cinco- lo sería exclusivamente en la etapa preparlamentaria, mientras que sólo uno -Pío Cabanillas- llegaría a serlo también en la etapa parlamentaria que sigue a las elecciones de junio de 1977. Y ello es llamativo, dado que no se puede olvidar que el

13 Las relaciones Gobierno-Cortes, ante la ausencia de una Constitución, que en aquel momento se elaboraba, fueron reguladas entonces por la Ley de 17 de noviembre de 1977 y por los Reglamentos provisionales de las Cámaras, de octubre del mismo año. 
primer Presidente del Gobierno de este periodo fue precisamente Arias Navarro, el último Presidente del período franquista; lo que haría pensar, dado el atenuado reformismo meramente neofranquista del programa Arias, en unas mayores dosis de continuidad personal en la constitución de su Gobierno postfranquista con respecto a la clase política gubernamental del antiguo régimen. En todo caso, sí debe señalarse también que, de estos seis miembros del Gobierno que lo fueron igualmente con el general Franco, todos ellos formarian parte de los dos Gabinetes formados por Arias ${ }^{14}$, en el período pre y postfranquista, mientras que solamente dos formarían parte de Gabinetes Suárez o Calvo-Sotelo ${ }^{15}$.

Parece obvio decir, pues, que, si se ha producido una importante ruptura o solución de continuidad entre el periodo franquista y el periodo aquí analizado, al menos en lo que se refiere a lo que cabría denominar como la clase política gubernamental; sobre todo, esta ruptura o discontinuidad es aún más apreciable si tomamos como referencia exclusivamente la etapa parlamentaria de este segundo período, en la que sólo llega a participar un Ministro proviniente de Gobiernos del régimen del general Franco. Por lo demás, el cambio sustancial con respecto al régimen anterior se va a apreciar también en muchos de los aspectos que se analizan a continuación.

\section{Esíabilidad y duración}

Desde el punto de vista de la duración y atendiendo a criterios formales, si se toma en consideración la permanencia en el cargo de los Presidentes del Gobierno y, consiguientemente, de los Gobiernos que de ellos dependieron como un todo, habria que concluir que los Gobiernos españoles han gozado de una gran estabilidad. Todos los Gobiernos han cubierto el periodo para el que fueron nombrados, es decir, han sido Gobiernos de legislatura, excepto en dos casos: el Gobierno Arias II -preparlamentario-, que seria sustituido por el Gabinete Suárez I en julio de

14 Pio Cabanillas, si bien formó parte del Gobierno Arias I, no sería incluido en el Gabinete Arias II, aunque sí llegaria a formar parte de los Gobiernos Suárez II y III y Calvo Sotelo, en la etapa parlamentaria. neral Franco:

${ }_{15}$ Ministros del período analizado que lo fueron también durante el régimen del ge-

arias Navarro, Carlos

Cabanillas Gallas, Pio

fraga Iribarne, Manuel

Pita da Veiga Sanz, Gabaiel

SOLIZ RUIZ, JOSE

Valdes Gonzalez-Roldan, Antonio
Franco-Carrero; Arias I, II

Franco-Arias I; Suárez II, III; Calvo-Sotelo

Franco; Arias II

Franco-Carrero; Arias I, II; Suárez I

Franco; Arias I, II

Franco-Arias I, II 
1976, y el Gobierno Suárez III, que finalizó con la dimisión del Presidente, en febrero de 1981.

Como ya se ha visto, ningún Gobierno ha sido, por tanto, derribado como efecto de una censura o crisis de las relaciones fiduciarias GobiernoCortes, o pérdida de la mayoría parlamentaria. Lo que sí se ha producido, en cambio, por parte del Gobierno, es el libre ejercicio del poder de disolución de las Cámaras, que ha llevado consigo, no sólo la finalización anticipada de la legislatura, sino también la finalización de la propia vida del Gabinete. En este sentido, es de resaltar el hecho de que, desde el inicio de la etapa parlamentaria, en junio de 1977, nunca las cámaras han llegado a finalizar el período de cuatro años para el que fueron elegidas, siendo siempre disueltas con anterioridad. Parece que se reinicia así la vieja tradición de nuestro parlamentarismo histórico —que lo es también de otros sistemas parlamentarios de tanta raigambre como el británico-, según la cual el modo habitual de finalizar la legislatura es la disolución anticipada de las Cámaras ${ }^{16}$. Estas disoluciones, decididas por el Gobierno, no han tenido siempre, sin embargo, similar motivación; con lo que el cambio de los Gabinetes producido ha respondido igualmente a una etiología diferente.

La disolución de las Cortes Constituyentes, el 29 de diciembre de 1978, respondió al doble motivo de, por un lado, permitir la puesta en práctica plena de los mecanismos parlamentarios del nuevo sistema establecido por la recientemente aprobada Constitución de 1978, y, por otro, aprovechar el influjo favorable al grupo entonces mayoritario - la UCD- que en el electorado había producido aquella aprobación. El Gobierno realizó, pues, una disolución, tratando de aprovecharse de una coyuntura política favorable. La disolución del 27 de agosto de 1982, tuvo, en cambio, una motivación bien diferente. Destrozado por sus tensiones internas el partido gobernante, la UCD, y perdida ya prácticamente la mayoria gubernamental, debido a las sucesivas escisiones producidas, el Gabinete Calvo-Sotelo no tuvo más remedio que acudir a la disolución, para asegurar la gobernabilidad del Estado. Cabría decir que la disolución le vino impuesta al Gabinete por las circunstancias políticas. La disolución del 22 de abril de 1986, por el contrario, se produjo -como la primera- con la intención de aprovechar una coyuntura politica favorable al Gobierno, tal y como fue el resultado afirmativo del referéndum sobre la permanencia de España en la OTAN, celebrado el 12 de marzo. Por otra parte, esta disolución se produjo solamente unos meses antes del final natural de la legislatura.

${ }^{16}$ Vease, con respecto a España, G. BAYON CHACÓN, El derecho de disolución del Parlamento. cit.; A. BAR, La disolución de las Cámaras legislativas en el ordenamiento constitucional español, cit. Con respecto al Derecho comparado, por ejemplo, G. GuARINo, Lo scioglimento delle Assemblee Parlamentari. Napoli 1948; B. S. MARKEsINIs, The Theory and Practice of Dissolution of Parliament. Cambridge 1972; P. Lauvaux, La dissolution des Assemblées parlementaires. París 1983. 
Sin embargo, es obvio que la estabilidad o duración de un Gobierno no puede medirse exclusivamente con esta referencia formal, y que un Gabinete no puede considerarse estable por el mero hecho de que hubiese durado una legislatura, aunque esta legislatura hubiese fenecido por disolución, con gran anticipación a su finalización natural; o por el hecho de que no hubiese sido derribado como consecuencia de una crisis en sus relaciones con las Cortes, o en el seno de la propia mayoría gubernamental. Duración y estabilidad no son, en este sentido, términos sinónimos o perfectamente intercambiables; pues; mientras que el primero tiene una exclusiva significación temporal, el segundo comprende, además, una clara significación política, lo que permite un diferente juicio valorativo sobre el mismo ${ }^{17}$. En otras palabras, y como se verá a continuación, si en términos estrictamente formales - y aun aquí con dificultad- pudiera llegarse a sostener la relativa estabilidad de los Gobiernos habidos en España desde diciembre de 1975 , si nos referimos a la duración temporal de los mismos y a los cambios experimentados, la conclusión ha de ser muy otra.

El Gobierno Arias II, si bien permaneció inalterado durante todo su mandato, éste llego a durar solamente siete meses, una infima parte del período de cinco años que preveía la entonces vigente Ley Orgánica del Estado (art. 14.2). El Gobierno Suárez I, que duró 12 meses, experimentaría tres cambios, el primero de los cuales se produciria ya a los dos meses de su nombramiento, sin embargo, en los tres casos, el cambio fue de muy corto alcance, pues solamente afectaria a uno de los puestos ministeriales. En total, una persona saldría del Gobierno y otra entraría, en cada uno de los tres casos ${ }^{18}$. El Gobierno Suárez II, con una duración total de 21 meses, experimentaria también tres cambios, dos de los cuales afectarían a un solo puesto ministerial -una dimisión, en el primer caso, y un nombramiento, en el segundo-, mientras que el último de ellos, a mitad de su mandato, afectó a cinco puestos. En total, 10 serian las personas afectadas por este último cambio: cuatro entraron en el Gobierno, cinco salieron y una cambió de cartera ${ }^{19}$. El Gobierno Suárez III, último de los presididos por éste y que finalizaría con su dimisión en febrero de 1981, llegaría a alcanzar los 23 meses de duración, y, como en los casos anteriores, experimentaría tres cambios, si bien de mucha mayor trascendencia.. El primero de los cambios afectaría a tres carteras - una persona entra en el Gobierno, otra sale, y una tercera cambia de puesto-. El segundo afectó a nueve carteras y supuso el cambio de 15 personas: seis nuevos Ministros entraron en el Gobierno, otros seis serian destituidos, y tres cambiarian de

17 Véase al respecto, J. R. MONTERo, «Parlamento, estabilidad política y estabilidad gubernamental: una recapitulación”, Revista de las Cortes Generales, 4, 1985, pp. 23-72; K. M. SUbATRA, «A theory of Government Instability in Parliamentary Systems», Comparative Political Studies, 13, 1980, pp. 253-263; K. VON BEYME, "El problema de la estabilidad de los Gobiernos: Un estudio comparado", en M. RAMiREZ (ed.), El control parlamentario del Gobierno en las democracias pluralistas. Barcelona, Labor, 1983, pp. 375-389.

18 Los cambios tuvieron lugar el 23-9-1976, el 15-4-1977, y el 11-5-1977.

19 Los cambios tuvieron lugar el 30-9-1977, el 11-2-1978, y el 25-2-1978. 
puesto. El tercero y último de los cambios fue aún más amplio -el más amplio de los registrados bajo los Gobiernos de la UCD- y afectó a once carteras y 19 personas, lo que permitiría hablar en la práctica, de una remodelación total o nuevo Gabinete. Siete Ministros entraron en el Gobierno, ocho salieron y cuatro cambiaron de cartera ${ }^{20}$. El Gobierno Calvo-Sotelo duraría 21 meses y durante ellos experimentaria cuatro cambios ministeriales. El primer cambio afectó a dos puestos y tres personas - una entró en el Gobierno, otra salió y una tercera cambiaría de cartera-. El segundo cambio, mucho más amplio, afectó a 10 carteras y 13 Ministros - seis entraron en el Gobierno, tres salieron y cuatro cambiaron de puesto- El tercer cambio fue de nuevo más reducido y afectó a cinco puestos - se nombró a un Ministro, otro cambió de puesto y tres salieron del Gobierno-. $Y$, finalmente, el cuarto y último cambio afectó solamente a una cartera -un Ministro entró en el Gobierno y otro salió_ ${ }^{21}$. El Gobierno González I, en sus 44 meses de duración experimentó un solo cambio, que afectó a seis puestos ministeriales, casi la mitad de las carteras existentes - cinco Ministros entraron en el Gobierno, otros cinco salieron y uno cambió de cartera- ${ }^{22}$. Por último, el Gobierno González II, que se encuentra en este momento en ejercicio - por lo que es excluido del cómputo total de duración media de los Gobiernos-, ha experimentado ya también un cambio a los 23 meses de su existencia, más amplio que el anterior, y que ha afectado a ocho carteras - seis Ministros entraron en el Gobierno, cuatro salieron y dos cambiaron de puesto- ${ }^{23}$. (Vid. Cuadro 1.)

El balance que se ofrece es, pues, de una duración media total de 21,33 meses por Gobierno. Permanencia media de cada Gabinete que se eleva un poco si se considera solamente a los Gobiernos habidos durante la etapa que hemos denominado "parlamentaria" - Gabinetes Suárez II y III, Calvo-Sotelo, y González I y II-, pasando ésta entonces a ser de 27,25 meses por Gobierno. Se trata, pues, de una duración media que, si bien en abstracto pudiera considerarse corta - apenas se alcanza la mitad de la duración de una legislatura fijada por la Constitución en cuatro años (48 meses) - en términos comparativos no lo es tanto. La duración media de los Gobiernos españoles del periodo analizado es, así, similar a la francesa (23,27 meses), japonesa (24 meses), danesa (26,2 meses) y holandesa (29,3 meses); y, si bien es inferior a la de los muy estables Gabinetes alemanes (38,1 meses), irlandeses (34,68 meses), británicos (32,93 meses), o austríacos (30,36 meses), es muy superior a la de los Gabinetes que se encuentran en el fondo de la tabla de la estabilidad gubernamental: los Gabinetes belgas (16 meses), finlandeses (11 meses), o italianos (10,8 meses) ${ }^{24}$

${ }^{20}$ Los cambios tuvieron lugar el 17-1-1980, el 3-5-1980, y el 9-9-1980.

${ }^{21}$ Los cambios tuvieron lugar el 1-9-1981, el 2-12-1981, el 30-7-1982, y el 13-9-1982.

22 El cambio tuvo lugar el 5-7-1985.

23 El cambio tuvo lugar el 12-7-1988.

24 Los datos son de elaboración propia. Véanse también al respecto, V. HermaN, "Comparative Perspectives on Ministerial Stability in Britain", en V. HERMAN, J. ALT (eds.), Cabinet Studies: A Reader. New York, St. Martin's, 1975, pp. 55-76. 
Por otra parte, parece haberse logrado romper la dinámica de inestabilidad gubernamental exacerbada que presidió nuestra historia parlamentaria. Así, si bajo el primer período de la Restauración -1875-1901los Gobiernos llegaron a tener una duración media de 22 meses, muy similar a la actual, tanto en períodos previos, como posteriores, ésta fue mucho más reducida. En el comienzo del régimen parlamentario, entre 1834 y 1873, la duración media de los Gobiernos fue de siete meses; bajo la Primera República duraron unos tres meses, tiempo igual a la media de duración de los Gabinetes de la Segunda República; y durante el segundo período de la Restauración - 1902-1923 - rozaron los ocho meses ${ }^{25}$.

Ahora bien, si la duración total de los Gabinetes no ha sido demasiado baja, sobre todo en términos comparativos -y más aún si se tiene en cuenta las circunstancias históricas por las que ha debido de pasar España en las últimas décadas-, la verdad es que si se consideran también los cambios o remodelaciones producidos en cada uno de los Gabinetes analizados, el tiempo de estabilidad se reduce considerablemente. Así, a lo largo del mandato de los siete Gobiernos de referencia, el tiempo medio de estabilidad total, es decir, sin cambio alguno en la estructura gubernamental, ha sido de 7,43 meses. El primer Gobierno socialista de Felipe González ha sido pues, no sólo el que mayor duración total ha logrado hasta el presente, con sus 44 meses de permanencia en el poder, sino el que mayor nivel de estabilidad absoluta ha conseguido, al lograr permanecer 31 meses sin cambio o remodelación alguna; y le sigue inmediatamente el Gobierno González II, que tardó 23 meses en ser alterado.

En este último aspecto, los Gobierno españoles sí han sido, en cambio, los más inestables de nuestro entorno democrático-parlamentario. Y ello no sólo por el corto tiempo medio de estabilidad absoluta, sin cambio alguno, sino por el número mismo de remodelaciones internas operadas en cada Gobierno -quince, en total-, que produce una media de 2,14 remodelaciones por Gobierno. En términos comparativos, si bien la distancia es grande, el caso español se acerca mucho al ejemplo británico $(1,54$ remodelaciones por Gabinete), canadiense $(1,29$ remodelaciones por Gabinete), o japonés (1,13 remodelaciones por Gabinete), pero se aleja muchísimo del caso de la mayoría de los Gabinetes europeos, en los que, si bien la duración total de los Gobiernos pueda ser similar en algunos casos a la española - como ya se ha visto-, las remodelaciones o cambios parciales en el seno de los mismos son casi inapreciables $(0,28$ remodelaciones por Gabinete). En este sentido, es importante señalar al respecto que son precisamente los Gobiernos homogéneos formados por un solo partido, los que tienden a producir mayor número de remodelaciones, como ma-

25 Vid. M. ARtola, Partidos y programas politicos. Madrid, Aguilar, 1974, vol. I, p. 349; J. J. Linz, La quiebra de las democracias. Madrid, Alianza, 1987, pp. 74-75; J. R. MONTERo, “Parlamento, estabilidad política y estabilidad gubernamental: una recapitulacion", cit., pp. 4547; A. BAR, El presidente del Gobierno en España: Encuadre constitucional y práctica politica. Madrid, Civitas, 1983, pp. 251 ss. 
nifiestan los casos británico y español; mientras que los Gabinetes de coalición - los más frecuentes en Europa-, si bien suelen tener una vida total menor, experimentan menos cambios, al verse su constitución asegurada por el pacto de coalición, que impide al Primer Ministro disponer libremente de los puestos gubernamentales ${ }^{26}$.

\section{Movilidad ministerlal}

La movilidad ministerial registrada en España desde el periodo de transición a la democracia hasta nuestros dias ha sido bastante grande. Se ha producido una gran permeabilidad en la estructura ministerial, siendo muy elevado el número de Ministros que han ocupado un solo cargo ministerial y que han estado muy poco tiempo en el Gobierno, dando así fácil acceso al mismo a nuevos nombres y rostros políticos. Esta movilidad o permeabilidad de la estructura ministerial no puede ser sino la consecuencia de la necesidad de renovación de la "clase politico-gubernamental» tradicional y de la introducción o creación de una nueva, no implicada en la gobernación del antiguo régimen dictatorial.

Asi, como ya se ha visto, de los 107 Ministros del período 1975-1988, aqui analizado, solamente seis $(5,61 \%)$ lo fueron previamente durante la vida y régimen del general Franco. Pero, es más, esta falta de continuidad se aprecia incluso entre las dos grandes fases en las que se puede dividir este periodo, la fase preparlamentaria anterior a las elecciones generales de junio de 1977, y la fase parlamentaria, que sigue inmediatamente a aqueIla fecha, y cuyo primer Gobierno es el Gabinete Suárez II. Así, solamente nueve Ministros del total $(8,41 \%)$ llegaria a ocupar cargos en Gobiernos formados en ambas fases, mientras que $83(77,57 \%)$ serían Ministros exclusivamente en los Gobiernos de la fase parlamentaria.

Efectivamente, la alta movilidad o permeabilidad de la estructura ministerial en España se manifiesta claramente por el hecho de que más de la mitad de los miembros del Gobierno lo han sido una sola vez $(54,21 \%)$; pero, sobre todo, por el bajísimo porcentaje de aquellos que lo han sido más de dos veces: el 18,73 por 100 (vid. Cuadro 2). Y, en similar sentido, esta falta de continuidad — que cabría denominar como movilidad externa- se manifiesta también en el hecho de que, si exceptuamos los Gabinetes Suárez III, González II y Calvo-Sotelo, este último en grado sumo, los demás Gobiernos han tendido a formarse con personas que no habian sido Ministros ya en anteriores Gobiernos; y ello a pesar de la con-

26 Vid. I BUDGE, “Party Factions and Government Reshuffles: A General Hypothesis Tested against Data from 20 Post-war Democracies", European Journal of Political Research, 13, 1985, pp. 327-333; V. HERMAN, “Comparative Perspectives on Ministerial Stability", cit., p. 57 y ss. 


\section{CUADRO 2. FRECUENCIA EN EL GOBIERNO: NOMBRAMIENTOS}

\begin{tabular}{|c|c|c|c|c|}
\hline $\begin{array}{l}\text { N. }{ }^{\circ} \text { DE VECES } \\
\text { MINISTRO }\end{array}$ & $\begin{array}{c}N^{\circ} \text { DE } \\
\text { MINISTROS }\end{array}$ & $\%$ & $\begin{array}{c}\text { N. }{ }^{\circ} \text { DE } \\
\text { NOMBRAMIENTOS }\end{array}$ & $\%$ \\
\hline $\begin{array}{r}1 \\
2 \\
3 \\
4 \\
5 \\
6\end{array}$ & $\begin{array}{r}58 \\
29 \\
9 \\
7 \\
2 \\
2\end{array}$ & $\begin{array}{r}54,21 \\
27,10 \\
8,41 \\
6,54 \\
1,89 \\
1,89\end{array}$ & $\begin{array}{l}58 \\
58 \\
27 \\
28 \\
10 \\
12\end{array}$ & $\begin{array}{r}30,05 \\
30,05 \\
14,00 \\
14,51 \\
5,18 \\
6,22\end{array}$ \\
\hline $\begin{array}{l}\text { Total } \\
\text { Media: }\end{array}$ & $\begin{array}{c}107 \\
1,80 \text { veces }\end{array}$ & 100 & 193 & 100 \\
\hline
\end{tabular}

tinuidad existente con respecto a la mayoría sostenedora del Gobierno y, aun, de su Presidente ${ }^{27}$. Así, como se puede comprobar en el Cuadro 3, frente al número de Ministros que sólo formaron parte de un mismo Gabinete $(54,21 \%)$, es igualmente bajo el número de Ministros que han for-

\section{CUADRO 3. GOBIERNOS A LOS QUE PERTENECIERON}

\begin{tabular}{|c|c|c|}
\hline N. ${ }^{\circ}$ DE GOBIERNOS & N. ${ }^{\circ}$ DE MINISTROS & $\%$ \\
\hline $\begin{array}{l}1 \\
2 \\
3 \\
4 \\
5\end{array}$ & $\begin{array}{r}58 \\
37 \\
8 \\
1 \\
3\end{array}$ & $\begin{array}{r}54,21 \\
34,58 \\
7,48 \\
0,93 \\
2,80\end{array}$ \\
\hline $\begin{array}{l}\text { Total } \\
\text { Media: } 1,64 \text { Gobiernos }\end{array}$ & 107 & 100 \\
\hline
\end{tabular}

27 Por orden jerárquico los Gobiernos que mayor número de Ministros «nuevos» han tenido, han sido: González I $(95,5 \%)$, Arias II $(75 \%)$, Suárez II (64\%), Suárez I $(56,5 \%)$, Suárez III (51\%), González II (43,5\%), y Calvo-Sotelo (28\%). 
mado parte de más de un Gobierno diferente, siendo aún menor aqui el porcentaje de aquellos que han formado parte de más de dos Gobiernos $(11,21 \%)$. Cifras, por otra parte, muy similares en ambos casos a las anteriores. Por término medio, pues, los Ministros españoles han formado parte del Gobierno solamente una vez $-1,8$ veces, exactamente-, y, por tanto, han pertenecido siempre a un mismo Gabinete - han formado parte de una media de 1,64 Gobiernos, en términos exactos-.

Por otra parte, esta movilidad personal ha tenido un relativo reflejo en la estabilidad de los Departamentos, es decir, en lo que cabría denominar como movilidad interna. Así, si, por un lado, se considera a los Ministros en su totalidad, sin hacer distinción alguna por el número de veces que hayan formado parte del Gobierno, dado el elevado número de Ministros que lo han sido solamente una vez, lo más frecuente, con gran diferencia, es que los Ministros ocupasen siempre la misma cartera ministerial durante su estancia en el Gobierno. En este sentido, efectivamente, si bien es cierto, como se ha visto con anterioridad, que los Gobiernos españoles han tendido a hacer proliferar las remodelaciones, éstas han supuesto preferentemente la entrada en el Gobierno de nuevos Ministros, y no el mero intercambio de carteras o puestos de responsabilidad entre Ministros que se mantenian en el Gobierno. Así, frente al 74,77 por 100 de los Ministros que ocuparon siempre la misma cartera o puesto en el Gobierno, con independencia del número de veces que hayan formado parte de éste, solamente un 10,28 por 100 ocuparon más de dos carteras diferentes (vid. Cuadro 4).

Sin embargo, la perspectiva es muy otra si se profundiza un poco más en el análisis. Asi, si distinguimos y separamos a los Ministros que

\section{CUADRO 4. PUESTOS O CARTERAS OCUPADOS EN EL GOBIERNO}

\begin{tabular}{lrr}
\hline N. ${ }^{\circ}$ DE PUESTOS & N. ${ }^{0}$ DE MINISTROS & $\%$ \\
& & \\
& 80 & 74,77 \\
Siempre en ei mismo puesto & 16 & 14,95 \\
2 puestos diferentes & 7 & 6,54 \\
3 puestos diferentes & 3 & 2,81 \\
4 puestos diferentes & 1 & 0,93 \\
5 puestos diferentes & & \\
\hline & 107 & 100 \\
Total & & \\
Media: 1,40 puestos & & \\
\hline
\end{tabular}


lo han sido más de una vez de aquellos que sólo recibieron un nombramiento, se comprueba como la permanencia de los primeros en el Gobierno, a través de sucesivos nombramientos o Gabinetes, no va necesariamente unida a la ocupación o desempeño siempre del mismo puesto o cartera ministerial. Por el contrario, solamente la mitad de los Ministros que permanecieron en el Gobierno de manera continua, ininterrumpida, a través de sucesivos nombramientos, ocuparon siempre el mismo puesto o cartera; mientras que no llegan siquiera a un cuarto de los Ministros que volvieron a serlo de manera discontinua o interrumpida los que volvieron a ocupar el mismo puesto o cartera que en la etapa anterior (vid. Cuadro 6). A pesar de todo, hay que reconocer que no es frecuente en España el caso de lo que cabría denominar "Ministro comodín»; es decir, aquel que es miembro del Gobierno un elevado número de veces, ocupando puestos o carteras ministeriales de todo tipo. Caso éste del que se registra una mayor frecuencia en otros países, como, por ejemplo, en Italia ${ }^{28}$. En conjunto, pues - y sin pretender entrar aqui en el desarrollo de un tema del que me ocuparé más adelante-, parece insinuarse, a primera vista, una cierta tendencia a la especialización por parte de los Ministros españoles.

Entre nosotros, el miembro del Gobierno que más número de puestos diferentes llegó a ocupar en el seno del mismo ha sido Calvo-Sotelo - cinco puestos diferentes-, quien es también, por otra parte, el Ministro que más tiempo acumulado ha permanecido en el Gobierno durante todo el período aquí analizado - 75 meses-. Le siguen inmediatamente, con cuatro puestos diferentes cada uno, Arias-Salgado, Cabanillas y Martín ViIla. Todos ellos han sido Ministros en Gobiernos de la UCD, lo que es una evidente manifestación más de la gran inestabilidad global que, como ya se ha visto, caracterizó a los Gabinetes de aquel período inicial de la democracia española, formados por el fenecido partido centrista. Lo normal ha sido, pues, que los Ministros españoles lo hayan sido solamente una vez, que hayan pertenecido sólo, o siempre, al mismo Gobierno, y que hayan ocupado siempre la misma cartera o puesto ministerial.

Por otra parte, el tiempo total acumulado de permanencia en el Gobierno por Ministro -es decir, agregando la duración de las diversas estancias en el Gabinete-, es bastante bajo, muy inferior a la media registrada en los demás países de Europa, y supera escasamente los dos años. La media es de 26,4 meses por Ministro; aunque la variación es grande, y va entre el máximo de 75 meses de estancia total en el Gobierno, de CalvoSotelo, y el mínimo de escasamente tres meses de Camuñas Solis, Garcia Ferrero y Pery Junquera. Ahora bien, esta cifra global se reduce drásticamente a la mitad si se considera separadamente el tiempo de perma-

${ }^{28}$ Vid. S. CASSESE, «IS There a Government in Italy?: Politics and Administration at the Top", en R. Rose, E. N. Suleiman (eds.), Presidents and Prime Ministers. Washington, AEI, 1980, pp. 171-202; M. DOGAN, "La selection des Ministres en Italie: Dix règles non-ecrites", International Political Science Review, 2, 1981, pp. 189-209; M. CALISE, R. MANNHEIMER, Governanti in Italia. Bologna, Mulino, 1982, pp. 109 ss. 
nencia continuada en el Gabinete por cada Ministro y en cada ocasión. Así, los Ministros españoles del período postfranquista han permanecido de manera continuada en cada puesto o cargo ministerial una media de 13,62 meses. Los casos más llamativos de continuidad ininterrumpida en el Gobierno son, desde luego, los de Felipe González y los siete Ministros de su primer Gobierno que han pasado a formar parte también del segundo Gabinete socialista y que aún permanecen en el cargo en el presente, tras la remodelación de este último que tuvo lugar en julio de 1988. Si el segundo Gabinete de F. González agotase la legislatura, estos Ministros llegarían a superar los 90 meses de permanencia ininterrumpida en el Gobierno; lo que sí es en realidad un verdadero récord de estabilidad y permanencia en el cargo, sobre todo si se tiene en cuenta que en tres de estos casos la cartera o puesto gubernamental ocupado ha sido, y continúa siendo, el mismo: Guerra en la Vicepresidencia, Romero en Agricultura, Pesca y Alimentación, y Serra en Defensa; además, claro está, del propio González en la Presidencia del Gobierno. El segundo lugar de permanencia continuada lo ocupa A. Suárez, que llegó a permanecer 63 meses seguidos en el Ejecutivo, 56 de ellos como Presidente del Gobierno. En el extremo opuesto, la permanencia continuada más breve en el Gobierno la registra Luis Ortiz, como Ministro de Obras Públicas del Gabinete Suárez I, cargo en el que permaneció escasamente dos meses ${ }^{29}$. (Vid. Cuadro 5.)

En el contexto parlamentario europeo, la media de duración total de presencia en el Gobierno de un Ministro, tras los varios nombramientos de los que pueda disfrutar - de manera continuada o interrumpida-, es de algo más de cuatro años (53,6 meses); mientras que la permanencia media en cada puesto, tras cada nombramiento, es de unos dos años (26 meses). Ambas cifras, pues, como ya queda dicho, duplican prácticamente los 20,4 meses de media de la duración total en el Gobierno, y los 13,6 meses de media de permanencia en cada puesto o cartera, de los Ministros españoles. Claro que, a pesar de que las cifras absolutas de inestabilidad son suficientemente indicativas de la situación real —cuya dinámica tiende a corregirse mínimamente en los dos últimos Gobiernos formados-, en lo que se refiere a los tiempos de duración de los Ministros en el Gobierno, el corto periodo de tiempo transcurrido desde la muerte del general Franco - momento en que se localiza el inicio de este análisis-, hasta nuestros días, sí ha jugado un papel decisivo, impidiendo de forma absoluta el que estos tiempos de permanencia en el Ejecutivo hayan podido ser mayores de lo que han sido; y ello no debe dejar de ser tenido en cuenta a la hora de su valoración ${ }^{30}$.

${ }^{29}$ Luis Ortiz González volvería, sin embargo, a ser Ministro de Obras Públicas más tarde, en el Gabinete Calvo-Sotelo, y por un periodo continuado de 21 meses.

${ }_{30} \mathrm{Vid}$. J. BLONDEL, Government Ministers in the Contemporary World. London, Sage, 1985, pp. 90 ss.; R. ROSE, "The Making of Cabinet Ministers", British Journal of Political Science, 1, 1971, pp. 393-414; V. HeRman, "Comparative Perspectives on Ministerial Stability in Britain", cit., p. 62 ss.; M. DogaN, "How to Become a Cabinet Minister in France: Career Pathways, 1970-1978", Comparative Politics, 12, 1979, pp. 1-24; J. L. BodIGuEL, "Que sont les Ministres devenues?", Pouvoirs, 36, 1986, pp. 135-142. 


\section{CUADRO 5. DURACIÓN EN EL GOBIERNO}

\begin{tabular}{|c|c|c|c|c|c|c|c|c|c|c|}
\hline \multirow{2}{*}{ MESES } & \multicolumn{2}{|c|}{ TOTAL (") } & \multicolumn{2}{|c|}{$\begin{array}{c}M^{\text {os }} \text { QUE } \\
\text { NO REPITEN }\end{array}$} & \multicolumn{6}{|c|}{$\begin{array}{l}M^{o s} \text { QUE } \\
\text { REPITEN }\end{array}$} \\
\hline & $\mathbf{N}^{\circ}$ & $\%$ & N..$^{\circ}$ & $\%$ & $\mathrm{~N}^{\circ}$ & $\begin{array}{l}\text { stal } \\
\%\end{array}$ & $\mathbf{N}^{\circ}$ & (1) $\%$ & $\mathrm{~N}^{\circ}$ & $\%$ \\
\hline $\begin{array}{r}<12 \\
12-24 \\
25-48 \\
49-72 \\
>72\end{array}$ & $\begin{array}{r}23 \\
35 \\
23 \\
19 \\
1\end{array}$ & $\begin{array}{r}22,8 \\
34,7 \\
22,8 \\
18,8 \\
0,9\end{array}$ & $\begin{array}{r}22 \\
23 \\
7 \\
- \\
-\end{array}$ & $\begin{array}{r}21,8 \\
22,8 \\
6,9 \\
- \\
-\end{array}$ & $\begin{array}{r}1 \\
12 \\
16 \\
19 \\
1\end{array}$ & $\begin{array}{r}0,9 \\
11,9 \\
15,8 \\
18,8 \\
0,9\end{array}$ & $\begin{array}{r}1 \\
9 \\
14 \\
16 \\
-\end{array}$ & $\begin{array}{r}0,9 \\
8,9 \\
13,9 \\
15,8 \\
-\end{array}$ & $\begin{array}{l}-3 \\
2 \\
3 \\
1\end{array}$ & $\begin{array}{l}-\overline{2,9} \\
1,9 \\
2,9 \\
0,9\end{array}$ \\
\hline Total & 101 & 100 & 52 & 51,5 & 49 & 48,5 & 40 & 39,6 & 9 & 8,9 \\
\hline
\end{tabular}

Duración media total por Ministro: 20,40 meses Duración media de la permanencia en cada puesto: 13,62 meses

CLAVE:

(*) Se excluyen los 6 Ministros incluidos en el Gobierno en la remodelación de 1988.

(1) De forma continuada.

(2) De forma discontinua o interrumpida.

Sin embargo, a pesar de la reflejada movilidad y permeabilidad de la estructura ministerial, que ha permitido la creación de una «clase gubernamental» nueva, y que ha sido determinada por la necesidad misma de su creación a la salida del régimen franquista, es apreciable ya en España una cierta tendencia a la consolidación de un determinado número de personas como parte de esa «clase gubernamental»; personas que se repiten con frecuencia en el conjunto de las formaciones de los Gabinetes habidos durante el periodo analizado. Ello se comprueba, en términos puramente matemáticos, por la relación inversa existente entre el número de Ministros registrados y el porcentaje de los nombramientos recibidos o acumulados por éstos a lo largo de todo el período. Efectivamente, el 18,73 por 100 de los Ministros, que lo han sido más de dos veces, acumula el 39,91 por 100 de los nombramientos; mientras que el 54,21 por 100 de los Ministros, que lo han sido solamente una vez, acumula sólo un 30,05 por 
100 de los nombramientos. En cambio, la relación se encuentra más equilibrada en el caso de los Ministros que lo han sido dos veces, el 27,10 por 100 , los cuales recibieron el 30,05 por 100 de los nombramientos. (Vid. Cuadro 2.)

Así pues, a pesar de la inestabilidad general registrada, esta consolidación de un determinado número de Ministros en la estructura gubernamental permite hablar también de unas ciertas dosis de continuidad en la dinámica o evolución gubernamental. Efectivamente, de los 49 Ministros que lo han sido en más de una ocasión $\left(48,51 \%\right.$ del total) ${ }^{31}, 40$ de ellos fueron miembros del Gobierno de manera continuada, no interrumpida (39,6\% del total), y, además, de ellos, 20 serían nombrados siempre para el mismo puesto o cartera (19,8\% del total). Estos 20 Ministros constituyen, pues, el verdadero núcleo de la continuidad gubernamental, por encima de los sucesivos cambios de Gobierno y remodelaciones habidas. (Vid. Cuadro 6.)

Por lo demás, este tipo de situación se repite también de forma similar en otros sistemas parlamentarios que registran, o han registrado, un elevado indice de inestabilidad gubernamental. Así, por ejemplo, en Italia, uno de los casos más llamativos de inestabilidad de los Gabinetes entre los regímenes parlamentarios europeos actuales, la continuidad guberna-

\section{CUADRO 6. CONTINUIDAD DE LOS MINISTROS QUE HAN SIDO MIEMBROS DEL GOBIERNO MÁS DE UNA VEZ}

\begin{tabular}{lrrrr}
\hline \multicolumn{1}{c}{ CONTINUIDAD } & N. & $\%$ (1) & $\%$ (2) \\
& & & & \\
& 20 & 40,82 & 19,80 \\
Ministros continuos en el mismo puesto & 20 & 40,82 & 19,80 \\
Ministros continuos en puestos diferentes & 2 & 4,08 & 1,98 \\
Ministros discontinuos en el mismo puesto & 7 & 14,28 & 6,93 \\
Ministros discontinuos en puestos diferentes & & & & \\
\hline & 49 & 100 & 48,51 \\
\hline Total & & & & \\
\hline
\end{tabular}

(1) Sobre el número de Ministros que repiten.

(2) Sobre el número total de Ministros, excluidos los 6 Ministros incluidos en la remodelación de 1988.

31 Se excluyen del cómputo en este caso los seis Ministros entrados en el Gobierno en la remodelación de julio de 1988. 
mental se puede decir que viene asegurada por la prácticamente continua presencia en los sucesivos Gobiernos de 36 Ministros, que acumulan la inmensa mayoría de los nombramientos realizados desde el año 1945. Entre estos casos, que llegaron a formar parte del Gobierno más de ocho veces, se encuentran nombres tan conocidos como los de Colombo, que permaneció en el Gobierno casi sin interrupción entre 1948 y 1982, siendo nombrado Ministro 25 veces y una vez Presidente del Gobierno; o Andreotti, que sería cinco veces Presidente del Gobierno y 16 veces Ministro ${ }^{32}$.

[Es curioso observar cómo la renovación de la clase política española en el período analizado ha producido mayores dosis de inestabilidad en el componente personal de la «clase político-parlamentaria» que en el de la «clase político-gubernamental». Así, de acuerdo con los datos del profesor LINZ, de las 1.653 personas que llegaron a ocupar escaños en el Congreso o en el Senado en las cuatro elecciones generales habidas entre 1977 y 1986, solamente 44 de ellas $(2,66 \%)$ serían elegidas en las cuatro legislaturas, $87(5,26 \%)$ lo serían en tres, $377(22,81 \%)$ lo serian en dos, mientras que la gran mayoría restante, 1.145 personas $(69,27 \%)$, serian elegidas parlamentarios en una sola ocasión ${ }^{33}$.]

\section{LA FORMACIÓN PROFESIONAL DE LOS MIEMBROS DEL GOBIERNO}

\section{Algunos datos personales}

No es la intención de este trabajo —como ya se ha dicho- entrar en un detallado estudio de carácter sociológico sobre el perfil del Ministro en España. Ello, además de exceder el marco metodológico que determina este análisis, ha sido objeto ya de estudio, siquiera en parte, con anterioridad, por lo que sería superfluo volver una vez más sobre los mismos temas ${ }^{34}$. Se tráta simplemente de señalar aquí aquellos aspectos que pa-

32 M. DOGAN, "Ministres inamovibles et personages éphémères dans les régimes à instabilité ministerielle", en Droit, institutions ot systèmenes politiques: Mélanges en hommage á Maurice Duverger. París, PUF, 1978, pp. 283-301; M. CaLISE, R. MANNheIMER, Governanti in Italia, cit. pp. 109 ss.; J. BLONDEL, Government Ministers in the Contemporary World, cit. pp. 238 ss.

${ }_{33}$ J. J. LINZ, “Consideraciones finales», en J. J. LINZ y J. R. MONTERo (eds.), Crisis y cambio: Electores y partidos en la España de los años ochenta. cit., pp. 645-662.

${ }^{34}$ Sobre esta materia véase el detallado trabajo de J. M. CuENCA TORIBIo y S. MIRANDA GARCIA, "Notas para una sociología de la élite de poder ministerial en la transición (1975-86)», en Homenaje al Profesor Sampedro. Madrid 1987, pp. 81-113. También, con datos parciales, similares a los aquí recogidos, si bien con algunas diferencias de concepto, lo que altera un tanto los datos estadisticos ofrecidos, A. BAR, "Spain: A Prime Ministerial Gobernment" en J. Blondel \& F. MülleR-Rommel (eds.), Cabinets in Western Europe. London, Macmillan, 1988, pp. 102-119. 
recen más significativos, desde el punto del análisis, y, sobre todo, aquellos que determinan la presencia del Ministro en el Gobierno, objeto propio de este estudio.

En este sentido, es digno de destacar ya que, mientras que en la formación académica y en la actividad profesional previa de los futuros Ministros apenas se produce variación sustancial alguna con respecto a etapas históricas anteriores, $\mathrm{e}$, incluso, con respecto a la práctica registrada en otros países de nuestro mismo entorno político-cultural, sí, en cambio, se experimenta un considerable rejuvenecimiento de la "clase ministerial», tanto con respecto al período franquista, como con respecto al entorno extranjero. Por otra parte, aunque con extremada lentitud, la mujer se va abriendo paso poco a poco dentro de la estructura gubernamental; lo cual, si bien no es una novedad en nuestra historia política, y aunque si suponga una diferencia con respecto al régimen anterior, se encuentra bastante lejos de la dinámica más reciente registrada en algunos paises de nuestro entorno europeo.

\section{a) La edad}

Efectivamente, en lo que a la edad de sus miembros se refiere, el Gobierno español ha experimentado en los últimos años un notable rejuvenecimiento, que es aún más apreciable en los Gabinetes de la fase parlamentaria del periodo aqui analizado. Quizá el símbolo más llamativo de ello lo sean las edades de los dos Presidentes del Gobierno más relevantes de todo el período, el centrista Adolfo Suárez y el socialista Felipe González. Ambos, con sus respectivos 44 y 40 años en el momento de su primer nombramiento para el cargo, fueron entonces los Primeros Ministros más jóvenes de Europa.

La edad media de los Ministros del periodo postfranquista es de 46,7 años, frente a la media de 51,7 años que tenían los Ministros nombrados bajo el régimen del general Franco ${ }^{35}$. Pero, este rejuvenecimiento es aún más apreciable si la comparación se establece con los Ministros de la fase parlamentaria del periodo postfranquista, pues la edad media de los Ministros nombrados a partir de entonces es de 44 años, frente a los mencionados 51,7 años del período franquista e, incluso, frente a los 52,7 años de media de los Ministros nombrados en la fase preparlamentaria del periodo postfranquista (vid. Cuadro 7). Ahora bien, nada hace pensar que ésta sea necesariamente una tendencia o regla general de la nueva situación democrática, sino que, más bien, este rejuvenecimiento ha de ser atribuido, una vez más, al cambio sustancial que se produjo en la élite política del

35 J. M. Cuenca Toribio, S. MIRANDA Garcia, "La élite ministerial franquista", Revista de Estudios Políticos, 57, 1987, pp. 107-148; A. De Miguel, Sociologia del tranquismo. Barcelona, Euros, 1975; Equipo Mundo, Los noventa Ministros de Franco. Barcelona, Dopesa, 1970; J. Bardavio, La estructura del poder en España. Madrid, IEE, 1969. 
CUADRO 7. EDAD AL PRIMER NOMBRAMIENTO MINISTERIAL

\begin{tabular}{|c|c|c|c|c|c|c|c|c|}
\hline EDAD & A & $\%$ & $\mathbf{B}$ & $\%$ & c & $\%$ & $\begin{array}{l}\text { FRAN- } \\
\text { QUISMO }\end{array}$ & $\%$ \\
\hline $\begin{array}{l}70-74 \\
65-69 \\
60-64 \\
55-59 \\
50-54 \\
45-49 \\
40-44 \\
35-39 \\
30-34 \\
25-29\end{array}$ & $\begin{array}{l}1 \\
5 \\
4 \\
1 \\
7 \\
6 \\
9 \\
- \\
-\end{array}$ & $\begin{array}{r}3,03 \\
15,15 \\
12,12 \\
3,03 \\
21,21 \\
18,18 \\
27,27 \\
- \\
-\end{array}$ & $\begin{array}{r}-2 \\
2 \\
2 \\
5 \\
19 \\
34 \\
17 \\
2 \\
-\end{array}$ & $\begin{array}{r}- \\
2,41 \\
2,41 \\
2,41 \\
6,02 \\
22,90 \\
40,96 \\
20,48 \\
2,41 \\
-\end{array}$ & $\begin{array}{r}1 \\
7 \\
5 \\
3 \\
12 \\
23 \\
37 \\
17 \\
2 \\
-\end{array}$ & $\begin{array}{r}0,94 \\
6,54 \\
4,67 \\
2,80 \\
11,21 \\
21,50 \\
34,58 \\
15,89 \\
1,87 \\
-\end{array}$ & $\begin{array}{r}2 \\
10 \\
17 \\
14 \\
19 \\
31 \\
18 \\
6 \\
1 \\
1\end{array}$ & $\begin{array}{r}0,84 \\
8,40 \\
14,28 \\
11,76 \\
15,96 \\
26,05 \\
15,12 \\
5,04 \\
0,84 \\
0,84\end{array}$ \\
\hline Edad media: & & & & & & 65 & סI, & 66 \\
\hline
\end{tabular}

CLAVE:

A: Ministros de la fase preparlamentaria del período postfranquista.

B: Ministros de la fase parlamentaria.

C: Ministros del período postfranquista, considerados conjuntamente (1975-1988).

Franquismo: Ministros del período franquista.

pais a la salida del régimen franquista. Y ello se manifiesta claramente, no sólo por el hecho de que la edad media de los últimos Ministros nombrados tienda a aumentar, sino por el hecho, ya reflejado, de que la edad de los Ministros de la fase preparlamentaria de este período, en la que los elementos de continuidad con el régimen anterior fueron muchos, fuese prácticamente igual a la del período franquista.

Por otra parte, si se analizan con detalle los grupos de edad, se comprueba cómo existe una evidente correlación entre los mismos y las diferentes etapas del período aquí analizado. Así, el Gobierno Arias II se encontraba formado mayoritariamente por personas pertenecientes a la generación que hizo la guerra civil, o muy cercanas a aquélla. Además de los Ministros militares -Pita da Veiga, Alvarez-Arenas, Franco Iribarnegaray, De Santiago-, los casos más significativos son los del propio Arias $\mathrm{Na}$ varro, Areilza, Garrigues, Solís o Fraga. Ello, evidentemente, habría de condicionar su visión política de la realidad española de los años setenta y su obsesivo temor al cambio democrático. Los Gobiernos de la UCD, a partir del primer Gabinete Suárez, estuvieron dominados principalmente por personas formadas en los años cincuenta, los años más oscuros del fran- 
quismo. Buena parte de ellos, pues, conocian muy bien al régimen anterior desde dentro, en el que habian llegado a ocupar cargos importantes, algunos, incluso, como Ministros, ya con Franco - Cabanillas-, ya, inmediatamente después, en el segundo Gabinete Arias —el propio Suárez, Martín Villa, Calvo-Sotelo, Osorio, Lozano, Pérez-Bricio-. A estos Ministros, a los que se unieron otros que poco tuvieron que ver con la dictadura, correspondió la labor de comenzar el desmontaje del aparato autoritario de la dictadura incrustado en el Estado. Y cabria decir que lo relativamente pacífico de la transición a la democracia en España se debe en buena medida a la tarea desempeñada precisamente por aquellos Gobiernos de la desaparecida UCD.

La llegada de los socialistas al Gobierno trajo consigo una nueva generación al poder. Se trata de la generación formada en su mayoría en los años sesenta, cuando la Universidad española comenzaba a desperezarse, y buena parte de los Ministros entonces nombrados llegaron a militar en aquellas épocas en la oposición clandestina al franquismo, en partidos radicales de izquierda. A esta tercera generación ha correspondido la consolidación y extensión de la democracia formalizada en la Constitución de 1978, y la culminación del edificio estatal en ella diseñado. Es significativo observar cómo, finalizado el proceso de cambio y estabilizada la situación política, la edad media del Gobierno tiende de nuevo a crecer, al producirse una consolidación en el aparato de poder precisamente de esta última generación, que, tras varios procesos electorales sucesivos, y en los diferentes niveles políticos, domina la nueva rutina democrática ${ }^{36}$.

Un fenómeno similar de cambio generacional, necesario cuando se ha tratado de renovar la clase politica tras un largo periodo de régimen dictatorial, se ha producido también en los casos italiano y portugués, en los cuales se produjo un notable rejuvenecimiento de la edad media gubernamental a la salida de las respectivas dictaduras, en los años cuarenta y cinco y setenta y cuatro, respectivamente ${ }^{37}$.

La edad media de los Ministros españoles, sobre todo de los pertenecientes a la etapa parlamentaria del período aquí analizado, se encuentra, pues, por debajo de la media de las democracias occidentales, dentro de las cuales más de la mitad de sus Ministros superan los cincuenta años ${ }^{38}$. Ello, además de las consideraciones ya realizadas, y desde el punto de vista de este trabajo, supone una importante limitación al principio de la especialización ministerial, dado que, como es obvio, la corta edad supone también cortas carreras políticas y una reducción de la experiencia profesional y politica del futuro Ministro.

36 En la última remodelación del Gabinete socialista, producida en julio de 1988, llegaron a ser incluidas en el Gobierno personas pertenecientes, incluso, a generaciones anteriores, como Semprún o Múgica, de 65 y 56 años en el momento de su nombramiento. (Sobre este tema, vid. J. Pradera, «Edad, sexo y Gobierno", El Pais, 9 julio 1988.

37 M. Calise, R. MANNHeimer, Governanti in Italia, op. cit.

36 Vid. J. BlondEL, Government Ministers in the Contemporary World, cit. pp. 33 y ss. 


\section{b) El sexo}

Si bien desde el punto de vista de este trabajo, y a efectos de la especialización o de la eficacia ministerial, el factor sexo es relativamente irrelevante, si es significativo señalar aquí la presencia de mujeres en los Gobiernos de la etapa democrática, como un elemento diferencial con respecto a otros períodos históricos.

La primera vez que una mujer ocupó un puesto ministerial en la historia política de España tuvo lugar durante la Segunda República, iniciada ya la guerra civil: Federica Montseny, destacada militante anarquista de la CNT, ocupó entonces la cartera de Sanidad y Asistencia Social en el segundo Gabinete Largo Caballero, formado en noviembre de 1936. Duraría poco en el cargo y, desde la caída de este Gabinete, en mayo de 1937, hasta la restauración plena del sistema democrático, en 1.977, ninguna mujer volvería a ocupar tan importante puesto ${ }^{39}$.

La segunda ocasión tuvo lugar en diciembre de 1981, cuando la segunda remodelación del Gabinete Calvo-Sotelo dio entrada en el Gobierno, en la cartera de Cultura, a Soledad Becerril, una licenciada en Filosofía y Letras, encuadrada en la rama liberal de la UCD, y que permanecería en el cargo hasta la caída del Gabienete Calvo-Sotelo, en diciembre de 1982. Finalmente, hubo que esperar hasta la primera remodelación del segundo Gabinete socialista de F. González, en julio de 1988, para que la mujer volviera a formar parte del Gobierno español. Entonces entraron en el mismo - lo que supone un nuevo hito- dos mujeres a la vez, Matilde Fernández y Rosa Conde. La primera de ellas, una destacada militante sindicalista de la UGT, a la que se le asignó la cartera de Asuntos Sociales, y la segunda, una profesional independiente, a la que se le encomendó el puesto de Portavoz del Gobierno. En este último caso - y es digno de ser resaltado-, tanto la presencia misma de la mujer, como el número de ellas en un mismo Gabinete, vino determinado en cierto modo por la resolución adoptada por el PSOE en su congreso de enero de 1988, de incluir un 25 por 100 de mujeres en los órganos de dirección del partido. Medida que la propia Matilde Fernández había colaborado decisivamente a hacer aprobar y que suponia un condicionante moral para el Gobierno socialista.

En todo caso, tampoco puede dejar de ser reseñada la poca relevancia y carácter general de las carteras asignadas a las Ministras, dentro del contexto intragubernamental. Carteras que, tanto en el caso de Federica Montseny, como de las dos recientes Ministras del Gobierno González II, fueron creadas ex profeso para ellas. Así, desde el punto de vista de la

39 No deja de ser contradictorio y altamente llamativo que haya sido precisamente una destacadisima militante anarquista la primera mujer que haya ocupado un puesto gubernamental en España. Vid., al respecto, A. BAR, «The CNT: Glory and Tragedy of Spanish Anarchosyndicalism"; en M. VAN DER LINDEN, W. THORPE (eds.), Revolutionary Syndicalism: An international Perspective. Aldershot, UK, Scolar, 1989. 
especialización ministerial, este hecho, como la presencia misma de la mujer en el Gobierno, en las presentes circunstancias históricas, son indicadores determinantes de bajo nivel global de especialización. Y ello por el hecho de que las mujeres, por su reciente incorporación a la vida política y profesional $y$, por consiguiente, su relativamente corta experiencia en ambos terrenos, tampoco han podido realizar carreras políticas lo suficientemente largas y adquirir, por lo mismo, la consiguiente especialización. En este sentido, debe resaltarse también la práctica inexistencia de mujeres en los escalones políticos previos de la Administración del Estado: durante el período analizado, sólo tres mujeres llegaron a ser Secretario de Estado y ninguna fue Subsecretario.

Por otra parte, el caso español no constituye, al respecto, una excepción. Por el contrario, y en términos generales, se puede decir que han sido muy pocas las mujeres que han llegado a ocupar cargos ministeriales en los Gobiernos democráticos occidentales, y es sólo a partir de los años setenta cuando su presencia comienza a proliferar. Antes de esa fecha, al igual que en España, solamente una mujer había llegado a ser Ministro en paises como Francia, Bélgica, o Austria, y, en todo caso, España se habia adelantado a casi todos ellos en el tiempo - el caso Montseny constituye, pues, una verdadera avanzadilla histórica- Hoy en día, son los países escandinavos, con Noruega y Suecia a la cabeza, los que mayor número de mujeres incluyen en sus Gobiernos, si bien el total general sigue siendo muy bajo. Así, solamente un 2,9 por 100 de los Ministros habidos en los paises del área occidental, entre 1945 y 1981, han sido mujeres ${ }^{40}$. En España, pues, este porcentaje es de 2,8 por 100 para el período postfranquista aqui analizado.

\section{La formación y la actividad previas de los Ministros}

Al contrario de lo que ocurria con los factores anteriormente analizados, en lo que respecta a la formación y a la actividad profesional de los Ministros se nota, en cambio, el peso de la tradición y una enorme continuidad con respecto al régimen anterior.

El análisis de este aspecto de la carrera ministerial plantea en España una enorme dificultad conceptual, dado lo complejo y polivalente de los curriculos de los Ministros españoles, pródigos en la realización de carreras académico-universitarias y en el pluriempleo profesional. Así, cuando existe más de una, que es en gran parte de los casos, se produce una enorme dificultad para determinar con precisión - a efectos de calibrar los niveles de especialización ministerial-cuál es verdaderamente la formación académica seguida de manera principal, y/o la actividad profesio-

40 J. BLONDEL, Government Ministers in the Contemporary World, cit. p. 31. 
nal, o, al menos, la predominante, que ocupaba con anterioridad a nuestros Ministros, y en qué momento de su vida. Funcionarios con diverso grado de dependencia de la Adminsitración y con actividades privadas paralelas, al lado de abogados que son al mismo tiempo empresarios y profesores de Universidad, y así un largo etcétera, hasta extremos insospechados en otros sistemas políticos, convierten el análisis de las carreras ministeriales en un auténtico problema, cuya resolución queda en buena parte a la apreciación subjetiva y al esquema conceptual del analista. No es de extrañar, pues, que los datos ofrecidos puedan variar un tanto de un estudio a otro.

Aquí, renunciando a realizar una forzada - y arriesgada - precisión individual sobre cuál es, o parece ser, la formación académica y la actividad profesional de cada Ministro con anterioridad a su nombramiento como tal, se valoran globalmente el conjunto de las carreras universitarias realizadas, por un lado, $y$, por otro, el conjunto de las actividades profesionales que han ocupado a los Ministros españoles del periodo postfranquista y con anterioridad a su acceso al Gobierno. Se tiene, por ello, en cuenta que ambas - carreras universitarias y actividades profesionales- pueden haberse realizado y ejercido de manera plural y al mismo tiempo en más de un caso.

\section{a) La formación académica}

En términos generales, y con respecto a la formacion académica, debe resaltarse el hecho del predominio absoluto de la existencia de grados universitarios entre los currículos de la práctica totalidad de los Ministros del período aquí analizado. Prescindiendo de las carreras militares, solamente a uno de los Ministros habidos desde diciembre de 1975, ha carecido de formación universitaria o asimilada alguna: José Luis Corcuera, quien llegó al Gobierno en su condición de destacado dirigente sindical, miembro de las ejecutivas de la UGT y del PSOE, si bien la cartera que le fue atribuida - Interior - poco tiene que ver con su actividad profesional previa. Hay que remontarse al periodo que cubre la Segunda República - y que fue en esto también un paréntesis con respecto a las etapas anteriores y posteriores a la misma- para encontrar de nuevo la presencia de personas no cualificadas académicamente en el seno del Gobierno. Durante aquel periodo, al menos 13 Ministros de los 119 que llegaron a formar parte del Gobierno, carecieron de todo grado académico. La presencia frecuente de partidos o grupos obreros en el Gobierno - PSOE, PCE, CNT-, tanto en el periodo de paz, como durante la guerra civil, fueron la causa de este elevadísimo porcentaje de personas no cualificadas académicamente entre los Ministros de entonces. Hoy en dia, el cambio radical de la estructura social española ha hecho que, a pesar de la presencia de un partido socialista en el poder, hubieran de pasar cerca de seis años, dos Gobiernos y dos remodelaciones ministeriales, desde que el PSOE formara su primer Gabinete en 1982, para que un «trabajador de cuello azul» alcanzase una poltrona ministerial. 
En to que se refiere ya en concreto a las titulaciones académicas registradas, al igual que ya ocurriera en periodos históricos anteriores, y de similar manera a lo que ocurre también en nuestro entorno sociopolítico, la formación juridica, la licenciatura en Derecho, es absolutamente dominante, figurando incluida en un 57,94 por 100 de los curriculos ministeriales. En la mayoría de los casos $(43,92 \%)$ figura incluso como la licenciatura única, siendo con frecuencia acompañada de otras - preferentemente Ciencias Económicas - en el 14,02 por 100 de los casos. Le sigue inmediatamente la formación económica, registrándose la licenciatura en 'Ciencias Económicas en un 23,36 por 100 de los curriculos; en la mayoría de los casos acompañada de la licenciatura en Derecho $(9,34 \%)$, pero también en solitario $(5,61 \%)$, o acompañada de otras licenciaturas, como Ciencias Políticas $(4,95 \%)$, etc. pero con frecuencia muy inferior. (Vid, Cuadro 8.)

A una enorme distancia ya, a la formación jurídica y económica sigue la formación técnica, la cual, en términos comparativos, ocupa un lugar muy poco destacado en los currículos académicos de los Ministros españoles. Agregando las diferentes ingenierías -industrial, caminos y agronómica, principalmente-, que figuran tanto en solitario como también acompañando a otras licenciaturas humanísticas -Derecho, Económicas y Políticas-, sólo alcanzan a estar incluidas en el 13,09 por 100 de los currículos.

La licenciatura en Ciencias Políticas figura en cuarto lugar en el orden de frecuencia en los currículos ministeriales, con una incidencia del 7,48 por 100 de los casos. Es curioso observar cómo esta carrera figura siempre acompañada de otras licenciaturas, no registrándose ni un sólo caso en el que Ciencias Políticas sea la licenciatura única.

La carrera militar y la licenciatura en Filosofía y Letras figuran en quinto lugar. Con respecto a la carrera militar, es obvio que el cambio de régimen politico haya afectado considerablemente a este tipo de formación profesional, siendo la que registra una mayor disminución con respecto a la etapa anterior. Caracterizado como lo estaba el régimen franquista por su origen y sosten militar, es lógico que la formación militar apareciese sobredimensionada en los currículos académicos de los miembros del Gobierno de entonces. Asi, del elevado 27,50 por 100 de los casos de aquel período (33 Ministros, excluidos los seis pertenecientes al Cuerpo Jurídico Militar), se ha pasado al 6,54 por 100 de ahora (siete Ministros, excluidos los tres pertenecientes al Cuerpo Jurídico Militar). Por su parte, la licenciatura en Filosofía y Letras, en sus diversas ramas, se registra en un 6,54 por 100 de los casos, tanto en solitario (2,80\%), como acompañando a otras licenciaturas.

Inmediatamente después, a escasa distancia porcentual, figuran los grados en Ciencias experimentales $(4,67 \%$ de los casos), y un conjunto de carreras varias, entre las que figuran Psicología, Sociología, Periodismo, Farmacia y Marina Mercante (en total, 5,61 \% de los casos). (Vid. Cuadro 8.) 
CUADRO 8. FORMACIÓN ACADÉMICO-UNIVERSITARIA DE LOS MINISTROS

\begin{tabular}{|c|c|c|c|}
\hline CARRERA & FRECUENCIA & $\%(1)$ & $\%(2)$ \\
\hline Derecho & 62 & 45,93 & 57,94 \\
\hline $\begin{array}{l}\text { Sólo Derecho } \\
\text { Derecho y Económicas } \\
\text { Derecho y otras }\end{array}$ & $\begin{array}{r}47 \\
10 \\
5\end{array}$ & $\begin{array}{r}34,82 \\
7,41 \\
3,70\end{array}$ & $\begin{array}{r}43,92 \\
9,35 \\
4,67\end{array}$ \\
\hline Económicas & 25 & 18,52 & 23,36 \\
\hline $\begin{array}{l}\text { Sólo Económicas } \\
\text { Económicas y Derecho } \\
\text { Económicas y otras }\end{array}$ & $\begin{array}{r}6 \\
10 \\
9\end{array}$ & $\begin{array}{l}4,44 \\
7,41 \\
6,67\end{array}$ & $\begin{array}{l}5,61 \\
9,34 \\
8,41\end{array}$ \\
\hline Ingeniería & 14 & 10,37 & 13,09 \\
\hline $\begin{array}{l}\text { Caminos } \\
\text { Industrial } \\
\text { Agrónoma }\end{array}$ & $\begin{array}{l}6 \\
6 \\
2\end{array}$ & $\begin{array}{l}4,44 \\
4,44 \\
1,49\end{array}$ & $\begin{array}{l}5,61 \\
5,61 \\
1,87\end{array}$ \\
\hline Ciencias Políticas & 8 & 5,93 & 7,48 \\
\hline Ciencias Políticas y otras & 8 & 5,93 & 7,48 \\
\hline Militar & 7 & 5,19 & 6,54 \\
\hline Filosofia y Letras & 7 & 5,19 & 6,54 \\
\hline $\begin{array}{l}\text { Sólo Filosofía y Letras } \\
\text { Filosofía y Letras y otras }\end{array}$ & $\begin{array}{l}3 \\
4\end{array}$ & $\begin{array}{l}2,22 \\
2,96\end{array}$ & $\begin{array}{l}2,80 \\
3,74\end{array}$ \\
\hline Ciencias & 5 & 3,70 & 4,67 \\
\hline Otras & 6 & 4,44 & 5,61 \\
\hline Ninguna & 1 & 0,74 & 0,93 \\
\hline Total & 135 & 100 & 一 \\
\hline
\end{tabular}

(1) Sobre frecuencia (135).

(2) Sobre el número total de Ministros (107). 
En todo caso, como se puede comprobar, el predominio absoluto de la formación jurídica y, aun -como ya se ha dicho anteriormente-, la existencia frecuente de más de una licenciatura en buena parte de los currículos ministeriales, no permite establecer una clara línea directa de conexión entre la formación académica y el puesto ministerial desempeñado con posterioridad, como factor de especialización. Cabría decir, pues, que la formación académica de nuestros Ministros crea las bases de una capacitación general, polivalente, pero no Ministros especializados. Si se excluye la formación militar y alguna otra de carácter técnico, habrá que esperar al momento posterior del ejercicio de una actividad profesional para encontrar ya las primeras bases de la verdadera especialización ministerial.

Por lo demás, en el panorama internacional la perspectiva suele ser muy similar: predominan las formaciones jurídica -si bien en porcentajes relativamente menores al español, algo inferiores al 50 por $100-$ y económica. La gran diferencia se establece en lo que se refiere a la presencia de Ministros no cualificados académicamente, que llegan a ocupar los porcentajes más elevados en países como Austria (19\%), Dinamarca (16 \%), o Suecia (12\%); siendo inferior su porcentaje en Gran Bretaña $(8 \%)$, Noruega $(8 \%)$, o Alemania $(6 \%){ }^{41}$. En España, dada la existencia de un solo caso, este porcentaje seria para el período analizado, del 0,93 por 100.

\section{b) La actividad profesional}

La actividad profesional de los Ministros, más compleja aún que su formación académica, debido a su multiplicidad, manifiesta también, sin embargo, una enorme similitud en sus contenidos básicos, tanto con respecto al precedente del régimen anterior, como con respecto a la práctica internacional. En cualquier caso, nos encontramos aquí, de nuevo, ante una situación similar, o quizá más dificultosa, que la encontrada al analizar la formación académica de la élite ministerial. El pluriempleo habitual en buena parte de los altos dirigentes políticos españoles hace muy difícil, cuando no imposible, reducir conceptual o analiticamente su actividad profesional a una sola o principal por persona. De aquí que en el cómputo global realizado, y teniendo en cuenta que en cada currículo lo más común es la existencia de más de una actividad profesional simultánea, se haya acudido al cálculo en función de la frecuencia con la que estas actividades se manifiestan. (Vid. Cuadros 9 y 10.)

En primer lugar, llama la atención sobre manera el enorme desequilibrio existente entre el peso del sector privado y el peso del sector público o funcionarial en la composición de los Gobiernos en España. EI predominio de la élite funcionarial es absolutamente aplastante: cerca de

41 J. Blondel, Government Ministers in the Contemporary World, cit. p. 45. 


\section{CUADRO 9. ACTIVIDAD PROFESIONAL DE LOS MINISTROS}

\begin{tabular}{|c|c|c|c|c|}
\hline \multirow{2}{*}{ ACTIVIDAD } & \multicolumn{2}{|c|}{ PERÍODO FRANQUISTA } & \multicolumn{2}{|c|}{ PERIOODO POSTFRANQUISTA } \\
\hline & $N^{\circ}$ DE MINISTROS & $\%$ & N. ${ }^{\circ}$ DE MINISTROS & $\%$ \\
\hline $\begin{array}{l}\text { Funcionarios } \\
\text { No funcionarios }\end{array}$ & $\begin{array}{l}88 \\
32\end{array}$ & $\begin{array}{l}73,33 \\
26,67\end{array}$ & $\begin{array}{l}77 \\
30\end{array}$ & $\begin{array}{l}71,96 \\
28,04\end{array}$ \\
\hline Total & 120 & 100 & 107 & 100 \\
\hline
\end{tabular}

CUADRO 10. ACTIVIDAD PROFESIONAL DE LOS MINISTROS: FRECUENCIA

\begin{tabular}{|c|c|c|c|c|c|c|c|}
\hline FUNCIONARIOS & $\mathbf{F}$. & $\begin{array}{l}\% \\
(1)\end{array}$ & $\begin{array}{l}\% \\
(2)\end{array}$ & $\begin{array}{l}\text { ACTIVIDAD } \\
\text { PRIVADA }\end{array}$ & F. & $\begin{array}{l}\% \\
(1)\end{array}$ & $\begin{array}{l}\% \\
\text { (2) }\end{array}$ \\
\hline $\begin{array}{l}\text { Prof. Universidad (3) } \\
\text { Letrado (4) } \\
\text { Administradores (5) } \\
\text { Diplomático } \\
\text { Inspector, Interventor (6) } \\
\text { Militar } \\
\text { Notario, Registrador } \\
\text { Magistrado, Fiscal } \\
\text { Cuerpo Juridico Militar } \\
\text { Ingeniero }\end{array}$ & $\begin{array}{r}28 \\
15 \\
14 \\
7 \\
7 \\
7 \\
5 \\
5 \\
3 \\
2\end{array}$ & $\begin{array}{r}30,11 \\
16,13 \\
15,05 \\
7,53 \\
7,53 \\
7,53 \\
5,38 \\
5,38 \\
3,23 \\
2,15\end{array}$ & $\begin{array}{r}26,17 \\
14,02 \\
13,08 \\
6,54 \\
6,54 \\
6,54 \\
4,67 \\
4,67 \\
2,80 \\
1,87\end{array}$ & $\begin{array}{l}\text { Abogado } \\
\text { Economista } \\
\text { Empresario } \\
\text { Ingeniero } \\
\text { Sindicalista } \\
\text { Profesor } \\
\text { Escritor } \\
\text { Sus labores }\end{array}$ & $\begin{array}{r}10 \\
9 \\
2 \\
2 \\
2 \\
1 \\
1 \\
1\end{array}$ & $\begin{array}{r}35,72 \\
32,15 \\
7,14 \\
7,14 \\
7,14 \\
3,57 \\
3,57 \\
3,57\end{array}$ & $\begin{array}{l}9,35 \\
8,41 \\
1,87 \\
1,87 \\
1,87 \\
0,93 \\
0,93 \\
0,93\end{array}$ \\
\hline Total & 93 & 100 & - & & 28 & 100 & - \\
\hline
\end{tabular}

CLAVE:

F: Frecuencia

(1) Sobre frecuencia [93].

(2) Sobre número total de Ministros [107].

(3) Incluye Catedráticos y niveles inferiores.

(4) Incluye Letrados de Cortes y del Consejo de Estado, Abogados del Estado y antiguos Letrados sindicales.

(5) Incluye TAC, Técnicos Comerciales del Estado y de Aduanas.

(6) Incluye Inspectores Tributarios, de Trabajo e Interventores. 
tres cuartos de los Ministros (el 71,96\%) nombrados desde la muerte del general Franco hasta nuestros dias pertenecen al estamento funcionarial, en sus diversos ámbitos y niveles, y con diferentes grados de dedicación. El porcentaje es ligeramente inferior al registrado durante el régimen franquista (el $73,33 \%$ ), lo cual no deja de ser sorprendente, si se tiene en cuenta el elevado peso especifico que la burocracia tiene en todo régimen dictatorial, y principalmente en uno de carácter militar, como lo fue el del general Franco. Ni que decir tiene que esa cifra supera también las medias registradas en otros países europeos; si bien debe señalarse aquí que este porcentaje se ve reducido en muchos de estos países, tanto por la existencia de un régimen de incompatibilidades más estricto en el sector funcionarial, como por la no consideración como estamento funcionarial de un sector de tanto peso en la formación de los Gobiernos como lo es el de los profesores universitarios. (Vid. Cuadro 9) ${ }^{42}$.

Efectivamente, en España, como en otros paises de nuestro entorno, los profesores universitarios constituyen el grueso de los componentes tradicionales de los Gobiernos (vid. Cuadro 10). Un 26,17 por 100 de los Ministros cuentan en su currículo profesional con esta actividad, aunque no siempre -en realidad, en los menos de los casos- realizada en régimen de dedicación exclusiva. De ellos, son los catedráticos de Universidad los que constituyen el grupo más numeroso (el $75 \%$; y, en conjunto, de nuevo aquí la dedicación al Derecho es la mayoritaria. El 10 por 100 de los catedráticos y el 5 por 100 de los profesores universitarios de nivel inferior lo son de diversas especialidades juridicas, lo que supone el 53,57 por 100 de los Ministros profesores de Universidad y el 14,02 por 100 del total de los Ministros. Por el contrario, el resto de las especialidades académicas tiene una presencia muy reducida y aparecen muy dispersas. (Vid, Cuadro 11.)

En segundo lugar, es digna de ser reseñada también la progresiva ausencia de la profesión militar en la formación de los Gobiernos postfranquistas. Solamente ha habido siete Ministros militares en todo el período (el 6,54\% del total de los Ministros), cuatro pertenecientes al Ejército de Tierra, dos a la Armada y uno al Ejército del Aire, los cuales ocuparon siempre carteras o puestos relacionados con la defensa nacional, excepto en un sólo caso -A. Ibáñez Freire- en el que le fue encomendada la cartera de Interior ${ }^{43}$. La progresiva «desmilitarización» del Gobierno en este periodo se aprecia claramente en la ubicación temporal de los nom-

42 Vid. M. Dogan (ed.) The Mandarins of Western Europe. Beverly Hills, Ca., Sage, 1979; F. BAECQUE, “Les fonctionnaires à l'assaut du pouvoir politique?», Pouvoirs, 40, 1987; J. BLONDEL, Government Ministers in the Contemporary World, cit. pp. 47 y ss.

43 A ellos habría que añadir tres Ministros pertenecientes al cuerpo jurídico militar, los cuales, sin embargo, no han sido contabilizados como militares - rompiendo la línea de análisis aqui seguida- dado que, por un lado, esta actividad ha tenido un carácter muy secundario en su vida profesional y pública, $y$, por otro, porque su inclusión como militares a efectos estadísticos acentuaría un tanto los matices militares de los Gobiernos aqui analizados, dando una imagen distorsionada de la realidad. 
CUADRO 11. MINISTROS PROFESORES DE UNIVERSIDAD

\begin{tabular}{lcrr}
\hline \multicolumn{1}{c}{ RANGO } & $\begin{array}{c}\text { N. }{ }^{\circ} \text { DE } \\
\text { MINISTROS }\end{array}$ & $\begin{array}{r}\% \\
(1)\end{array}$ & $\begin{array}{c}\% \\
(2)\end{array}$ \\
\hline & & & \\
Catedráticos & 21 & 19,63 & 75,00 \\
Derecho Administrativo & 4 & 3,74 & 14,29 \\
D. Financiero-Hacienda & 3 & 2,80 & 10,71 \\
D. Político & 2 & 1,87 & 7,14 \\
D. Mercantil & 1 & 0,93 & 3,57 \\
Economía & 4 & 3,74 & 14,29 \\
Sociología & 2 & 1,87 & 7,14 \\
Latín & 1 & 0,93 & 3,57 \\
Historia & 1 & 0,93 & 3,57 \\
Bioquímica & 1 & 0,93 & 3,57 \\
Optica & 1 & 0,93 & 3,57 \\
Física & 1 & 0,93 & 3,57 \\
Otros Niveles & 7 & 6,54 & 25,00 \\
& & & \\
\hline
\end{tabular}

(1) Sobre el total de Ministros [107].

(2) Sobre el total de Profesores de Universidad [28].

bramientos: los siete Ministros Militares lo fueron en algún momento durante la fase preparlamentaria, mientras que solamente dos de ellos - los generales Gutiérrez Mellado e Ibáñez Freire- llegarian a ser de nuevo Ministros en la fase parlamentaria. $Y$, en ésta, los militares dejaron ya de formar parte de los Gobiernos a partir del Gabinete Calvo-Sotelo, sin que los dos posteriores Gobiernos socialistas de F. González hayan registrado tampoco nombramiento alguno de este carácter.

Con respecto al sector privado, el panorama sustancial no es muy diferente. Predomina la profesión jurídica, si bien la situación se encuentra un poco más equilibrada por el mayor peso específico de los economistas y empresarios. En realidad, Derecho y Economia se reparten en proporción prácticamente igual las dedicaciones profesionales de los miembros del Gobierno provinientes del sector privado, durante el período de referencia, siendo en muchos de los casos actividades compartidas, al igual que la Economia con las diversas Ingenierias. (Vid. Cuadro 10.) 
En fin, el enorme peso del funcionariado en la formación de los Gobiernos españoles, no conforme en general con el peso global del sector público en la vida social o económica de España, hace pensar, en una primera aproximación, más que en una cierta tendencia hacia la especialización material, en una tendencia hacia la capacitación técnica o gestora de los Ministros, por cuanto no cabe duda de que su experiencia profesional en la función pública les permite tener unos amplios conocimientos sobre los resortes internos de la Administración.

\section{LA CARRERA POLITICA DE LOS MINISTROS}

A pesar de la corta vida del nuevo sistema democrático español, y en contra de lo que ello pudiera hacer pensar, la mayor parte de las personas que han sido miembros del Gobierno durante el periodo analizado cuentan con una relativamente larga y densa carrera política. Carrera política que ha sido realizada a través de dos cauces principales: bien la Administración Pública, en cualquiera de sus niveles o ramas; bien el Parlamento -incluyéndose en esta vía tanto la pertenencia a las Cortes Generales, como la pertenencia a alguno de los Parlamentos autonómicos-; o bien a través de ambas vias, simultánea o sucesivamente.

Pero no ha sido sólo una "carrera política", en el sentido propio, lo que ha llevado a nuestros Ministros al Gobierno, sino que también han llegado a ser incluidas en éste personas aparentemente ajenas al juego político, o que, al menos, no habian ocupado previamente cargo público alguno de designación política. Se trata en este caso de personas que han llegado a ser nombradas Ministros directamente, sin haber necesitado pasar por ninguno de los dos cauces político-institucionales mencionados: la Administración o el Parlamento. Ante la ausencia de toda experiencia política previa en el seno de la estructura del Estado, se sobreentiende, pues, que su designación obedece exclusivamente a una cualificación técnica o profesional que les hace idóneos para el cargo. Sin embargo, a efectos analíticos, más que este último aspecto, lo verdaderamente relevante es el hecho en sí mismo de que la ruta al Gobierno no haya pasado —como de hecho no ocurre siempre y necesariamente- por veredas políticas o institucionales. Bien que, como se verá más adelante, no han sido muchos los que en España han transitado por tal camino, «no político», hacia el Gobierno.

Así pues, en la carrera que lleva al futuro Ministro a formar parte del Gobierno se pueden distinguir dos vías principales, a) la politica o institucional, y b) la no institucional, que convencionalmente cabria denominar profesional. La carrera o via política es aquella que ha seguido el Ministro 
y que le ha llevado al Gobierno a través de canales político-institucionales; es decir, i) a través de nombramientos políticamente realizados para los más altos cargos de la Administración -carrera que cabe denominar politicio-administrativa-, o ii) a través de su elección popular para las instancias representativas más importantes: las Cortes Generales o los Parlamentos autonómicos - carrera que cabe denominar político-parlamentaria-. (Vid. Gráfico 1.)

La carrera político-administrativa excluye, por tanto, el acceso a la Administración, o la mera progresión profesional en ella, a través de los cauces formales y objetivos previstos por la normativa administrativa vigente para los funcionarios profesionales - concursos, oposiciones, etc.-. Se trata, en definitiva, de cargos de libre designación por parte del Ejecutivo, que pueden afectar tanto a funcionarios, como a personas profesionalmente ajenas a la función pública con anterioridad. Por otra parte, y al contrario que en otro estudio anterior ${ }^{44}$, he adoptado aquí un concepto bastante amplio de la carrera político-administrativa, incluyendo en ella no sólo los nombramientos para altos cargos de la Administración central, en el sentido técnico ${ }^{45}$, sino también para otros puestos de libre designación gubernamental, tanto en la Administración periférica, como en la autónoma.

\section{GRÁFICO 1. CARRERA POLÍTICA DE LOS MINISTROS}

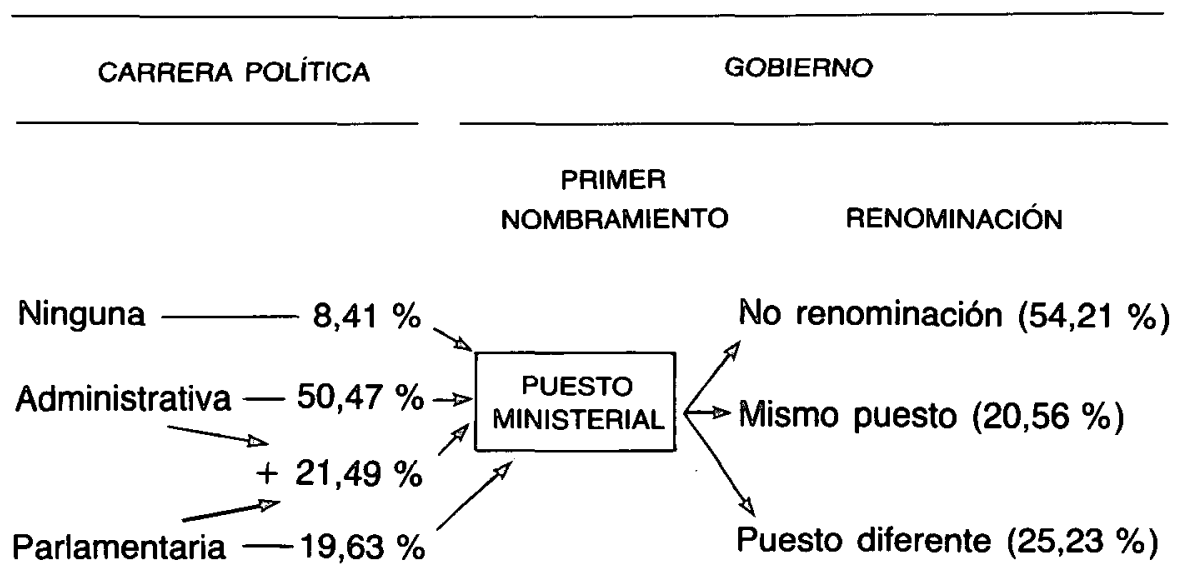

4 Vid. A. BAR, "Spain: A Prime Ministerial Government», en J. BLONDEL, F. MüLleRROMMEL (eds.), Cobinets in Western Europe. cit.

${ }_{45}$ Los Secretarios de Estado, Subsecretarios y Secretarios Generales con rango de Subsecretario, de acuerdo con el artículo 8.1 de la LOACE de 1983. 
Por actividad o carrera politico-parlamentarla se entiende aquella realizada en el sentido propio de la palabra, lo que supone la existencia de un Parlamento democrático; cosa que, para el período analizado y como es conocido, no se produjo en España hasta después de las elecciones generales de junio de 1977. La pertenencia a las Cortes del régimen franquista no ha sido considerada ni contabilizada, por tanto, como parte de la carrera político-parlamentaria de los Ministros que de ellas fueron miembros. Y ello, no sólo por razones políticas obvias, sino porque en este análisis de la estructura gubernamental —como se verá más adelante - se tienen en cuenta algunos aspectos relacionados con la actividad parlamentaria que no se podian producir en las Cortes corporativas del régimen franquista, por lo que su inclusión dentro del concepto global de carrera político-parlamentaria distorsionaría los datos del análisis. Por el contrario, y dada su significación especifica, se incluye también dentro de este concepto la pertenencia previa a alguno de los Parlamentos autonómicos, cuya experiencia, como práctica política, no se distingue demasiado de la que pueda producir la pertenencia a las Cortes Generales.

Con respecto a la conceptuación global de la carrera política de los Ministros, plantea un problema especial la consideración de la militancia o activismo político dentro de un partido u organización sindical. La militancia política, o pertenencia a un partido político determinado - y lo mismo cabe decir de un sindicato-, es en sí misma una experiencia política de importancia, que, sobre todo cuando ello ha supuesto la dedicación exclusiva y la ocupación de altos puestos de responsabilidad dentro de la organización debería ser considerada como una vía específica o, al menos, una parte significativa de la carrera política de un Ministro. Sin embargo, en este trabajo ello no es así, y esta forma de actividad política, cuando se encuentra aislada en un currículo ministerial, es decir, cuando esta actividad no se ha traducido - como consecuencia de la misma - en la ocupación de cargos políticos, ya administrativos, ya parlamentarios, ha sido considerada como parte de la vía profesional, es decir, no politica, al Gobierno.

Y esta conceptuación, puramente analítica, se basa en el hecho de que, por un lado, lo verdaderamente significativo para este estudio es la determinación de si los Ministros han llegado a ser miembros del Gobierno gracias a la ocupación previa, o no, de cargos políticos en la estructura estatal, y la influencia que ello pueda tener en los diferentes niveles de especialización de los mismos, Pero, por otro lado, la corta vida y la especial debilidad o inconsistencia que ha caracterizado $-\mathrm{y}$ aún distinguea nuestro sistema de partidos, unido a lo reducido de la militancia en los mismos ${ }^{46}$, han determinado la ausencia de una suficientemente amplia

46 Vid. A. BAR, "El sistema de partidos en España. Ensayo de caracterización», Sistema, 47, 1982, pp. 3-46, y «¿Normalidad o excepcionalidad?: Para una tipología del sistema de partidos español», Sistema, 65, 1985, pp. 3-37. 
clase o burocracia político-partidista profesional, por lo que la práctica totalidad de la misma ha tenido que reconducir su activismo a la ocupación de los cargos públicos existentes en los diferentes niveles de la estructura estatal. Por el contrario, si un Ministro era destacado militante partidista, o sindical, pero fue llamado a formar parte del Gobierno directamente, sin haber pasado antes por ninguno de los cauces institucionales mencionados que constituyen la carrera política, lo significativo de su nombramiento no es, pues, su militancia, sino su cualificación personal, que le ha llevado al Gobierno. En este sentido, pues, la militancia político-partidista, o sindical, se convierte en insignificante como para ser considerada separadamente como vía política independiente hacia el Gobierno, y, cuando no lleva consigo el desempeño de cargos públicos estatales -en cuyo caso formaría parte de la via política-, se encuadra dentro de la via profesional.

De hecho, del análisis realizado se deriva que, en España, es absolutamente excepcional el caso de un destacado activista político-partidista o sindical que haya llegado a ocupar un puesto en el Gobierno sin haber pasado antes por los cauces politico-administrativo o político-parlamentario anteriormente mencionados. Como se volverá a ver más adelante, de los nueve Ministros que no han llegado a ocupar cargo público o institucional alguno con anterioridad a su nombramiento como miembros del Gobierno, solamente uno de ellos - Matilde Fernández- puede ser considerado como un destacado militante político profesionalizado - miembro por largo tiempo de las ejecutivas de la UGT y del PSOE-, mientras que en algunos de los demás casos, si bien se registra igualmente una militancia partidista, ésta no ha adquirido los niveles de profesionalidad ni tan relevantes como en el caso mencionado.

Así pues, mientras que la actividad parlamentaria y, por tanto, la posibilidad de realizar una carrera política en este terreno, sólo pudo tener lugar a partir de junio de 1977 - lo que aquí se ha denominado fase parlamentaria del período estudiado-, la actividad político-administrativa y, por lo tanto, la carrera politica realizada en esta vía, en cambio, sí pudo realizarse con anterioridad a aquella fecha. Ello, necesariamente, afecta al equilibrio de los porcentajes de presencia de ambas carreras políticas en los currículos de los Ministros, y asi debe ser tenido en cuenta.

\section{La carrera político-administrativa}

Pasado de lleno el análisis de los datos ofrecidos por la realidad, llama la atención, en primer lugar, el predominio absoluto de la vía políticoadminitrativa como cauce de acceso al Gobierno. Más de la mitad de la Ministros han ocupado solamente cargos de responsabilidad político-adminitrativa con anterioridad a su nombramiento como tales (el 50,47\%); pero esta cifra se incrementa aún hasta rozar los tres cuartos de los Mi- 
nistros del periodo si a ellos se les une aquellos Ministros que, además de haber desempeñado cargos político-administrativos, también ocuparon un escaño parlamentario, simultánea o sucesivamente, con anterioridad a su nombramiento. El porcentaje es entonces el 71,96 por 100 de los Ministros. Mientras que, por el contrario, solamente un 19,63 por 100 de los Ministros accedió al Gobierno habiendo realizado exclusivamente una carrera politico-parlamentaria (porcentaje que se eleva hasta el $41,12 \%$ si a ellos se añade aquellos que también ocuparon puestos en la Administración, simultánea o sucesivamente). $Y$, finalmente, sólo nueve Ministros $(8,41 \%)$ accedieron al Gobierno sin haber ocupado con anterioridad cargo político alguno en la Administración, o escaño en el Parlamento. (Vid. Cuadro 12-A.)

Sin embargo, si analizamos la evolución del peso específico de las vías de origen de los Ministros en cada uno de los Gobiernos habidos du-

\section{CUADRO 12-A. LA «CARRERA POLÍTICA» DE LOS MINISTROS}

\begin{tabular}{|c|c|c|c|}
\hline VIA SEGUIDA & \multicolumn{2}{|c|}{$\begin{array}{c}N^{\circ} .^{\circ} \mathrm{DE} \\
\text { MINISTROS }\end{array}$} & \multirow{2}{*}{$\begin{array}{c}\% \\
\\
50,47 \\
19,63 \\
21,49 \\
8,41\end{array}$} \\
\hline $\begin{array}{l}\text { Sólo la vía administrativa } \\
\text { Sólo la vía parlamentaria } \\
\text { Vía administrativa + parlamentaria } \\
\text { Sólo la vía profesional }\end{array}$ & $\begin{array}{r}54 \\
21 \\
23 \\
9\end{array}$ & & \\
\hline \multirow[t]{2}{*}{ Total } & \multicolumn{2}{|l|}{107} & 100 \\
\hline & FRECUENCIA & (1) & (2) \\
\hline $\begin{array}{l}\text { Total vía administrativa } \\
\text { Total vía parlamentaria }\end{array}$ & $\begin{array}{l}77 \\
44\end{array}$ & $\begin{array}{l}63,64 \\
36,36\end{array}$ & $\begin{array}{l}71,96 \\
41,12\end{array}$ \\
\hline Total & 121 & 100 & \\
\hline
\end{tabular}

(1) \% sobre frecuencia.

(2) \% sobre número de Ministros. 
rante el período analizado, se comprueba cómo existe una apreciable tendencia a la reducción del peso de la vía administrativa, para verse contrapesada por la vía parlamentaria. Así, en los dos últimos Gobiernos socialistas, son mayores en número los Ministros que han llegado a ocupar escaños parlamentarios con anterioridad a su nombramiento, que los que ocuparon puestos de relevancia política en la Administración pública. Esta tendencia no tiene nada de sorprendente en un sistema de gobierno parlamentario como es el nuestro, en el que la norma general lleva a extraer los Ministros preferentemente del propio Parlamento; $y$, si observamos la práctica comparada, todo hacer pensar que esta tendencia se mantenga $y$, aún, aumente en el futuro. (Vid. Cuadro 12-B.)

La carrera político-administrativa, por lo demás, no sólo es aquella de la que proviene un mayor número de Ministros, sino que, en la mayoría de los casos, la presencia previa de Ministros en cargos administrativos de responsabilidad política no ha sido puramente accidental, sino que se trata de una presencia larga y continuada. Así, la media de cargos previos ocupados por aquellos que siguieron esta vía de acceso al Gobierno es de casi tres cargos por Ministro (2,91 cargos), siendo, desde luego, aplastante mayoría aquellos Ministros que Ilegaron a ocupar más de un cargo políticoadministrativo en su camino hacia el Gobierno (vid. Cuadro 13.)

Con repecto al tipo de cargos político administrativos ocupados, es el puesto de Subsecretario el que con mayor frecuencia figura en los currículos ministeriales. Un 31,17 por 100 de los Ministros que siguieron esta vía han llegado a ocupar este importante cargo de responsabilidad político-administrativa, que ocupa el segundo rango jerárquico en la mayoría de los Departamentos ministeriales españoles ${ }^{47}$. El segundo lugar en el orden de frecuencias lo ocupa el puesto del Secretario General Técnico, cargo que en España tiene una doble significación, técnica y política. Política, desde luego, en la medida en que representa un nivel político-administrativo muy elevado, que exige una confianza de ese carácter en la designación; pero, técnica también, no sólo por su función, sino en la medida en que se busca en la designación de este cargo una especial capacitación técnico-juridica que no se requiere en otro tipo de puestos y que le distingue ${ }^{48}$. Su frecuencia, pues, en los curriculos ministeriales es un

${ }^{47}$ Sobre las Subsecretarias, vid. L. DE LA MORENA, «Las Subsecretarías en el derecho orgánico español: Apuntes para su configuración institucional», Documentación Administrativa, 101-102, 1966, pp. 41-67; A GuAITA, "Secretarias de Estado y Subsecretarias", Revista Española de Derecho Administrativo, 18, 1978, pp. 333-357, A. BAR, "La estructura y funcionamiento del Gobierno en España: Una aproximación analítica», en A. BAR et al., El Gobierno en la Constitución Española y en los Estatutos de Autonomias. Barcelona, Diputacio, 1985, pp. 13-50.

49 Sobre las Secretarias Generales Técnicas, vid. A. DIETTA, Las Secretarias Generales Técnicas. Madrid 1961; J. L. CARRO, "Las Secretarias Generales Técnicas", en Estudios de Derecho Administrativo. Madrid, CE, 1972; E GARClA DE ENTERRIA, "Aspectos de la Administración consultiva», Revista de Administración Pública, 24, 1970. 
CUADRO 12-B. LA «CARRERA POLÍTICA» DE LOS MINISTROS (\% POR GOBIERNOS)

\begin{tabular}{|c|c|c|c|c|c|c|c|}
\hline VIAA SEGUIDA & A.II & S.I & S.II & S.III & c-s & G.I & G.II \\
\hline $\begin{array}{l}\text { Sólo administrativa } \\
\text { Sólo parlamentaria } \\
\text { Admva. + Parlam. } \\
\text { Sólo profesional }\end{array}$ & $\frac{90,00}{\overline{10,00}}$ & $\frac{86,96}{\overline{13,04}}$ & $\begin{array}{r}52,00 \\
24,00 \\
20,00 \\
4,00\end{array}$ & $\begin{array}{r}45,95 \\
16,22 \\
35,13 \\
2,70\end{array}$ & $\begin{array}{l}48,00 \\
16,00 \\
36,00 \\
-\end{array}$ & $\begin{array}{l}22,73 \\
36,36 \\
27,27 \\
13,64\end{array}$ & $\begin{array}{l}34,78 \\
39,14 \\
13,04 \\
13,04\end{array}$ \\
\hline Total & 100 & 100 & 100 & 100 & 100 & 100 & 100 \\
\hline $\begin{array}{l}\text { Via administrativa } \\
\text { Vía parlamentaria } \\
\text { Vía profesional }\end{array}$ & $\frac{90,00}{10,00}$ & $\frac{86,96}{13,04}$ & $\begin{array}{r}72,00 \\
44,00 \\
4,00\end{array}$ & $\begin{array}{r}81,08 \\
51,35 \\
2,70\end{array}$ & $\begin{array}{l}84,00 \\
52,00 \\
-\end{array}$ & $\begin{array}{l}50,00 \\
63,63 \\
13,64\end{array}$ & $\begin{array}{l}47,82 \\
52,18 \\
13,04\end{array}$ \\
\hline
\end{tabular}

CLAVE:

A.ll: Segundo Gobierno Arias.

S.I: Primer Gobierno Suárez.

S.Ii: Segundo Gobierno Suárez.

S.III: Tercer Gobierno Suárez.

C-S: Gobierno Calvo-Sotelo.

G.I.: Primer Gobierno González.

G.II: Segundo Gobierno González. 


\section{CUADRO 13. CARRERA POLÍTICO-ADMINISTRATIVA DE LOS MINISTROS}

\begin{tabular}{|c|c|c|c|}
\hline $\begin{array}{l}\text { N. }{ }^{\circ} \text { DE CARGOS } \\
\text { OCUPADOS }\end{array}$ & $\begin{array}{l}\text { N..DE } \\
\text { MINISTROS }\end{array}$ & $\begin{array}{l}\% \\
\text { (1) }\end{array}$ & $\begin{array}{l}\% \\
(2)\end{array}$ \\
\hline $\begin{array}{r}1 \\
2 \\
3 \\
4 \\
5 \\
6 \\
\geqslant 7\end{array}$ & $\begin{array}{r}16 \\
22 \\
15 \\
13 \\
7 \\
1 \\
3\end{array}$ & $\begin{array}{r}20,78 \\
28,57 \\
19,48 \\
16,88 \\
9,10 \\
1,30 \\
3,90\end{array}$ & $\begin{array}{r}14,95 \\
20,56 \\
14,02 \\
12,15 \\
6,54 \\
0,93 \\
2,79\end{array}$ \\
\hline $\begin{array}{l}\text { Total } \\
\text { Media: } 2,91 \text { cargos }\end{array}$ & 77 & 100 & 71,94 \\
\hline
\end{tabular}

(1) Sobre el número de Ministros que siguieron la via administrativa [77].

(2) Sobre el total de Ministros [107].

signo típico de cierta especialización. Un 14,29 por 100 de los Ministros que siguieron la via político-adminitrativa han llegado a desempeñar este cargo.

El tercer lugar en el orden de frecuencias lo ocupa el cargo de Secretario de Estado. Este sí es un puesto de extraordinaria relevancia en la carrera hacia el Gobierno. En realidad, el Secretario de Estado es ya en sí mismo una especie de Ministro de escala reducida y puede, incluso, llegar a tomar parte en los Consejos de Ministros, si bien de manera eventual ${ }^{49}$. Un 11,69 por 100 de los Ministros que siguieron la vía político-administrativa han Ilegado a ser Secretarios de Estado. Sin embargo, al considerar este porcentaje, debe tenerse en cuenta que el puesto de Secretario de Estado es de reciente creación (fue introducido al inicio de la fase parlamentaria del período aquí analizado, en julio de 1977, por el Gobierno Suárez II) ${ }^{50}$,

49 Sobre los Secretarios de Estado, vid. A. GuAita, «Secretarias de Estado y Subsecretarias", cit.; C. F. MOLINA DEL POzo, «Ampliación del nivel político de la Administración española en la actual etapa democrática: los Secretarios de Estado», Revista de Administración Pública, 90, 1979, pp. 97-166; L. MARTín REBOLLo, «Ante la reforma administrativa: Los Ministros y otros miembros del Gobierno", Documentación Administrativa, 180, 1980, pp. 233-346; A. BAR, «La estructura y funcionamiento del Gobierno en España», cit.

so Los Secretarios de Estado fueron creados por el RD 1558/1977, de 4 de julio, que organizaba el segundo Gobierno Suárez. 


\section{CUADRO 14. TIPO DE CARGOS OCUPADOS}

\begin{tabular}{lrrr}
\multicolumn{1}{c}{ CARGo } & FRECUENCIA & \multicolumn{1}{c}{$\%$} & \multicolumn{1}{c}{$\%$} \\
& & $(1)$ & $(2)$ \\
\hline & & & \\
Secretario de Estado & 9 & 4,10 & 11,69 \\
Subsecretario & 24 & 10,90 & 31,17 \\
Secretario General & 4 & 1,82 & 5,19 \\
Secretario General Técnico & 11 & 5,00 & 14,29 \\
Consejero autonómico & 3 & 1,36 & 3,90 \\
Alcalde & 6 & 2,73 & 7,79 \\
Gobernador Civil & 8 & 3,64 & 10,40 \\
Otros cargos & 155 & 70,45 & 201,30 \\
& & & \\
\hline & & & \\
Total & 220 & 100 & - \\
\hline
\end{tabular}

(1) Sobre frecuencia [220].

(2) Sobre el número de Ministros que siguieron la vía administrativa [77].

\section{CUADRO 15. SECRETARIOS DE ESTADO Y SUBSECRETARIOS DEL PERIODO 1976-1986}

\begin{tabular}{|c|c|c|c|c|c|}
\hline $\begin{array}{l}\text { CARGO } \\
\text { OCUPADO }\end{array}$ & $\mathbf{N}^{\circ}$ & $\begin{array}{l}\text { LLEGAN A } \\
\text { MINISTRO* }\end{array}$ & $\begin{array}{l}\% \\
\text { (1) }\end{array}$ & $\begin{array}{l}\% \\
\text { (2) }\end{array}$ & $\begin{array}{l}\% \\
\text { (3) }\end{array}$ \\
\hline $\begin{array}{l}\text { Secretario de Estado sólo } \\
\text { Subsecretario sólo } \\
\text { Secretario Estado + Sub- } \\
\text { secretario }\end{array}$ & $\begin{array}{r}40 \\
138 \\
13\end{array}$ & $\begin{array}{r}8 \\
13 \\
2\end{array}$ & $\begin{array}{r}20,00 \\
9,42 \\
15,38\end{array}$ & $\begin{array}{r}34,78 \\
56,52 \\
8,69\end{array}$ & $\begin{array}{l}4,19 \\
6,80 \\
1,05\end{array}$ \\
\hline Total & 191 & 23 & - & 100 & 12,04 \\
\hline
\end{tabular}

* Secretarios de Estado y Subsecretarios que llegaron a ser Ministro con posterioridad.

(1) Porcentaje horizontal, sobre el respectivo número de ocupantes del cargo.

(2) Porcentaje vertical, sobre los cargos que llegaron a ser Ministro [23].

(3) Porcentaje vertical, sobre el número total de cargos considerados [191]. 
con lo cual ha sido menor la posibilidad de llegar a ocupar este cargo, en comparación con los de Subsecretario o Secretario General Técnico, existentes ya desde hace largo tiempo; de otra manera, hubiera sido, sin duda, diferente la jerarquia de frecuencias, pasando este cargo a ocupar un lugar primordial - y así es lo más posible que ocurra en el futuro-.

De hecho, si cambiamos la perspectiva y analizamos los Secretarios de Estado y Subsecretarios que lo fueron en el periodo 1976-1986 - un total de 191-, vemos cómo, mientras que solamente un 9,42 por 100 de los que fueron sólo Subsecretarios llegó a alcanzar el cargo de Ministro con posterioridad, este porcentaje se eleva considerablemente entre los Secretarios de Estado. Así, un 20 por 100 de los que ocuparon solamente este cargo llegaría a ser Ministro posteriormente, duramente el periodo analizado. (Vid. Cuadro 15). De ello se deduce fácilmente que el escalón o puesto previo que más posibilidades ofrece de llegar a convertir en Ministros a sus ocupantes es el de Secretario de Estado, seguido inmediatamente por el haber ocupado sucesivamente ambos cargos, de Subsecretario y de Secretario de Estado. (Vid. Cuadro 15.)

Con respecto a los demás cargos ocupados previamente por los $\mathrm{Mi}$ nistros en la Administración, llama la atención el bajísimo número de ellos que han sido consejeros o miembros de los Gobiernos autonómicos regionales: solamentei tres. Esta baja frecuencia -que diferencia el caso español de los casos alemán, belga o italiano- ${ }^{51}$, aún teniendo en cuenta el poco tiempo transcurrido desde que incluso los regímenes preautonómicos comenzaron a ser establecidos, permite pensar en la existencia de una alta barrera divisioria, no fácilmente traspasable, entre las élites gobernantes en el ámbito regional o autonómico y las que lo hacen en el aparato central del Estado. (Ello volverá a ser observado más adelante, al analizar la carrera parlamentaria de los Ministros). Sin embargo, desde el punto de vista de la especialización o capacitación técnica de los Ministros para el desempeño de su cargo, cabe pensar que este tipo de puestos sería quizá uno de los más adecuados, junto con los de Secretario de Estado y Subsecretario, como escuela previa. (Vid. Cuadro 14.)

\section{La carrera político-parlamentaria}

Desde un punto de vista global, y como ya se ha visto con anterioridad, es reducido el número de Ministros que han ocupado escaños parlamentarios -ya en las Cortes Generales, ya en un Parlamento autonómico - con anterioridad a su nombramiento como miembro del Gobierno. Solamente un 41,13 por 100 de los Ministros analizados han seguido en su conjunto esta vía política hacia el Gobierno; pero, es aún menor el por-

st Vid. J. Blondel, F. Müller-Rommel (eds.), Cabinets in Western Europe. cit. 
centaje de ellos que la han realizado de manera exclusiva (el $19,63 \%$ ), por lo que lo más frecuente ha sido, pues, el que la via parlamentaria haya coincidido, simultánea - cuando ello ha sido posible- o sucesivamente, con el seguimiento también de la vía político-administrativa (vid. Cuadros 12-A y 16). Hay que tener aqui en cuenta, sin embargo, y como ya se dijo anteriormente, que la experiencia parlamentaria solamente ha podido comenzar a adquirirse $-y$, por lo tanto, a computarse - a partir de las elecciones generales de 1977, por lo que se ha rechazado como parte de la «carrera parlamentaria» de los Ministros el haber sido miembro de las Cortes franquistas; mientras que, en cambio, sí se ha computado como parte de la "carrera político-administrativa" previa el haber ocupado cargos de tal responsabilidad bajo el régimen del general Franco.

Sin embargo, aunque la distancia sigue siendo grande entre el peso específico de la vía político-administrativa al Gobierno y el de la vía políticoparlamentaria, los datos cambian un poco si se pasa a una perspectiva específica o relativa. De esta manera, si se consideran sólo aquellos Ministros que lo fueron durante la fase parlamentaria del período analizado, es decir, con posterioridad a las elecciones generales de 1977, y que, por lo tanto, tuvieron la oportunidad de seguir esta vía política al Gobierno - descartando, pues, a quienes, por haber sido Ministros en la fase no parlamentaria, no pudieron haberla seguido-, se comprueba cómo el porcentaje de ellos que efectivamente llegaron a ser parlamentarios antes de ser nombrados Ministros es superior a la mitad $(53,01 \%)$ y se acerca un poco al porcentaje de aquellos - de todo el periodo- que, habiendo podido seguir la vía político-administrativa al Gobierno, realmente la siguieron, los cuales suponen cerca de los tres cuartos de todos los Ministros $(71,96 \%)$. (Vid. Cuadros 12-A y 16.)

\section{CUADRO 16. CARRERA POLÍTICO-PARLAMENTARIA DE LOS MINISTROS}

\begin{tabular}{|c|c|c|c|c|}
\hline $\begin{array}{c}\text { VIA } \\
\text { SEGUIDA }\end{array}$ & $\begin{array}{c}N^{\circ} \text { DE } \\
\text { MINISTROS }\end{array}$ & $\begin{array}{l}\% \\
\text { (1) }\end{array}$ & $\begin{array}{l}\% \\
(2)\end{array}$ & $\begin{array}{l}\% \\
\text { (3) }\end{array}$ \\
\hline $\begin{array}{l}\text { Sólo parlamentaria } \\
\text { Parlamentaria + Administrativa }\end{array}$ & $\begin{array}{l}21 \\
23\end{array}$ & $\begin{array}{l}19,63 \\
21,50\end{array}$ & $\begin{array}{l}25,30 \\
27,71\end{array}$ & $\begin{array}{l}47,73 \\
52,27\end{array}$ \\
\hline Total & 44 & 41,13 & 53,01 & 100 \\
\hline
\end{tabular}

(1) Sobre el total de Ministros [107].

(2) Sobre el número de Ministros de la fase parlamentaria [83].

(3) Sobre el número de Ministros parlamentarios [44]. 
Lo que sí parece querer apuntarse ya es una cierta tendencia a la persistencia y aumento de la importancia de la vía político-parlamentaria. Y ello, no tanto por el número de Ministros que han seguido exclusivamente este tipo de vía política hacia el Gobierno - como se ha visto ya, es superior el número de Ministros que han seguido tanto la vía administrativa como la parlamentaria ( $v i d$. cuadro $12-\mathrm{A}$ ) - , sino porque, a pesar de haberse celebrado solamente cuatro elecciones generales desde 1977 hasta el presente, más de la mitad de los Ministros que fueron previamente parlamentarios llegaron a serlo en dos o más de las elecciones celebradas (vid. Cuadro 17). En este sentido, es de reseñar que precisamente los tres únicos Ministros que llegaron a ser previamente parlamentarios en las cuatro elecciones generales habidas - M. Chaves, E. Múgica y V. Zapatero-, han sido nombrados Ministros en el último de los Gobiernos formados - González II-, y son tres de los diez Ministros nombrados entonces que no habian sido miembros del Gobierno con anterioridad, por lo que constituyen la tercera parte de los Ministros actuales que han podido llegar a ser parlamentarios en las cuatro elecciones generales habidas.

Así pues, a pesar de que la carrera político-administrativa de los Ministros es mucho más densa, es mayor el número de cargos ocupados en esta vía antes de llegar al Gobierno (vid. Cuadro 13) - y ha sido mayor el tiempo a lo largo del cual pudo haberse realizado-, la carrera políticaparlamentaria no es tampoco una vía fácil de acceso al Gobierno y exige

\section{CUADRO 17. NÚMERO DE VECES ELEGIDO PARLAMENTARIO ANTES DE SER NOMBRADO MINISTRO}

\begin{tabular}{|c|c|c|c|c|}
\hline $\begin{array}{l}\mathrm{N} .{ }^{\circ} \text { DE VECES } \\
\text { PARLAMENTARIO }\end{array}$ & $\begin{array}{l}N^{\circ} .^{\circ} \text { DE } \\
\text { MINISTROS }\end{array}$ & $\begin{array}{l}\% \\
\text { (1) }\end{array}$ & $\begin{array}{l}\% \\
(2)\end{array}$ & $\begin{array}{l}\% \\
\text { (3) }\end{array}$ \\
\hline $\begin{array}{r}1 \\
2 \\
3 \\
4\end{array}$ & $\begin{array}{r}18 \\
16 \\
7 \\
3\end{array}$ & $\begin{array}{r}40,91 \\
36,36 \\
15,91 \\
6,82\end{array}$ & $\begin{array}{r}21,69 \\
19,28 \\
8,43 \\
3,61\end{array}$ & $\begin{array}{r}16,82 \\
14,95 \\
6,54 \\
2,80\end{array}$ \\
\hline $\begin{array}{l}\text { Total } \\
\text { Media: } 1,89 \text { veces }\end{array}$ & 44 & 100 & 53,01 & 41,11 \\
\hline
\end{tabular}

(1) Sobre el número de Ministros que siguieron la via parlamentaria [44].

(2) Sobre el número de Ministros de la fase parlamentaria [83].

(3) Sobre el total de Ministros [107]. 
ya también una cierta persistencia, que, sin duda, será mayor en el futuro, cuando sea más elevado el número de elecciones parlamentarias celebradas. De hecho, y salvando las ya indicadas limitaciones a la comparación, mientras que la carrera político-administrativa exige haber llegado a ocupar una media de 2,91 cargos antes de ser nombrado Ministro, la carrera político-parlamentaria requiere poco menos: haber sido elegido representante del pueblo una media de 1,89 veces. (Vid. Cuadros 13 y 17.)

Claro que, aun en el supuesto de haber sido elegido parlamentario en las cuatro elecciones generales habidas, el tiempo real de experiencia parlamentaria previa que tendria el Ministro español es muy corto, dado lo también corto de la existencia del presente sistema democrático. En este caso, el tiempo máximo sería de 10,6 años (127 meses); tiempo que se queda muy lejos - por ejemplo- de los 14 años de media que le cuesta a un parlamentario británico llegar a ser miembro del Gabinete ${ }^{52}$.

En cualquier caso, se ha considerado como parte de la carrera político-parlamentaria previa la elección como miembro de las Cámaras en la misma legislatura en la que tiene lugar el nombramiento como Ministro, aunque hayan pasado pocas semanas entre la constitución formal de aquéllas y el posterior nombramiento gubernamental. Se trata, en sí misma, de una elección parlamentaria previa al nombramiento como Ministro - y, por lo tanto, computable como tal-, aunque en la práctica el Ministro no haya llegado, en realidad, a adquirir experiencia alguna en la vida parlamentaria, como miembro activo de la Cámara, debido a lo inmediato de su nombramiento como miembro del Gobierno.

Por otra parte, con respecto a la relativa escasez de Ministros político-parlamentarios, debe resaltarse también que uno de los factores que han contribuido a ello ha sido la inexistencia total de Gobiernos de coalición durante el período analizado. Sabido es que los Gobiernos de coalición, debido a su propia sustancia, tienden hacia conformaciones puramente políticas y, por los mismo, a formarse en base exclusivamente parlamentaria. La no necesidad de este tipo de composiciones politicas en España ha hecho prescindible al Parlamento como fuente suministradora de Ministros. De hecho, esta afirmación —como volverá a verse con detalle más adelante- encuentra su sostén, no sólo en el elevadísimo número de Ministros de origen parlamentario existentes — por ejemplo- en Italia o Bélgica, países con habituales Gobiernos de coalición, sino, en nuestra propia experiencia, en el mayor número de Ministros parlamentarios existentes en los Gobiernos de la UCD; partido que, por su propia estructura interna, tendió a formar sus Gabinetes en base a coaliciones de las diferentes tendencias en el seno del mismo y con representación parlamentaria.

Con respecto al tipo de escaño ocupado, la práctica totalidad de los Ministros que han seguido esta vía política han sido miembros del Congreso

52 R. Rose, "The Making of Cabinet Ministers», cit., p. 402. 
de los Diputados en algún momento (el 97,73\%), mientras que solamente seis de ellos (el $13,64 \%$ ) han sido también senadores previamente. El Senado no ha sido, pues, un escalón previo muy frecuentado por los futuros Ministros. Es más, en todos los casos, excepto en dos de ellos, los senadores hubieron de pasar con posterioridad por el Congreso de los Diputados, para completar su carrera politico-parlamentaria antes de llegar al Gobierno ${ }^{53}$. (Vid. Cuadro 18.)

\section{CUADRO 18. VIAA PARLAMENTARIA SEGUIDA POR LOS MINISTROS}

\begin{tabular}{|c|c|c|c|c|}
\hline ESCAÑO & $\begin{array}{c}N^{\circ} \text { DE } \\
\text { MINISTROS }\end{array}$ & $\begin{array}{l}\% \\
\text { (1) }\end{array}$ & $\begin{array}{l}\% \\
\text { (2) }\end{array}$ & $\begin{array}{l}\% \\
\text { (3) }\end{array}$ \\
\hline $\begin{array}{l}\text { Diputado sólo } \\
\text { Senador sólo } \\
\text { Diputado + Senador } \\
\text { Diputado + Diputado autonómico }\end{array}$ & $\begin{array}{r}37 \\
1 \\
5 \\
1\end{array}$ & $\begin{array}{r}84,10 \\
2,27 \\
11,36 \\
2,27\end{array}$ & $\begin{array}{r}44,58 \\
1,20 \\
6,02 \\
1,20\end{array}$ & $\begin{array}{r}34,58 \\
0,93 \\
4,67 \\
0,93\end{array}$ \\
\hline Total & 44 & 100 & 53,00 & 41,11 \\
\hline
\end{tabular}

(1) Sobre el número de Ministros que siguieron la vía parlamentaria [44].

(2) Sobre el número de Ministros de la fase parlamentaria [83].

(3) Sobre el total de Ministros [107].

Tampoco es frecuente la experiencia parlamentaria previa adquirida en un Parlamento autonómico. Por el contrario, solamente uno de los Ministros de todo el período ha llegado a ocupar antes un escaño de este tipo -F. Pons-; pero, ni siquiera ello ha sido en exclusiva, dado que este Ministro había sido ya antes miembro del Congreso de los Diputados. De nuevo aquí, sin embargo, ha de tenerse en cuenta que los primeros Parlamentos autonómicos comenzaron a constituirse en el año 1980, y solamente han sido tres los Gobiernos formados desde entonces, por lo que no ha sido muy grande la oportunidad que ha habido de que se hubiese

53 De los seis Ministros que fueron senadores previamente, cuatro hubieron de ser también diputados antes de su nombramiento - La Cierva, Fontán, González Seara y Morán-; mientras que sólo dos de ellos fueron exclusivamente senadores con anterioridad - Calvo Ortega y Fuentes Quintana-. 
producido este tipo de experiencia en la carrera politico-parlamentaria de los Ministros. Asi pues, si bien es ello llamativo, no puede, sin embargo, derivarse de este hecho, por lo de ahora, regla alguna al respecto.

Sin embargo, mientras que en el caso de la carrera político-administrativa hemos visto cómo los puestos ocupados eran en su mayoría cargos de gran importancia o responsabilidad política, lo que hace pensar en una capacitación técnica del futuro Ministro; en el caso de la carrera político-parlamentaria son muy escasos los Ministros que han cubierto esta vía al Gobierno que han llegado a ocupar cargos de importancia en el seno de las Cámaras, lo que les hubiera permitido adquirir unos conocimientos y una experiencia mayores o más intensos de los que puede producir la mera y simple ocupación del escaño. Así, por ejemplo, solamente ocho de ellos llegaron a ocupar la presidencia de una Comisión y solamente cinco fueron presidente o portavoz de un respectivo Grupo parlamentario; sólo uno llegó a ser previamente Presidente de la Cámara, A. Fontán -Presidente del Senado en la legislatura 1977-79-, y solamente seis fueron vicepresidente de Comisión. (Vid. Cuadro 19.)

\section{CUADRO 19. TIPO DE PUESTOS OCUPADOS EN EL PARLAMENTO}

\begin{tabular}{llrr}
\hline & & & \\
Presidente de la Cámara & 1 & 5,00 & 2,27 \\
Presidente de Comisión & 8 & 40,00 & 18,18 \\
Vicepresidente de Comisión & 6 & 30,00 & 13,64 \\
Portavoz de Grupo & 5 & 25,00 & 11,36 \\
\hline & & & \\
\hline Total & 20 & 100 & 45,45 \\
\hline
\end{tabular}

(1) Sobre frecuencia.

(2) Sobre el 'número de Ministros que siguieron la vía parlamentaria [44]. 


\section{Los Ministros-parlamentarios}

El sistema constitucional español es un sistema parlamentario en el pleno sentido técnico del término, y, como tal, no sólo permite (art. 70.1.b CE), sino que cabria decir que llama a la compatibilización de los cargos de Ministro y parlamentario al mismo tiempo. Compatibilización que - sin que quepa en el marco de este análisis entrar en un estudio detallado de sus causas - vendría determinada por la integración funcional y mutua colaboración de poderes que caracteriza a esta forma de gobierno.

Pues bien, la experiencia de los once años transcurridos desde que las elecciones generales de junio de 1977, abrieran de nuevo las puertas del Parlamento en España, demuestra que, si bien esta es la línea que se ha tendido a seguir, no siempre los miembros de los Gobiernos habidos han sido parlamentarios al mismo tiempo. Solamente dos tercios de los Ministros compatibilizaron ambas funciones al mismo tiempo, mientras que el tercio restante no ocupaba escaño parlamentario alguno durante su mandato. (Vid. Cuadro 20-A.)

En conjunto, han sido hasta ahora los Gobiernos de la fenecida UCD los que porcentualmente mayor número de Ministros parlamentarios han tenido en su seno, si bien los Gobiernos del PSOE les siguen a escasa distancia. Así, mientras que los primeros han llegado a contar con un 70,1 por 100 de Ministros simultáneamente parlamentarios, los segundos cuentan, hasta el presente, con un 64,4 por 100. (Vid. Cuadrado 20-A.)

\section{CUADRO 20-A. MINISTROS PARLAMENTARIOS EN LOS GOBIERNOS DEL PERÍODO 1977-1988}

\begin{tabular}{|c|c|c|c|c|c|c|}
\hline \multirow[b]{2}{*}{ ESCAÑO } & \multicolumn{2}{|c|}{ GOBIERNOS UCD } & \multicolumn{2}{|c|}{ GOBIERNOS PSOE } & \multicolumn{2}{|c|}{ TOTAL } \\
\hline & $\mathbf{N}^{\circ}$ & $\%$ & $\mathbf{N}^{\circ}$ & $\%$ & $\mathrm{~N}^{\circ}$ & $\%$ \\
\hline $\begin{array}{l}\text { Senadores } \\
\text { Diputados } \\
\text { No parlamentarios }\end{array}$ & $\begin{array}{r}6 \\
55 \\
26\end{array}$ & $\begin{array}{r}6,9 \\
63,2 \\
29,9\end{array}$ & $\begin{array}{l}-28 \\
17\end{array}$ & $\begin{array}{l}-\overline{64,4} \\
35,6\end{array}$ & $\begin{array}{r}6 \\
83 \\
43\end{array}$ & $\begin{array}{r}4,5 \\
62,9 \\
32,6\end{array}$ \\
\hline Total & 87 & 100 & 45 & 100 & 132 * & 100 \\
\hline
\end{tabular}

\footnotetext{
* El exceso sobre el número real de 83 personas que fueron Ministros durante el período parlamentario se debe al número de ellas que fueron Ministro en más de una ocasión y en más de un Gobierno (vid. Cuadros 2 y 3 ).
} 
Si se analizan en detalle los contenidos de cada uno de los cinco Gabinetes formados desde las elecciones generales de 1977 (vid. Cuadro 20-B), Ilama la atención, en primer lugar, la práctica ausencia de senadores en la conformación de los Gobiernos españoles. Solamente el segundo Gabinete Suárez, formado precisamente tras las elecciones generales de 1977, recoge en su seno a los seis únicos Ministros simultáneamente senadores de todo el período analizado. $Y$, lo que es altamente significativo de la escasa relevancia parlamentaria de su designación, solamente uno de ellos - Calvo Ortega - era senador por elección popular, mientras que los cinco restantes lo eran por designación regia. Ello es una clara indicación de que ni siquiera estos cinco senadores de designación regia fueron nombrados Ministros en función de su cualificación política, en tanto que senadores, sino más bien debido a otro tipo de cualificaciones personales, que fueron también, por otra parte, las que les llevaron a ser nombrados senadores por el Rey (de hecho, algunos de ellos habian sido ya Ministros con anterioridad, en Gobiernos de la fase preparlamentaria del periodo analizado: Abril, Lavilla, Martín Villa, Oreja) ${ }^{54}$. Desde entonces, y

CUADRO 20-B. MINISTROS PARLAMENTARIOS EN LOS GOBIERNOS DEL PERÍODO 1977-1988

\begin{tabular}{|c|c|c|c|c|c|c|c|c|c|c|}
\hline ESCAÑO & S.II & $\%$ & S.III & $\%$ & C-s & $\%$ & G.I & $\%$ & G.II & $\%$ \\
\hline $\begin{array}{l}\text { Senador } \\
\text { Diputado } \\
\text { No parla. }\end{array}$ & $\begin{array}{c}6^{*} \\
11 \\
8\end{array}$ & $\begin{array}{l}24,0 \\
44,0 \\
32,0\end{array}$ & $\begin{array}{r}-28 \\
9\end{array}$ & $\begin{array}{l}\overline{75,7} \\
24,3\end{array}$ & $\begin{array}{r}- \\
16 \\
9\end{array}$ & $\begin{array}{l}- \\
64,0 \\
36,0\end{array}$ & $\begin{array}{l}-\overline{12} \\
10\end{array}$ & $\begin{array}{l}- \\
54,5 \\
45,5\end{array}$ & $\begin{array}{r}-16 \\
7\end{array}$ & $\begin{array}{l}\overline{69,6} \\
30,4\end{array}$ \\
\hline Total & 25 & 100 & 37 & 100 & 25 & 100 & 22 & 100 & 23 & 100 \\
\hline
\end{tabular}

CLAVE:

S.ll: Segundo Gobierno Suárez.

S.III: Tercer Gobierno Suárez.

C-S: Gobierno Calvo Sotelo.

G.I: Primer Gobierno González.

G.II: Segundo Gobierno González.

: Incluye 1 Senador electivo y 5 de designación real.

${ }^{54}$ Los seis Ministros que simultanearon su cargo con el escaño de Senador fueron Abril Martorell, Fuentes Quintana, Lavilla Alsina, Martín Villa, Oreja Aguirre y Calvo Ortega. 
tras la aprobación de la Constitución de 1978, la totalidad de los Ministrosparlamentarios habidos han provenido exclusivamente del Congreso de los Diputados.

En segundo lugar $-\mathrm{y}$ sorprendentemente-, como se puede comprobar en el Cuadro 20-B, la proporción de Ministros parlamentarios al mismo tiempo en la formación de los sucesivos Gobiernos parecía experimentar un lento pero progresivo descenso desde el máximo del 75,7 por 100 alcanzado por el tercer Gabinete Suárez, hasta el mínimo del 54,5 por 100 del primer Gabinete González. Sin embargo, tras las elecciones generales de 1986, en las que el PSOE decidió incluir en sus listas electorales a la práctica totalidad de los Ministros que por entonces formaban el Gobierno, y a pesar de que no todos ellos volverian a ser nombrados Ministros con posterioridad, la formación del segundo Gabinete González determinó una radical inflexión en la tendencia descrita y alcanzó la proporción más alta hasta entonces registrada de Ministros parlamentarios en su seno - un 88,2 por 100-; lo que implicaba que solamente dos Ministros no eran parlamentarios simultáneamente. Sin embargo, la remodelación del Gabinete que tuvo lugar en julio de 1988, que dio entrada a seis nuevos Ministros, de los cuales solamente uno - E. Múgica- era parlamentario al mismo tiempo, supuso una nueva reducción de este indice, que bajó hasta el 69,6 por 100 del total de los Ministros. (Vid. Cuadro 20-B.)

La proporción de Ministros miembros del Parlamento en un sistema parlamentario como el nuestro, en el que, sin embargo, no existe obligación constitucional alguna de que los Ministros ocupen al mismo tiempo un escaño parlamentario, tiene una cierta relevancia, en la medida en que puede servir de indicador —uno más, no el único- del carácter «técnico» o «político" de cada uno de los Gabinetes. En este sentido, cabría decir que los Gabinetes formados mayoritariamente por miembros del Parlamento tienden a ser Gabinetes de carácter «político" de manera preferente; mientras que los Gabinetes en los que es mayor la proporción de Ministros no parlamentarios tienden a ser preferentemente «técnicos" 0 "profesionales". Y ello es así, porque, normalmente, el puesto de parlamentario presupone la existencia de una cualificación o de un activismo políticos, que no tienen por qué existir necesariamente en el currículo de los Ministros no parlamentarios. Los primeros han de pasar por todo un largo proceso de confrontación politica, que comienza ya antes de la formación de las listas electorales, en el seno de los partidos, y que se culmina con la misma campaña electoral; lo que requiere generalmente unos elevados niveles de activismo militante, o de profesionalismo político. Mientras que los segundos, aún habiendo desempeñado previamente cargos de responsabilidad política en el seno de la Administración, no tienen necesariamente que pasar por un proceso similar, ni, por tanto, reunir semejante cualificación política; pudiendo, por el contrario, ser profesionales cualificados por sus conocimientos técnicos, e, incluso, no haber desempeñado cargo político previo de ningún tipo - como de hecho ha ocurrido en el 8,41 por 100 de los casos analizados (vid. Cuadro 12-A)-. 
En este sentido, la formación del primer Gabinete González hizo pensar en una cierta acentuación de los contenidos técnicos o profesionales sobre los políticos, dado que en él, no sólo los Ministros no parlamentarios eran casi iguales en número a los simultáneamente parlamentarios (Vid. Cuadro 20-B), sino que varios de ellos no eran siquiera miembros del PSOE. Por otra parte, la proporción Ministros parlamentarios/Ministros no parlamentarios era aún más llamativa si se tiene en cuenta que el número de escaños obtenidos por el PSOE en las elecciones de 1982 fue muy superior al obtenido por la UCD en elecciones anteriores; lo que significa que tenía un número potencial más elevado de candidatos parlamentarios de los que disponer para la formación del Gobierno, que, sin embargo, no fueron aprovechados. Con ello, por un lado, se trataba de superar el excesivo peso del elemento politico, que habia lastrado los Gabinetes de la UCD - y que habia sido tanto causa como efecto de la inestabilidad de los mismos-; y, por otro, se trataba de compensar la posible carencia de cuadros técnicos especialmente capacitados de la que adolecía el partido, al verse repentinamente con la práctica totalidad del poder del Estado en sus manos de manera exclusiva. Por entonces el PSOE seguia una política de atracción y de colaboración con los sectores profesionales e independientes de la sociedad, que se habia iniciado ya con la misma formación de las listas electorales para la convocatoria de 1982.

Sin embargo, la constitución del segundo Gabinete González en 1986 supuso un cambio radical en esta línea. El porcentaje de Ministros no parlamentarios fue reducido drásticamente y desaparecieron los Ministros no militantes del partido. Tras los cuatro primeros años de gobierno, el PSOE habia adquirido ya unos niveles de militancia cualificada que le permitían actuar y gobernar en exclusiva, sin necesidad de acudir a sectores ajenos al partido. Y ello se notó ya en la formación de las listas electorales para las elecciones de 1986, las cuales se formaron exclusivamente con militantes del partido. Sin embargo, el desgaste político propio de la actividad gubernamental continuada y el apreciable anquilosamiento de ciertos sectores del Gobierno Ilevaron al Presidente González a realizar una importante remodelación de su Gabinete en julio de 1988, por la que se vieron afectados doce Ministros. Esta remodelación supuso una parcial marcha atrás en el criterio seguido en la formación de este segundo Gobierno socialista y se volvió a dar entrada en el Gabinete a Ministros independientes, no pertenecientes al PSOE - C. Aranzadi, R. Conde, J. Semprún-, y a Ministros no parlamentarios. De hecho, de los seis nuevos Ministros que entonces entraron en el Gobierno, como ya se ha visto, solamente uno -E. Múgica- era miembro del Congreso de los Diputados.

En conjunto, pues, los Gobiernos españoles han ignorado a la Cámara Alta, como centro de extracción y de vinculación parlamentaria de sus miembros. Y ello está en relación directa con el escaso papel del Senado en las relaciones Gobierno-Parlamento dentro de nuestro sistema, a partir de la Constitución de 1978. Por lo demás, la media general de 69,8 
por 100 de Ministros-parlamentarios por Gabinete (vid. Cuadro 18-A) es relativamente baja, si se la compara con la media existente en otros sistemas parlamentarios de nuestro entorno, de similar regulación constitucional. Así, si exceptuamos los casos de la Gran Bretaña, donde es obligatoria la ocupación de un escaño parlamentario por parte de los miembros del Gabinete, y de Francia, donde, al contrario, existe una incompatibilidad constitucional entre la función gubernamental y la parlamentaria, la media de Ministros-parlamentarios por Gobierno ronda en torno al 78 por 100; siendo Austria uno de los países con más bajo índice de Ministros-parlamentarios (alrededor del $48 \%$ ), e Italia el de índice más elevado (alrededor del $95 \%$ ). El caso Español se encuentra en una situación muy similar a la de Holanda (alrededor del $66 \%$ ) y de Alemania (alrededor del $68 \%$ ).

\section{LA ESPECIALIZACIÓN MINISTERIAL}

Si se tiene en cuenta que la moderna expansión de la actividad gubernamental ha aumentado considerablemente la importancia y dificultad de los aspectos técnicos de la labor de los Ministros, parece lógico concluir también la relevancia de la existencia de un cierto grado de especialización por parte de éstos con respecto a la materia y al tipo de actividad que van a tener que aumir una vez llegados al Gobierno. Relevancia que se va a manifestar, tanto con respecto a la toma de decisiones en el seno del Gabinete, como con respecto al resultado o eficacia de las mismas.

El problema surge, sin embargo, a la hora de definir el concepto de especialización minisierial como factor determinante de la actuación del Gobierno. Para un gran sector de la doctrina el problema se reduce a discernir si el Gobierno está compuesto por técnicos, o por políticos, es decir, si se trata de un Gabinete predominantemente - o de manera absoluta-, técnico, o político. Y aunque no está tampoco muy claro qué es lo que debe incluirse realmente dentro de cada una de estas dos categorías, en términos muy generales parece asociarse la categoría político con la presencia mayoritaria de Ministros parlamanterios o provinientes de los órganos de dirección del partido o partidos formantes del Gabinete; mientras que la categoría récnico se asocia con la presencia de Ministros no parlamentarios y carentes de militancia política. En este sentido, lo político parece querer significar la preocupación exclusiva por los intereses partidistas y el mantenimiento del poder como un objetivo en si mismo, con ignorancia de los fines generales o superiores para cuya consecución es en realidad un medio; mientras que lo técnico vendría a significar la preocupación exclusiva por la eficacia, por la satisfacción inmediata de necesidades más perentorias, olvidando metas más amplias en su alcance material y temporal. 
La verdad es que esta conceptuación, aceptable en términos vulgares o puramente periodísticos, es muy simple y, no sólo plantea serias dudas con respecto al contenido sustancial de cada una de las dos categorias en que se divide, sino que dice muy poco con respecto a la actuación y eficacia gubernamental en un sistema parlamentario de gobierno, en el que tanto el elemento político como el elemento técnico parecen imprescindibles. Así considerados, el predominio absoluto del elemento técnico supondria una total relegación del carácter parlamentario del Gobierno, ignorando las raíces políticas y parlamentarias del mismo, sin cuya consideración el Gobierno no puede funcionar; y el predominio absoluto del elemento politico relegaría a un segundo término el factor eficacia, que debe caracterizar la actuación gubernamental y justifica la existencia misma del Gobierno. Por otra parte, la procedencia parlamentaria o política de un Ministro no tiene por qué ser necesariamente excluyente de su capacitación técnica para el desempeño de la cartera que le es encomendada $y$, por consiguiente, de la consecución de elevados niveles de eficacia en la realización de la política gubernamental. Son, pues, otros y más complejos los factores que determinan el éxito de la actuación gubernamental.

En este sentido, el presente estudio pretende aportar el concepto de especialización ministerial, como uno de esos factores que, desde mi punto de vista, supera y subsume las categorias mencionadas y tiene un mayor peso específico en la determinación de la actuación gubernamental. Si bien, debe decirse ya que aspectos como el carácter técnico o político de los Ministros, en el sentido antes mencionado, tienen un papel decisivo en la determinación de la especialización ministerial, como lo tienen también los factores que fueron analizados en apartados anteriores de este mismo trabajo - la edad, el sexo, la formación, la actividad profesional, la carrera politica y la estabilidad ministerial-.

En términos generales, la especialización ministerial viene a ser equivalente a la capacitación de los Ministros para el desempeño de la tarea que se les encomienda. Así, parece lógico pensar que tanto una como la otra estarían compuestas por dos tipos de elementos: primero, un conocimiento profundo de la materia específica de la que se encarga el respectivo Departamento ministerial, y, segundo — sin que ello suponga una prelación en importancia-, una capacidad de gestión y dirección de carácter administrativo. Es dudosa y difícil de determinar la importancia del porcentaje de presencia de ambos elementos en el currículo ministerial, a efectos de prever o calibrar la eficacia de la actuación de un Ministro. (Tampoco la eficacia de la actuación ministerial, ni de la gubernamental en su conjunto, dependen en exclusiva de ello, siendo también decisiva, como ya se ha dicho, la intervención de factores externos). Por otra parte, en lo que se refiere a la capacidad de dirección o gestión administrativa, es ello también algo de muy difícil previsión y medida, quizá sólo enjuiciable por el resultado de la propia gestión ministerial. Por lo demás, este tipo de habilidad es algo que, al menos hasta cierto nivel, debe presuponerse en personas que, gracias a sus condiciones políticas o profesionales, han lle- 
gado a ocupar un puesto de tanta relevancia como la dirección de un Departamento ministerial en el Gobierno. Así pues, este aspecto de la especialización ministerial va a ser aquí obviado, para referirnos exclusivamente al primero de ellos, al conocimiento profundo de la materia específica de la que se encarga el Departamento gubernamental que va a dirigir el Ministro.

En términos muy similares, B. HEADEY entiende que tres son los papeles que un Ministro asume en el desempeño de su cargo: ser el representante de su Departamento, tanto hacia el exterior, como hacia el interior del Gobierno, con respecto a los otros miembros del Gabinete; ser el jefe ejecutivo del Departamento, lo que supone ser el supremo director del trabajo en el seno del mismo; y ser lo que literalmente denomina key issues Minister, es decir, concentrar su dedicación exclusivamente en los asuntos clave del Departamento; asuntos clave que le pueden venir impuestos por la dinámica política del momento, o porque él así los elija, lo que supone dejar todos los demás, al menos en buena medida, al cargo de sus subordinados. Su investigación con respecto a los miembros del Gabinete británico descubre precisamente que éstos emplean la mayor parte de su tiempo en su dedicación a estos «asuntos clave» ${ }^{55}$.

El corolario de todo ello es, por tanto, que el principal papel de un Ministro es su dedicación a aquellos aspectos más importantes -clavesdel objeto material de su Departamento; aspectos en los que el Ministro puede realmente dejar su impronta, realizar su propia visión o interpretación de la política gubernamental, o del programa del partido que sostiene al Gobierno. En los otros papeles su importancia es secundaria. Si excluimos la defensa de la política de su Departamento - cuyo diseño le corresponde- frente a los demás miembros del Gobierno en las reuniones del Gabinete, el resto del papel representativo puede ser en buena medida asumido por otros miembros inferiores del Departamento. De hecho, incluso en muchas de las reuniones intragubernamentales de coordinación ni siquiera asisten los Ministros, sino cargos inferiores, como los Secretarios de Estado y los Subsecretarios (por ejemplo: la Comisión General de Subsecretarios, las Comisiones Interministeriales, etc.). Y, en lo que se refiere al papel del jefe ejecutivo, la dirección del trabajo del Departamento, no sólo no suele requerir la intervención novedosa de cada Ministro, por estar sometido en gran medida a las leyes fijas de la rutina administrativa, sino que es este un apartado típicamente delegado a los cargos inferiores del Ministerio. En España, esta labor está formalmente atribuida a los Subsecretarios ${ }^{56}$.

Así pues, si un Ministro dedica la mayor parte de su tiempo a lo que son los aspectos clave de la materia departamental, única dedicación, por

ss B. HAADEY, British Cabinet Ministers: The Roles of Politicians in Executive Office. London, Allen and Unwin, 1974.

56 Vid. artículo 15 de la LRJAE, de 1957. 
otra parte, en la que el Ministro va a gozar de plena autonomía y responsabilidad (art. 98.2 CE), dentro, claro está, del marco programático del Gobierno, es lógico pensar en lo importante que es el que los miembros del Gobierno, aun antes que buenos administradores, sean unos buenos conocedores de la materia objeto de su Departamento; sean unos buenos conocedores de la materia objeto de su Departamento; sean unos expertos o especialistas en la misma. La distinción más adecuada que cabría hacer entonces entre los Ministros - más que entre políticos y técnicos- sería aquella que los divide entre especialistas y amateurs, o, quizá, entre especialistas y generalistas, atendiendo a su conocimiento específico, o no, de la materia objeto de su Departamento.

En este sentido, pues, el concepto de especialización ministerial es entendido aqui como la coincidencia material entre el objeto del cargo o puesto ocupado por el Ministro en el Gabinete y el objeto de dedicación de la carrera o via seguida por éste previamente hacia el Gobierno.

Claro que, por un lado, a lo largo de su carrera -política o profesional-hacia el Gobierno, el futuro Ministro ha podido pasar por diferentes tipos de formación y actividad, y estar consiguientemente, en contacto con varios tipos de materias, a veces con muy poca relación entre ellas; $y$, por otro, puede haber sido también muy diferente el tiempo dedicado a cada una de esas materias o actividades. En este sentido, es muy difícil poder hablar de la existencia de Ministros especialistas puros, o amateurs puros, en la medida en que el conocimiento que se pueda tener de una determinada materia puede ser más o menos profundo, y, por otra parte, la larga carrera política de un Ministro le permite llegar a adquirir conocimientos más o menos profundos sobre más de una materia de las que son objeto de la dedicación gubernamental. Así, la especialización ministerial puede ser el resultado de toda o de algunas etapas solamente de la carrera política ministerial, y es frecuentemente el resultado sólo de las últimas de las etapas de esta carrera.

Asi pues, de acuerdo con este concepto, la especialización es más una categoría cualitativa que cuantitativa. No es, por tanto, una categoría absoluta ni unidimensional; es decir, se puede hablar de diferentes niveles de especialización y de especialización en más de un campo o materia. Los Ministros pueden estar, por tanto, más o menos especializados en su propia materia, de acuerdo con el contenido de la carrera o vía política seguida hacia el Gobierno. Por ello, para determinar el grado de especialización de los Ministros ha de estudiarse en detalle el currículo de los mismos, en el que intervienen, tanto a) la formación académica inicial, como b) la actividad profesional desempeñada, como c) la carrera política seguida hasta su nombramiento como miembro del Gobierno. (Vid. Gráfico 2.)

a) La formación académica inicial, el título universitario, etc., si bien es la base primera de la especialización ministerial, no aporta mucho para determinar ésta de manera específica, en la medida en que la mayoría 


\section{GRÁFICO 2. LA CARRERA PREMINISTERIAL}
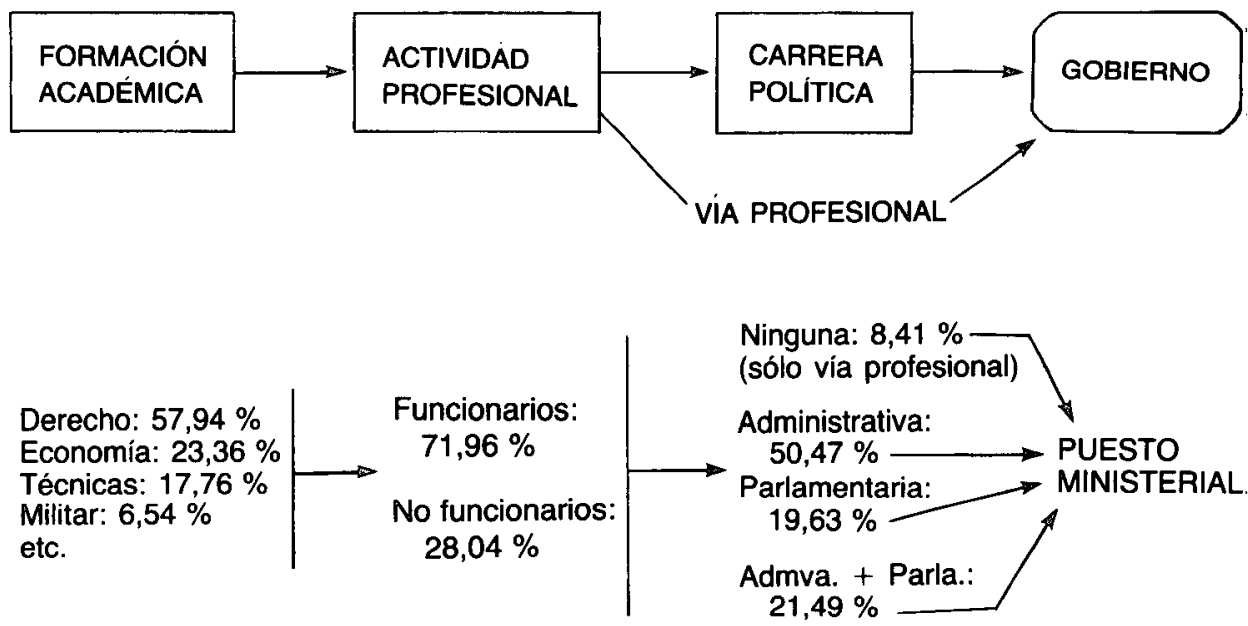

de los casos registran licenciaturas en Derecho (el 57,94 \% de los Ministros), o en Economía (el 23,36\% de los Ministros), cuando no las dos al mismo tiempo, o junto con otras (vid. Cuadro 8). Licenciaturas que, debido a su polivalencia, si fueran consideradas como factor determinante e la especialización, permitirian hablar indistintamente, tanto de la existencia de Ministros especialistas, como de Ministros generalistas, en función de la propia perspectiva. Por otra parte, como ocurre en uno de los casos registrados - J. L. Corcuera-, esta formación académica oficial puede que no exista en absoluto, existiendo sólo una formación autodidacta. En este sentido, pues, la formación académica inicial no ha sido considerada aqui como factor de especialización.

b) La actividad profesional desempeñada por el futuro Ministro es mucho más relevante como factor determinante de la especialización, y, sobre todo, cuando ha sido el único camino seguido para llegar al Gobierno, debido a la inexistencia de todo cargo o nombramiento político previo; situación esta última en la que se encuentra sólo nueve de los Ministros analizados (vid. Cuadro 12-A). Su importancia decae, en cambio, cuando el Ministro ha realizado o seguido una carrera política hacia el Gobierno, dado que, en este caso, son los puestos políticos ocupados el principal punto de referencia y factor determinante de la especialización.

En este sentido, y como ya se vio con anterioridad, aquí se entiende por actividad o carrera profesional cualquier tipo de actividad desempe- 
ñada al margen de cualquier nombramiento o elección política dentro de la estructura o aparatos del Estado. Así, a estos efectos, desde el punto de vista de la especialización ministerial, forma parte de la carrera o vía profesional al Gobierno, tanto haber sido abogado o director de empresa, como haber sido militante político o sindicalista profesional, a cualquier nivel, siempre que ello no haya representado el ocupar cargos políticos institucionales en la estructura estatal. Por otra parte, dada la posibilidad de que exista más de una actividad profesional en el currículo de cada Ministro, y ante la dificultad de determinar con precisión en todos los casos cuál de ellas es la predominante, se ha considerado como factor determinante de especialización la existencia de coincidencia en el objeto con el puesto ministerial ocupado posteriormente de cualquiera de ellas.

c) La carrera política al Gobierno es, por el contrario, aquella que se ha seguido a través de cargos públicos de designación política en la estructura estatal, tanto a través de la elección popular como a través del nombramiento directo. Como ya se ha visto también, la carrera política pudo, pues, haberse realizado a través de dos vías: i) la vía administrativa, entendiendo por tal el haber sido nombrado para altos puestos de designación y responsabilidad política en el marco de la Administración Pública, en cualquiera de sus ámbitos, sea el destinatario del cargo funcionario de carrera o no $(50,47 \%$ de los casos); y ii) la vía parlamentaria, o aquella que supone la elección directa para instituciones representativas tales como las Cortes Generales o los Parlamentos autonómicos $(19,63 \%$ de los casos).

Pero las vias administrativa y parlamentaria no son excluyentes, ni sucesiva ni simultáneamente, pudiendo haber sido seguidas ambas por un mismo miembro del Gobierno, en momentos diferentes o, cuando ello ha sido posible, al mismo tiempo. Así, efectivamente, un 21,49 por 100 de los Ministros del período analizado han ocupado tanto cargos político-administrativos como escaños parlamentarios, antes de su nombramiento. (Vid. Gráficos 1 y 2, y Cuadro 12-A). Por otra parte, se ha considerado como factor determinante de especialización: i) en la vía político-administrativa, teniendo en cuenta la posibilidad frecuente del desempeño de más de un cargo administrativo - y de contenidos diferentes - por cada Ministro, lo que dificulta enormemente cualquier tipo de precisión más afinada, la mera coincidencia en su objeto de alguno de ellos con la materia objeto del Departamento gubernametal ocupado con posterioridad; y ii) en la via políticoparlamentaria, la ocupación en el Parlamento de algún tipo de puesto cualificado por su especialización material, tal como -principalmente - ser Presidente o miembro de una Comisión especializada, o ser Presidente de la Cámara, o de Grupo parlamentario, siempre que ello guarde relación directa con el tipo de puesto ocupado posteriormente en el Gobierno. En ninguno de los dos casos se ha tenido en cuenta, pues, el factor tiempo -duración o permanencia en los cargos preministeriales-, dada la inmensa dificultad de análisis que ello supondría. 
Considerados globalmente el conjunto de los Ministros analizados, con independencia de la via de acceso al Gobierno que hubieran seguido, se comprueba como la actividad profesional previa es el escalón de la carrera preministerial que mayor índice de coincidencia registra con respecto al contenido material del cargo gubernamental ocupado -aisladamente o en conjunción con las otras vías de acceso al Gobierno-. Esta coincidencia se da en el 57,94 por 100 de los casos, seguida inmediatamente de las vias administrativa y parlamentaria, mientras que la inexistencia total de cualquier tipo de coincidencia se eleva sólo hasta el 16,82 por 100 de los Ministros. (Vid. Cuadro 21-A.)

\section{CUADRO 21-A. COINCIDENCIA ENTRE LA ACTIVIDAD PROFESIONAL, LA CARRERA POLÍTICA Y EL PRIMER CARGO MINISTERIAL OCUPADO (ACUMULADA)}

\begin{tabular}{|c|c|c|c|}
\hline COINCIDENCIA & FRECUENCIA & $\begin{array}{l}\% \\
\text { (1) }\end{array}$ & $\begin{array}{l}\% \\
\text { (2) }\end{array}$ \\
\hline $\begin{array}{l}\text { Coincide la actividad profesional } \\
\text { Coincide la vía administrativa } \\
\text { Coincide la via parlamentaria } \\
\text { No hay coincidencia }\end{array}$ & $\begin{array}{l}62 \\
57 \\
21 \\
18\end{array}$ & $\begin{array}{l}39,24 \\
36,08 \\
13,29 \\
11,39\end{array}$ & $\begin{array}{l}57,94 \\
53,27 \\
19,63 \\
16,82\end{array}$ \\
\hline Total & 158 & 100 & - \\
\hline
\end{tabular}

(1) Sobre frecuencia [158].

(2) Sobre número total de Ministros [107].

Ahora bien, como ya se ha dicho anteriormente, la especialización ministerial no es una categoria absoluta, sino que es susceptible de gradación. El grado máximo de especialización vendria dado, pues, por la perfecta coincidencia entre el contenido material de los diferentes estadios de la carrera preministerial y el del cargo gubernamental ocupado por el Ministro; es decir, por la adaptación de las vías profesional, administrativa y parlamentaria a la actividad ministerial posterior. Sin embargo, ésta coincidencia o adaptación difícilmente se consigue plenamente y sólo se ha podido registrar en el currículo de ocho de los Ministros analizados $(7,48$ $\%$ del total). Lo más frecuente es la coincidencia de las vías profesional y 
administrativa (28,97\% de los casos), o que coincidan sólo la actividad profesional previamente desarrollada $(19,63 \%$ de los casos $)$, o sólo el contenido de la vía político-administrativa seguida $(14,95 \%$ de los casos $)$. (Vid. Cuadro 21-B.)

CUADRO 21-B. COINCIDENCIA ENTRE LA ACTIVIDAD PROFESIONAL, LA CARRERA POLÍTICA Y EL PRIMER CARGO MINISTERIAL OCUPADO (POR MINISTROS)

\begin{tabular}{lrr}
\multicolumn{1}{c}{ COINCIDENCIA } & \multicolumn{1}{c}{ N. $^{\circ}$ DE } \\
& MINISTROS & $\%$ \\
& & \\
\hline & 8 & \\
Coinciden actividad prof. + vía admva. + vía parla. & 31 & 28,48 \\
Coinciden las vías prof. + admva. & 2 & 1,87 \\
Coinciden las vías prof. + parla. & 2 & 1,87 \\
Coinciden las vías admva. + parla. & 21 & 19,63 \\
Coincide sólo la actividad prof. & 16 & 14,95 \\
Coincide sólo la vía admva. & 9 & 8,41 \\
Coincide sólo la via parla. & 18 & 16,82 \\
No hay coincidencia & & \\
\hline & & \\
Total & 107 & 100 \\
\hline
\end{tabular}

En este sentido, es prácticamente imposible poder hablar de una plena capacitación técnica de los Ministros españoles para el cargo que se les ha atribuido. Sin embargo, a la inversa, debe señalarse también que no es muy alto el porcentje de Ministos que carecen totalmente de cualquier tipo de especializción (sólo el $16,82 \%$ ). En el medio se encuentran, pues, el grueso de los Ministros.

Por otra parte, sorprende el hecho de la falta prácticamente total de coincidencia o continuidad entre las vías profesional y parlamentaria, por un lado, y administrativa y parlamentaria, por otro. Ambos pares de vias solamente coinciden entre sí en un 1,87 por 100 de los casos, repectivamente (vid. Cuadro 21-B). Ello hace pensar en la indiferencia de la capacitación profesional de los parlamentarios a la hora de realizar una actividad específica en el seno de las Cámaras, y es una manifestación clara, por otra parte - y como se verá de nuevo más adelante-, de la relativa irrelevancia de la vía político-parlamentaria como cauce de especialización preministerial (vid. Cuadro 21-A). 
La vía político-administrativa al Gobierno es, después de la vía profesional, la que mayor índice de especialización recoge -y produce-. Un 53,27 por 100 de los Ministros que siguieron esta vía política ha desempeñado en el curso de la misma tareas coincidentes con el objeto de su cargo ministerial posterior.

Efectivamente, si se analizan por separado los Ministros de acuerdo con la vía que les llevó al gobierno, se comprueba como en el caso de los Ministros que siguieron sólo la vía político-administrativa (Cuadro 22), no sólo es elevado el grado general de especialización, sino que hay una gran continuidad entre la actividad profesional previa, la carrera político-administrativa y el cargo ministerial ocupado, que coinciden en el 48,15 por 100 de los casos. En orden decreciente, siguen los casos en los que sólo existe una coincidencia entre el cargo ministerial y el contenido de la carrera político-administrativa, faltando la coincidencia de la actividad profesional previa (24,07\% de los casos), y aquellos en los que, por el contrario, sólo coincide la actividad profesional previamente desarrollada, pero no el contenido de la carrera político-administrativa ( $1.11 \%$ de los casos). No existe coincidencia alguna entre el cargo ministerial posterior y la carrera preministerial en el restante 16,67 por 100 de los casos. (Vid. Cuadro 22.)

En el caso de loa Ministros que siguieron sólo la vía parlamentaria, al contrario que en el caso de la vía político-administrativa, la desconexión

CUADRO 22. COINCIDENCIA ENTRE LA ACTIVIDAD PROFESIONAL, LA CARRERA POLITICA Y EL PRIMER CARGO MINISTERIAL OCUPADO DE LOS MINISTROS QUE SIGUIERON SÓLO LA VÍA ADMINISTRATIVA

\begin{tabular}{|c|c|c|c|}
\hline COINCIDENCIA & $\begin{array}{c}N^{\circ} \text { DE } \\
\text { MINISTROS }\end{array}$ & $\begin{array}{l}\% \\
\text { (1) }\end{array}$ & $\begin{array}{l}\% \\
\text { (2) }\end{array}$ \\
\hline $\begin{array}{l}\text { Coinciden actividad prof. + vía admva. } \\
\text { Coincide sólo la vía admva. } \\
\text { Coincide sólo actividad prof. } \\
\text { No hay coincidencia }\end{array}$ & $\begin{array}{r}26 \\
13 \\
6 \\
9\end{array}$ & $\begin{array}{l}48,15 \\
24,07 \\
11,11 \\
16,67\end{array}$ & $\begin{array}{r}24,29 \\
12,15 \\
5,61 \\
8,41\end{array}$ \\
\hline Total & 54 & 100 & 50,46 \\
\hline
\end{tabular}

(1) Sobre el número de Ministros [54].

(2) Sobre el número total de Ministros [107]. 
entre la actividad profesional previa, las materias objeto de su dedicación especial durante su paso por el Parlamento y el contenido del cargo ministerial ocupado es prácticamente total: solamente un 4,76 por 100 de los Ministros registran algún tipo de coincidencia entre los mencionados estadios de su carrera politica. Los mayores indices de coincidencia se dan en este caso sólo entre el contenido específico de la actividad parlamentaria desarrollada y el cargo ministerial $(38,10 \%$ de los Ministros), y entre la actividad profesional previa y este último (33,33\% de los Ministros), mientras que no existe ningún tipo de coincidencia en un elevado 3,81 por 100 de los Ministros que siguieron esta vía al Gobierno. (Vid. Cuadro 23.)

CUADRO 23. COINCIDENCIA ENTRE LA ACTIVIDAD PROFESIONAL, LA CARRERA POLITICA Y EL PRIMER CARGO MINISTERIAL OCUPADO DE LOS MINISTROS QUE SIGUIERON SÓLO LA VÍA PARLAMENTARIA

\begin{tabular}{|c|c|c|c|}
\hline COINCIDENCIA & $\begin{array}{c}N^{\circ} \text { DE } \\
\text { MINISTROS }\end{array}$ & $\begin{array}{l}\% \\
\text { (1) }\end{array}$ & $\begin{array}{l}\% \\
\text { (2) }\end{array}$ \\
\hline $\begin{array}{l}\text { Coinciden actividad prof. + vía parlam. } \\
\text { Coincide sólo la vía parlam. } \\
\text { Coincide sólo actividad prof. } \\
\text { No hay coincidencia }\end{array}$ & $\begin{array}{l}1 \\
8 \\
7 \\
5\end{array}$ & $\begin{array}{r}4,76 \\
38,10 \\
33,33 \\
23,81\end{array}$ & $\begin{array}{l}0,93 \\
7,48 \\
6,54 \\
4,67\end{array}$ \\
\hline Total & 21 & 100 & 19,62 \\
\hline
\end{tabular}

(1) Sobre número de Ministros [21].

(2) Sobre número total de Ministros [107].

Con respecto a los Ministros que siguieron tanto la vía político-administrativa como la parlamentaria, el panorama es muy similar al de aqueIlos que sólo siguieron la vía administrativa. Así, son mayores aquí los grados de especialización o continuidad entre la actividad profesional previa y las dos vías políticas de acceso al Gobierno seguidas, que coinciden con el cargo guernamental ocupado en un 34,78 por 100 de los casos. En orden descendente siguen los Ministros en los que coinciden sólo la actividad profesional previa y el contenido de la carrera político administrativa $(21,74 \%)$, y en los que coincide sólo la carrera político-administrativa 
$(13,04 \%)$. La inexistencia total de coincidencia entre la carrera preministerial realizada y el cargo gubernamental ocupado se eleva aquí al 13,04 por 100 de los Ministros. (Vid. Cuadro 24.)

CUADRO 24. COINCIDENCIA ENTRE LA ACTIVIDAD PROFESIONAL, LA CARRERA POLITICA Y EL PRIMER CARGO MINISTERIAL OCUPADO DE LOS MINISTROS QUE SIGUIERON LAS VÍAS ADMINISTRATIVA Y PARLAMENTARIA

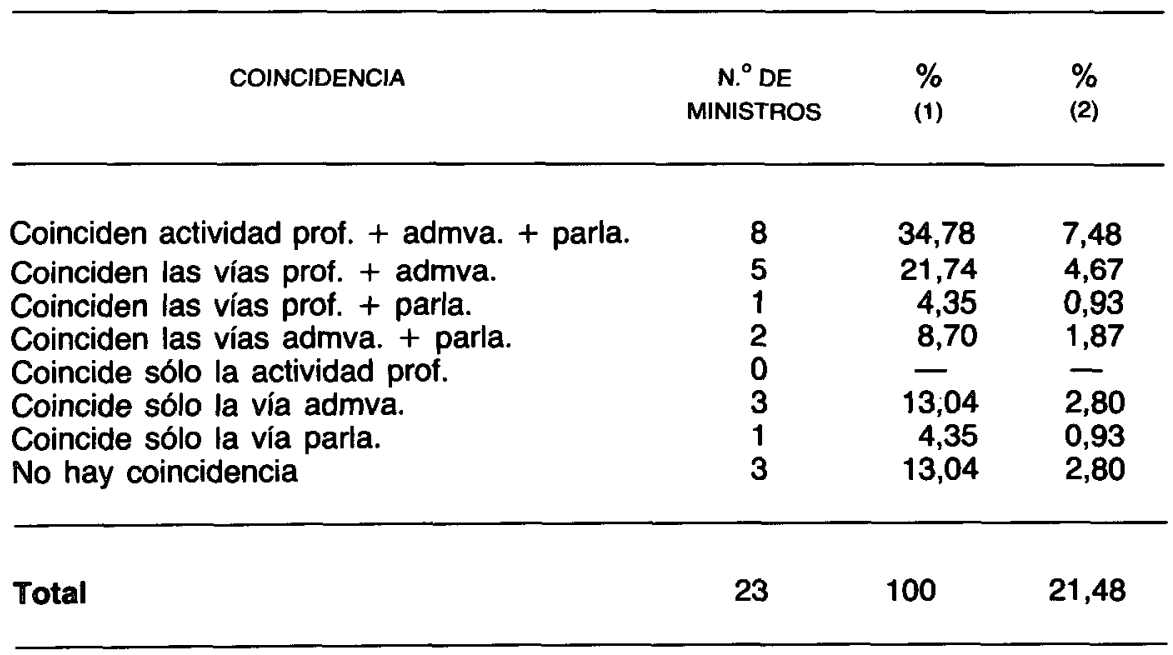

(1) Sobre número de Ministros [23].

(2) Sobre número total de Ministros [107].

La diferencia tan grande existente entre las dos vías - la administrativa y la parlamentaria- como cuces de especialización ministerial, se debe tanto a su propia sustancia, como a la cualificación personal de quienes van a ocupar puestos en el seno de ambas. Asi, no sólo los puestos administrativos de designación y responsabilidad política — de los que aqui nos ocupamos- suelen tener unas mayores exigencias de preparación técnica especifica, sino que las personas que se destinan a ocuparlos lo suelen ser más en función de esta misma preparación o conocimiento de la materia, que en función de su militancia o relevancia política, sin excluir, desde luego, la existencia de ésta. Por el contrario, los escaños parlamentarios, por un lado, dado lo sustancialmente general de su objeto, no demandan unos conocimientos específicos o especial capacitación técnica 
previa, y por otro, las tareas parlamentarias en España se suelen atribuir a los parlamentarios con indiferencia prácticamente total de su currículo o formación profesional; ocupándose, efectivamente, los parlamentarios de los más variados temas. En este sentido, y dadas, además, las exigencias de la confrontación política previa que lleva al Parlamento, las personas destinadas a ocupar escaños en el seno del mismo lo son en función de su militancia o relevancia política, y no de su cualificación profesional o técnica.

El nivel de especialización es mucho más elevado, como cabe esperar, en el caso de los Ministros que accedieron directamente al Gobierno, sin haber tenido que realizar una carrera política previa; es decir, en el caso de los Ministros que siguieron sólo la aquí denominada vía profesional. Y ello es lógico, pues, inexistente la cualificación política, es sólo su cualificación profesional la que les permite llegar al Gobierno. Ello hace que en su nombramiento se busque específicamente la adecuación de esa cualificación profesional al cargo ministerial al que van a ser destinados. Asi, como se puede comprobar en el Cuadro 25, existe una coincidencia plena entre la actividad profesional previa y el cargo ministerial ocupado con posterioridad en el 88,89 por 100 de los Ministros que siguieron exclusivamente esta vía hacia el Gobierno.

Finalmente, a modo de resumen de lo dicho, se comprueba cómo, analizadas por separado las vias de acceso al Gobierno seguidas, la ade-

CUADRO 25. COINCIDENCIA ENTRE LA ACTIVIDAD PROFESIONAL, LA CARRERA POLÍTICA Y EL PRIMER CARGO MINISTERIAL OCUPADO DE LOS MINISTROS QUE SIGUIERON SOLLO LA

$$
\text { VÍA PROFESIONAL }
$$

\begin{tabular}{lccc}
\hline \multicolumn{1}{c}{ COINCIDENCIA } & $\begin{array}{c}\text { N. }{ }^{\circ} \text { DE } \\
\text { MINISTROS }\end{array}$ & $\begin{array}{c}\% \\
(1)\end{array}$ & $\begin{array}{c}\% \\
(2)\end{array}$ \\
\hline & & & \\
$\begin{array}{l}\text { Coincide la actividad profesional } \\
\text { No hay coincidencia }\end{array}$ & 8 & 88,89 & 7,48 \\
& 1 & 11,11 & 0,93 \\
\hline Total & 9 & 100 & 8,41 \\
\hline
\end{tabular}

(1) Sobre el número de Ministros [9].

(2) Sobre el número total de Ministros [107]. 
cuación entre el contenido específico de cada una de estas vías y el cargo ministerial ocupado posteriormente es muy superior en el caso de la vía profesional $(88,89 \%$ de los que siguieron esta vía), menor en el caso de los que siguieron la vía politico-administrativa $(74,03 \%$ de los casos), y mucho más reducida en el caso de los que siguieron la vía parlamentaria (el $47,73 \%$ ). (Vid. Cuadro 6.)

\section{CUADRO 26. COINCIDENCIA ENTRE EL CONTENIDO ESPECÍFICO DE LA VÍA POLIITICA SEGUIDA HACIA EL GOBIERNO Y EL PRIMER CARGO MINISTERIAL OCUPADO (POR MINISTROS)}

VIA SEGUIDA
COINCIDE SOLO LA VIÁ SEGUIDA

N. ${ }^{\circ}$ DE MINISTROS
$\%$

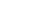

\begin{tabular}{lrr}
\hline & & \\
Vía administrativa $(N=77)$ & 57 & 74,03 \\
Vía parlamentaria $(N=44)$ & 21 & 47,73 \\
Vía profesional $(N=9)$ & 8 & 88,89
\end{tabular}

Si referimos este análisis a cada uno de los siete Gabinetes formados durante el período analizado, y acumulando los diferentes grados de especialización, es decir, de coincidencia entre el contenido material de la carrera preministerial de cada uno de los Ministros y los puestos que éstos ocuparon en los respectivos Gobiernos, vemos cómo los mayores indices de especialización los registran los Gobiernos de la UCD, y, más en concreto, el tercer Gabinete Suárez, en el que, no sólo el más alto nivel de especialización posible registra el mayor porcentaje de Ministros (en un $13,51 \%$ de éstos hay una plena coincidencia entre las carreras profesional y politica - administrtiva y parlamentaria - y su puesto ministerial), sino que solamente un 8,11 por 100 de sus miembros no registraban ningún tipo de coincidencia entre el contenido material de sus carreras preministeriales y el objeto de su cargo gubernamental. (Vid. Cuadro 27.)

Esta diferencia entre los niveles de especialización de los Gobiernos de la UCD y del PSOE no debe sorprender demasiado y, quizá, una explicación de ello se encuentre, no tanto en su decisión consciente de sus Presidentes de designar, o no, sólo o preferentemente, a Ministros especialistas, como en el hecho de que la clase política que compuso los Gobiernos de PSOE se creó en su mayoria en el momento de acceso del partido al poder central del Estado por primera vez, lo que necesariamente impidió que sus miembros contasen con la realización de largas carreras 
CUADRO 27. COINCIDENCIA ENTRE LA ACTIVIDAD PROFESIONAL, LA CARRERA POLITICA Y EL PRIMER CARGO MINISTERIAL OCUPADO DE LOS MINISTROS (\% POR GOBIERNOS)

\begin{tabular}{|c|c|c|c|c|c|c|c|}
\hline COINCIDENCIA & A.II & S.I & S.II & S.III & C-s & G.I & G.11 \\
\hline $\begin{array}{l}\text { Prof. + admva. + parla. } \\
\text { Prof. + admva. } \\
\text { Prof. + parla. } \\
\text { Admva. + parla. } \\
\text { Sólo vía prof. } \\
\text { Sólo vía admva. } \\
\text { Sólo vía parla. } \\
\text { No hay coincidencia }\end{array}$ & $\begin{array}{l}\overline{50,00} \\
\overline{-} \\
25,00 \\
15,00 \\
\overline{10,00}\end{array}$ & $\begin{array}{l}\overline{43,48} \\
\overline{-} \\
\overline{26,00} \\
21,74 \\
\overline{8,98}\end{array}$ & $\begin{array}{l}\overline{-} \\
48,00 \\
- \\
24,00 \\
12,00 \\
4,00 \\
12,00\end{array}$ & $\begin{array}{r}13,51 \\
40,54 \\
- \\
2,71 \\
13,51 \\
10,81 \\
10,81 \\
8,11\end{array}$ & $\begin{array}{r}12,00 \\
32,00 \\
\overline{4} \\
4,00 \\
4,00 \\
16,00 \\
12,00 \\
20,00\end{array}$ & $\begin{array}{r}9,09 \\
13,64 \\
4,55 \\
- \\
27,27 \\
9,09 \\
18,18 \\
18,18\end{array}$ & $\begin{array}{r}4,35 \\
13,04 \\
4,35 \\
4,35 \\
34,78 \\
8,70 \\
13,04 \\
17,39\end{array}$ \\
\hline $\begin{array}{l}\text { Alguna coincidencia } \\
\text { Ninguna coincidencia }\end{array}$ & $\begin{array}{l}90,00 \\
10,00\end{array}$ & $\begin{array}{r}91,31 \\
8,69\end{array}$ & $\begin{array}{l}88,00 \\
12,00\end{array}$ & $\begin{array}{r}91,89 \\
8,11\end{array}$ & $\begin{array}{l}80,00 \\
20,00\end{array}$ & $\begin{array}{l}81,82 \\
18,18\end{array}$ & $\begin{array}{l}82,61 \\
17,39\end{array}$ \\
\hline Total & 100 & 100 & 100 & 100 & 100 & 100 & 100 \\
\hline
\end{tabular}

CLAVE:

A.ll: Segundo Gobierno de Arias.

S.I: Primer Gobierno Suárez.

S.ll: Segundo Gobierno Suárez.

S.III: Tercer Gobierno Suárez.

C-S: Gobierno Calvo-Sotelo.

G.I: Primer Gobierno González.

G.II: Segundo Gobierno González.

políticas y, por lo tanto, hubiesen adquirido la base necesaria para la especialización. Ello se comprueba, por ejemplo, en el hecho de que los dos primeros Gobiernos del PSOE sean precisamente los que menor porcentaje registran de Ministros llegados al Gabinete exclusivamente a través de la vía político-administrativa (sólo un $22,73 \%$ el primero, y un $34,78 \%$ el segundo); via que, no sólo se distingue por sus altas dosis de politización y forma de realizarse - a través de la libre designación-, lo que implica una identificación con la mayoria gobernante (de aqui la renovación producida con la llegada del PSOE al Gobierno), sino que es habitualmente la que mayores niveles de especialización produce entre los miembros del Gobierno. Mientras que, por el contrario, son los Gabinetes del PSOE los 
que mayor porcentaje de miembros provenientes exclusivamente de la vía político-parlamentaria, reúnen (el 36,36 \% y un 39,14\%, respectivamente); vía que, como ya se ha visto también, es la que menor índice de especialización produce. (Vid. Cuadros 12-B y 27.)

También es significativo el hecho de que, en coherencia con lo anterior, sean precisamente los dos Gabinetes del PSOE los que recojan el mayor porcentaje de miembros provenientes de la via profesional, o no política (un 13,64 \% de sus miembros el primero, y un 13,04\% el segundo); lo cual si bien podría haber elevado el índice general de especialización, de hecho no lo hace, debido, como se ha visto, al bajo número de miembros provenientes de la vía político-administrativa, lo que compensa a la baja la situación.

\section{CONCLUSIONES}

Una de las primeras dudas que surge al analista tras el estudio realizado es si el corto tiempo transcurrido desde la muerte del general Franco, momento en el que se data el inicio del período analizado, permite ya llegar a la elaboración de unas conclusiones definitivas sobre la dinámica de la estructura gubernamental desde entonces. La verdad es que las líneas generales de la evolución producida, lo cambiante de la situacion, al menos hasta muy recientemente, hacen casi imposible convertir estas conclusiones en algo más que unas meras hipótesis, derivadas de los datos surgidos del análisis científico realizado.

Lo primero que cabe concluir con toda certeza es la discontinuidad del contenido de la actual estructura gubernamental con respecto al régimen dictatorial que la ha precedido. La ruptura se ha producido no sólo en el marco jurídico-constitucional que delimita la formación y actividad del Gobierno en la actualidad, sino también en la composición personal de los Gabinetes. Lo que cabría denominar como la «élite ministerial» se ha renovado en su práctica totalidad, y no sólo por un mero cambio vegetativo, sino por motivos politicos. También aspectos puramente personales, como la edad y el sexo de los nuevos Ministros, han coincidido en el cambio: la edad media se ha reducido y las mujeres, aunque en número escaso, han accedido al Gobierno.

Uno de los aspectos importantes que ha acompañado el cambio de la élite ministerial ha sido precisamente la inestabilidad, tanto gubernamental como ministerial,-que ha caracterizado el periodo, sobre todo en su primera fase. Inestabilidad que ha sido tanto la causa como el producto de la necesidad de sustituir a la vieja clase política del franquismo en su práctica totalidad. 
Existen, sin embargo, algunos elementos de continuidad en el aspecto sociológico. La formación y la profesión previa de los Ministros es predominantemente jurídica y, en menor medida, económica, como lo fue en el pasado. Pero ello es común también a otros Gabinetes de nuestro entorno político. Lo que es menos común, en cambio, es el peso aplastante del funcionariado en la composición profesional de nuestros Gobiernos, y el predominio dentro de este sector de los profesores universitarios.

$Y$, si son los funcionarios de carrera profesional el sector mayoritario en la formación de los Gabinetes españoles, también es la vía políticoadministrativa la que con más frecuencia ha sido transitada en el camino hacia el Gobierno. Dos tercios de los Ministros cuentan con experiencia politica en este terreno, frente al tercio restante, que ocupó previamente escaños parlamentarios. Esta situación, sin embargo, manifiesta una tendencia a corregirse, y es posible que con el paso del tiempo y cuando hayan sido mayores en número los procesos electorales realizados, el desequilibrio se compense plenamente $y$, aun, se invierta. Por otra parte, han sido muy pocos - sólo nueve - los Ministros que en España han accedido al Gobierno directamente, sin haber realizado previamente una carrera política, en los términos y analizados.

Todo ello, por lo demás, está en íntima relación con el tema de la especialización ministerial. Si, por un lado, aspectos como la baja edad media - hasta el presente- de nuestros Ministros, o la gran movilidad de la élite ministerial, así como lo reducido del número de profesionales accedidos directamente al Gobierno, sin haber realizado una carrera política previamente, son factores que tienden a producir un bajo nivel de especialización, bien por el poco tiempo existente para tener una amplia experiencia política, bien por el bajo número de Ministros utécnicos"; la verdad es que ésta, computada científicamente como lo ha sido en las páginas anteriores, no ha sido baja. A ello ha contribuido de manera decisiva precisamente el amplio número existente de Ministros que han realizado su carrera política a través de la vía administrativa, y lo denso de la misma en buena parte de los casos. Esta carrera político-administrativa les ha permitido entrar en contacto directo con las materias sobre las que luego hubieron de actuar desde el Gobierno.

La carrera político-parlamentaria por el contraria, ha producido unos bajísimos niveles de especialización ministerial, siendo muy pocos los $\mathrm{Mi}$ nistros que durante su paso por las Cortes Generales trabajaron de manera específica sobre temas con los que luego habrian de tratar en su respectivo Departamento. Todo lo contrario ocurrió con los Ministros "profesionales", es decir, aquellos carentes de carrera política, los cuales, todos excepto uno, fueron designads para ocupar carteras directamente relacionadas con el objeto material de su dedicación profesional previa.

En conjunto, pues, puede decirse que, si bien los mayores niveles de especialización ministerial se produjeron entre los Ministros provinien- 
tes de la via «profesional», seguidos jerárquicamente por los provinientes de la via político-administrativa, $y$, en tercer lugar, por los provinientes de la vía politico-parlamentaria; el menor número total de los primeros y el bajo número de los terceros se han compensado mutuamente, haciendo que el mayor número de Ministros provenientes de la vía político-administrativa haya determinado finalmente el relativamente alto nivel global de especialización ministerial registrado ${ }^{57}$.

${ }^{57}$ La versión final de este trabajo fue culminada en agosto de 1988 . Ello debe tenerse en cuenta en la valoración de los datos contenidos en el mismo. 